Universidade de São Paulo

INSTITUTO DE FÍSICA

\title{
Estudo da Fissão de Núcleos Pesados Induzida por Fótons e Prótons a Energias Intermediárias e Altas via Monte Carlo
}

\author{
Evandro Oliveira Andrade Segundo
}

Dissertação de mestrado apresentada ao Instituto de Física da Universidade de São Paulo para a obtenção do título de Mestre em Ciências.

Orientador:

Prof. Dr. Airton Deppman

Comissão Examinadora:

Prof. Dr. Airton Deppman - IFUSP

Prof. Dr. Marcos Nogueira Martins - IFUSP

Prof. Dr. Paulo Roberto Silveira Gomes - UFF

São Paulo 
Evandro Oliveira Andrade Segundo

\title{
Estudo da Fissão Induzida de Núcleos Pesados por Fótons e Prótons a Energias Intermediárias e Altas via Monte Carlo
}

\author{
Orientador: \\ Dr. Airton Deppman \\ USP - UNIVERSIDAdE DE SÃo PAUlO \\ INSTITUTO DE FÍSICA
}

São Paulo - SP 


\section{FICHA CATALOGRÁFICA}

\section{Preparada pelo Serviço de Biblioteca e Informação}

do Instituto de Física da Universidade de São Paulo

Segundo, Evandro Oliveira Andrade

Estudo da fissão induzida de núcleos pesados por fótons e prótons a energias intermediárias e altas via Monte Carlo. - São Paulo, 2012.

Dissertação (Mestrado) - Universidade de São Paulo. Instituto de Física, Depto. Física Experimental

Orientador: Prof. Dr. Airton Deppman

Área de Concentração: Reações Nucleares e Espalhamento (Reações Específicas)

Unitermos: 1. Mecânica estatística; 2. Física computacional; 3. Método de Monte Carlo.

USP/IF/SBI-026/2012 
A meus pais Evandro e Fátima. 


\section{Agradecimentos}

Agradeço a meus pais Evandro e Fátima, cujas palavras sábias e os exemplos sólidos tem me conduzido por um caminho de vitórias. Seu amor incondicional me trouxe até aqui.

Ao meu orientador, prof. Dr. Airton Deppman, que tem instruído meus passos nos caminhos da ciência e me ensinado a pensar, sempre com dedicação. Verdadeiro mestre e amigo.

Ao prof. Dr. Fermin Garcia, presente no início da minha formação científica e, em grande medida, responsável pelo meu sucesso atual.

Aos colegas Danilo Souza e Júlio César, pela prontidão com que sempre tiraram minhas dúvidas sobre suas contribuições anteriores ao código CRISP.

Ao colega Dr. Pedro Rossi. Sua participação em nosso grupo de pesquisa é valiosa e suas contribuições foram muito úteis a este trabalho.

Ao colega Ricardo Romão, cujo profissionalismo e zelo são uma inspiração. Seu auxílio em computação me tirou de dificuldades muitas vezes.

Ao colega Israel Medina. Nossas discussões sobre o código CRISP foram orientadoras.

A minha noiva Débora Pio, pelo ouvir paciente e pela compreensão. Suas palavras de apoio sempre me fortalecem.

Meu sincero agradecimento aos meus amigos, irmãos em Cristo, cujos nomes bastariam para encher esta página, que sempre fizeram da minha alegria também a deles.

Acima de tudo, agradeço ao meu Senhor Jesus, que me deu os pais, os mestres, os colegas, a noiva e os amigos, assim como me deu a benção de conhecer e estudar a obra de Suas mãos. A Ele seja a Glória! 
"Education without values, as useful as it is, seems rather to make man a more clever devil". 


\section{Resumo}

Este trabalho é dedicado ao estudo de reações de fissão de núcleos pesados induzidas por fótons e prótons a energias intermediárias e altas, fazendo uso, para tanto, do código de Monte Carlo CRISP, sendo um trabalho inteiramente computacional. Estudou-se um novo conjunto de parâmetros para a fórmula de massa semi-empírica proposta por Pearson em seu trabalho de 2001, a partir da qual se passou à simulação de reações de fissão induzidas por fótons dos núcleos ${ }^{208} \mathrm{~Pb},{ }^{232} \mathrm{Th},{ }^{237} \mathrm{~Np}$ e ${ }^{238} \mathrm{U}$, e fissão induzida por prótons nos núcleos ${ }^{197} \mathrm{Au},{ }^{208} \mathrm{~Pb}$, ${ }^{237} \mathrm{~Np}$ e ${ }^{241} \mathrm{Am}$. Os modelos de Bohr e Wheeler para fissão, de 1939, e o modelo de Weisskopf para emissão de partículas de 1937 foram empregados na simulação. Para os parâmetros de densidade de níveis, um conjunto de parâmetros foi obtido para as fórmulas empíricas de Dostrovsky de 1958 e para a razão de fissão. Foram calculadas seções de choque de fotofissão para os núcleos ${ }^{208} \mathrm{~Pb},{ }^{232} \mathrm{Th},{ }^{237} \mathrm{~Np}$ e ${ }^{238} \mathrm{U}$, produtos de reações de spallation induzidas por prótons nos núcleos ${ }^{208} \mathrm{~Pb}$ e ${ }^{197} \mathrm{Au}$, e distribuições de massa dos fragmentos de fissão em reações de Bremsstrahlung com o ${ }^{238} \mathrm{U}$ e em reações induzidas por prótons com os núcleos ${ }^{197} \mathrm{Au},{ }^{208} \mathrm{~Pb}$, ${ }^{237} \mathrm{~Np}$ e ${ }^{241} \mathrm{Am}$. São apresentadas comparações a dados experimentais de todos os cálculos realizados. Também se obteve um modelo para aproximar os valores de barreira de fissão obtidos pelo método ETFSI (Extended Thomas-Fermi plus Strutinsky Integral).

Palavras-chave: Monte Carlo, fotofissão, spallation, fragmentos de fissão. 


\section{Abstract}

This work is dedicated to the study of heavy nuclei fission induced by intermediate- and high-energy photons and protons, by using to this end the Monte Carlo code CRISP, therefore being an entirely computacional work. A new set of parameters for the 2001 semi-empirical mass formula proposed by Pearson is studied. Then we simulate fission reactions induced by photons and protons on ${ }^{208} \mathrm{~Pb},{ }^{232} \mathrm{Th},{ }^{237} \mathrm{~Np}$ and ${ }^{238} \mathrm{U}$, and fission induced by protons on ${ }^{197} \mathrm{Au},{ }^{208} \mathrm{~Pb},{ }^{237} \mathrm{~Np}$ e ${ }^{241} \mathrm{Am}$. The Bohr-Wheeler model for describing the fission process and the Weisskopf model for the emission probability of particles were used to perform the calculation. Regarding the level density parameters, a set of parameters is presented for the empirical formulas of Dostrovsky and for the fission ratio. This work also presents calculated fotofission cross section for induced reactions on ${ }^{208} \mathrm{~Pb},{ }^{232} \mathrm{Th},{ }^{237} \mathrm{~Np}$ and ${ }^{238} \mathrm{U}$ nuclei, spallation products of proton induced reactions on ${ }^{208} \mathrm{~Pb}$ and ${ }^{197} \mathrm{Au}$, and fragment mass distributions of Bremsstrahlung reactions with ${ }^{238} \mathrm{U}$ and of proton induced reactions on ${ }^{197} \mathrm{Au},{ }^{208} \mathrm{~Pb},{ }^{237} \mathrm{~Np}$ and ${ }^{241} \mathrm{Am}$. Comparisons to experimental data are shown for all calculations. A model to aproximate the fission barrier values obtaind by the ETFSI - Extended Thomas-Fermi plus Strutinsky Integral method is also presented.

Keywords: Monte Carlo, photofission, spallation, fission fragments. 


\section{Sumário}

\section{Lista de Figuras}

\section{Lista de Tabelas}

1 Introdução $\quad$ p. 13

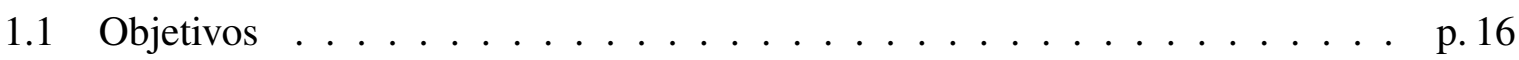

2 Metodologia $\quad$ p. 18

2.1 Fundamentação teórica . . . . . . . . . . . . . . . . . p. 18

2.1.1 Modelo estatístico de evaporação de Weisskopf . . . . . . . . . . p. p. 18

2.1.2 Modelo para a probabilidade de fissão . . . . . . . . . . . p. 22

2.1.3 Modelo multimodo para distribuições de massa de fragmentos . . . . p.30

2.2 Ferramentas Computacionais . . . . . . . . . . . . . p. 31

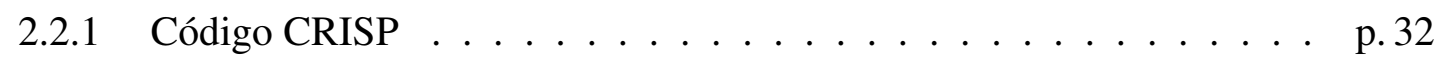

2.2.2 Plataforma ROOT . . . . . . . . . . . . . . p. 33

2.3 Descrição do método . . . . . . . . . . . . . . . p. 34

2.3.1 Fórmula semi-empírica de massa . . . . . . . . . . p. 35

2.3.2 Cálculo de evaporação . . . . . . . . . . . . . . . . . p. 37

2.3.3 Cálculo de fissão . . . . . . . . . . . . . . . . . . . p. 39 
2.3.4 Cálculo dos fragmentos de fissão . . . . . . . . . . . . p. p 43

2.3.5 Modelo microscópico da barreira de fissão . . . . . . . . . . . . p.50

3 Resultados e Discussão $\quad$ p. 52

3.1 Fórmula semi-empírica de massa $\ldots \ldots \ldots \ldots \ldots$ p. 52

3.2 Razão de fissão . . . . . . . . . . . . . . . . . . . . . p. 56

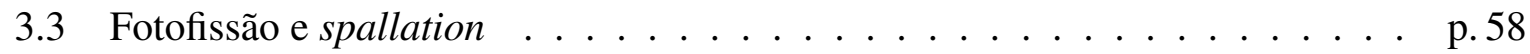

3.4 Distribuição de massa de fragmentos de fissão . . . . . . . . . . . . . p.63

3.5 Barreira de fissão $\ldots \ldots \ldots \ldots \ldots \ldots \ldots$ p. 71

3.6 Perspectivas do trabalho $\ldots \ldots \ldots \ldots \ldots \ldots \ldots$ p. 73

4 Conclusões $\quad$ p. 74

$\begin{array}{lr}\text { Referências Bibliográficas } & \text { p.76 }\end{array}$ 


\section{Lista de Figuras}

2.1 (a) Esquema da energia potencial nuclear no ponto de equilíbrio e no ponto de sela, com indicação dos níveis no estado de transição. (b) Esboço em curvas de nível da superfície de energia potencial em função de dois parâmetros de deformação arbitrários. O ponto de sela está indicado no ponto de equilíbrio instável. . . . . . . . . . . . . . . . . . p. 23

2.2 Variação da superfície nuclear em função dos coeficientes de deformação $\alpha_{2}$ e $\alpha_{4}$. Adaptado de [40]. . . . . . . . . . . . . . . . . . . . . p. 28

2.3 Diversos pontos de cela para deformação simétrica, para diferentes valores do parâmetro de fissilidade $x_{0}$. Adaptado de [39]. . . . . . . . . . . . . p.30

2.4 Energia de ligação por nucleon $[66] \ldots \ldots \ldots \ldots \ldots$. . . . . . . . . . . . .

2.5 Sub-rotina para o cálculo do termo entre chaves na equação (2.28) da barreira de fissão. . . . . . . . . . . . . . . . . . . p.42

2.6 Distância $d$ entre as superfícies de cada fragmento em função de $Z^{2} / A^{1 / 3}$. Os dados experimentais foram obtidos de [29]. . . . . . . . . . . . . p.49

2.7 Barreira de fissão prevista pelo método ETFSI. . . . . . . . . . . . . p.51

3.1 Diferença entre a massa experimental [68] e a massa calculada pela fórmula semi-empírica de massa quando utilizados os parâmetros da referência [64]. p.53

3.2 Diferença entre a massa experimental e a massa calculada pela fórmula ajustada. p. 54 
3.3 Energia de excitação dos fragmentos de fissão na aproximação $E_{f r a g} \simeq E_{f}$ (linha preta) e quando contabilizada de acordo com $E_{\text {frag }}=M_{f}-\left(m_{f r a g}+\right.$ $\left.m_{\text {frag } 2}\right)+E_{f}-T_{\text {frag }}\left(\right.$ linha vermelha) para (a) ${ }^{241} \mathrm{Am}+660 \mathrm{MeV} \mathrm{p} \mathrm{(b)}{ }^{237} \mathrm{~Np}$ $+660 \mathrm{MeV}$ p (c) ${ }^{208} \mathrm{~Pb}$ a $500 \mathrm{MeV}$ p (d) ${ }^{208} \mathrm{~Pb}$ a $1000 \mathrm{MeV}$ p (e) ${ }^{197} \mathrm{Au}+800$ $\mathrm{MeV}$.

3.4 Energia de excitação dos fragmentos de fissão na aproximação $E_{f r a g} \simeq E_{f}$ (linha preta) e quando contabilizada de acordo com $E_{\text {frag }}=M_{f}-\left(m_{f r a g}+\right.$ $\left.m_{\text {frag } 2}\right)+E_{f}-T_{\text {frag }}$ (linha vermelha) para (a) ${ }^{238} \mathrm{U}$ a $50 \mathrm{MeV}$ e (b) ${ }^{238} \mathrm{U}$ a $3.5 \mathrm{GeV}$

3.5 Forma do parâmetro $r_{f}$, razão de fissão. p. 57

3.6 Seções de choque de fotofissão. (a) ${ }^{208} \mathrm{~Pb}$ (b) ${ }^{232} \mathrm{Th}$ (c) ${ }^{238} \mathrm{U}$ e (d) ${ }^{237} \mathrm{~Np} \ldots \ldots$. . . p. 59

3.7 Seções de choque dos produtos de spallation da reação ${ }^{197} \mathrm{Au}+800 \mathrm{MeV}$ p. . p. 60

3.8 Seções de choque dos produtos de spallation da reação ${ }^{208} \mathrm{~Pb}+1 \mathrm{GeV}$ p. . . . p. 62

3.9 Distribuições de massa do núcleo fissionante. (a) ${ }^{241} \mathrm{Am}$, (b) ${ }^{237} \mathrm{~Np}$ (c) ${ }^{238} \mathrm{U}$ a $50 \mathrm{MeV}$ e (d) ${ }^{238} \mathrm{U}$ a $3500 \mathrm{MeV}$.

3.10 Distribuições de massa do núcleo fissionante. (a) ${ }^{208} \mathrm{~Pb}$ a $500 \mathrm{MeV}$ p (b) ${ }^{208} \mathrm{~Pb}$ a $1000 \mathrm{MeV}$ p e (c) ${ }^{197} \mathrm{Au}$ a $800 \mathrm{MeV}$.

3.11 Distribuições de massa dos fragmentos. (a) ${ }^{241} \mathrm{Am}\left(E_{\text {frag }} \simeq E_{f}\right)$, (b) ${ }^{241} \mathrm{Am}$, (c) ${ }^{237} \mathrm{~Np}\left(E_{\text {frag }} \simeq E_{f}\right),(\mathrm{d}){ }^{237} \mathrm{~Np}$, (e) ${ }^{208} \mathrm{~Pb}$ a $500 \mathrm{MeV} \mathrm{p}\left(E_{\text {frag }} \simeq E_{f}\right)$ e (f) ${ }^{208} \mathrm{~Pb}$ a $500 \mathrm{MeV}$. . . . . . . . . . . . . . . . p. 66

3.12 Distribuições de massa dos fragmentos. (a) ${ }^{208} \mathrm{~Pb}$ a $1000 \mathrm{MeV} \mathrm{p}\left(E_{\text {frag }} \simeq E_{f}\right)$ (b) ${ }^{208} \mathrm{~Pb}$ a $1000 \mathrm{MeV}$ p (c) ${ }^{197} \mathrm{Au}$ a $800 \mathrm{MeV}$ p $\left(E_{\text {frag }} \simeq E_{f}\right)$ e (d) ${ }^{197} \mathrm{Au} \mathrm{a}$

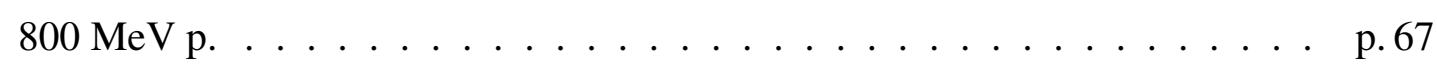


3.13 Distribuição de $Z^{2} / A$ para núcleos no final da cascata intranuclear para as reações ${ }^{208} \mathrm{~Pb}+500 \mathrm{MeV}$ p, ${ }^{208} \mathrm{~Pb}+1000 \mathrm{MeV}$ p, ${ }^{208} \mathrm{~Pb}+100 \mathrm{MeV} \gamma,{ }^{208} \mathrm{~Pb}$ $+500 \mathrm{MeV} \gamma,{ }^{208} \mathrm{~Pb}+900 \mathrm{MeV} \gamma \mathrm{e}^{208} \mathrm{~Pb}+1000 \mathrm{MeV} \gamma \ldots \ldots$. . . . . . 69

3.14 Distribuições de massa dos fragmentos. (a) ${ }^{2238} \mathrm{U}$, energia máxima do fóton em $50 \mathrm{MeV}$ e (b) ${ }^{2238} \mathrm{U}$, energia máxima do fóton em $3500 \mathrm{MeV}$. . . . . . . p p.70

3.15 Diferença entre a barreira de fissão calculada pelo método ETFSI e aquela obtida pelo modelo de Nix. . . . . . . . . . . . . . . . . p.71

3.16 Diferença entre a barreira de fissão calculada pelo método ETFSI e aquela obtida pelo modelo proposto neste trabalho. . . . . . . . . . . p.72 


\section{Lista de Tabelas}

3.1 Valores dos parâmetros relevantes da fórmula semi-empírica de massa e das fórmulas empíricas de Dostrovsky para o cálculo de densidade de níveis. . . . p.52

3.2 Valores da razão de fissão, $r_{f}$, para cada intervalo de $Z^{2} / A \ldots \ldots$. . . . . p.58

3.3 Valores dos parâmetros relevantes do modelo de fissão multimodo. . . . . . . p. 63

3.4 Valores dos parâmetros da fórmula sugerida para ajustar as previsões de barreira de fissão calculadas com o método ETFSI. . . . . . . . . . . . . p. 72 


\section{$1 \quad$ Introdução}

Anteriormente ao ano de 1939, estudava-se a possibilidade de se ter radioatividade induzida por meio do bombardeamento de nêutrons em núcleos de massa intermediária e pesados, e a possível produção de núcleos transurânicos a partir do mesmo método, trabalho esse desenvolvido por Fermi e colaboradores [1, 2].

Em 1939, na sequência desses estudos, O. Hahn e F. Strassmann [3] descobriram que a irradiação de urânio com nêutrons dava origem a elementos de massa intermediária. Lise Meitner e O. R. Frisch [4] propuseram que o núcleo de urânio se tornava excitado pela absorção de nêutrons, o suficiente para se dividir em fragmentos de massas aproximadamente iguais, fenômeno que passou a ser conhecido como fissão nuclear. Em seguida, Bohr e Wheeler desenvolveram sua teoria do processo de fissão com base na analogia do núcleo com uma gota líquida [5].

A observação de que para núcleos pesados a repulsão mútua entre as cargas já começa a anular em grande parte a força nuclear forte, esta posta em analogia com a tensão superficial que se opõe às deformações sofridas por uma gota, foi muito importante ao desenvolvimento da teoria. Em seu trabalho, Bohr e Wheeler propuseram um tratamento detalhado do mecanismo de fissão, incluindo uma estimativa de sua probabilidade de ocorrência em comparação com a probabilidade de emissão de radiação e de emissão de nêutrons, tendo em vista precisamente a analogia entre o núcleo e uma gota líquida. A energia crítica de deformação resulta estar em conexão com a energia potencial de uma gota no estado de equilíbrio instável e dependendo dos números atômico e de massa.

A determinação da massa nuclear, essencial não apenas ao cálculo correto das probabilidades de fissão e emissão mas também ao estudo da síntese de núcleos super-pesados e à 
astrofísica, traz consigo a necessidade de se levar em conta que a massa de um núcleo com $\mathrm{N}$ nêutrons e $\mathrm{Z}$ prótons é menor do que a soma das massas dos nucleons quando livres por um valor correspondente à chamada energia de ligação nuclear.

A primeira formulação de um modelo para o cálculo da fórmula de massa se deu em 1935 com a proposta da fórmula semi-empírica de massa de Weizsäcker [6], baseada no modelo da gota líquida, sendo, portanto, uma fórmula baseada em características nucleares macroscópicas. Diversos modelos tem sido propostos a fim de se chegar a valores de massa precisos, desde modelos que mesclam propriedades macroscópicas e microscópicas como a fórmula extendida de Bethe-Weizsäcker [7] e o modelo de Weizsäcker-Skyrme proposto recentemente por Wang et al. $[8,9]$ a outros totalmente microscópicos baseados em campo médio, como a abordagem que utiliza o método Hartree-Fock-Bogoliubov não-relativístico juntamente com funcional de energia-densidade Skyrme [10], e os modelos que já consideram campo médio relativístico e forças de Gogney [11]. Estes modelos microscópicos, em todo ou em parte, oferecem na maioria dos casos resultados análogos, exceto para núcleos na drip line de nêutrons e núcleos super-pesados. Portanto, estudos tem sido realizados no sentido de avaliar as possibilidades de extrapolação de cada um desses modelos [12].

Embora alguns dos modelos acima citados possam oferecer excelentes resultados, há dificuldades computacionais na sua implementação, especialmente quando o cálculo da massa nuclear é apenas parte de um programa maior dedicado, por exemplo, à simulação do processo de fissão. Deste modo, a busca por fórmulas macroscópicas melhores continua sendo de grande interesse.

Continua também atraindo atenção estudos de reações induzidas por fótons, tanto em núcleos leves como pesados $[13,14]$. Fótons se mostraram mais adequados ao estudo de ressonânicas Delta [14] do que píons, devido à possibilidade de interagirem com mais nucleons no interior do núcleo, o que não ocorre com píons, cujas interações tendem a se restringir à superfície. Além disso, a fotofissão tem sido utilizada no estudo do mecanismo de fotoabsorção, de modo que até a seção de choque total de fotoabsorção, de difícil medição em particular 
para núcleos de alto $Z$, tem sido substituída pela seção de choque total de fotofissão, já que a fissão é um canal importante no estudo de núcleos pesados a energias maiores [15]. Uma aplicação para fotofissão que tem sido estudada nos últimos anos é a identificação e mensuração da quantidade de actinídeos em reservatórios de lixo nuclear em substituição a métodos destrutivos ou mesmo à contagem de nêutrons para a quantificação de emissores alfa $[16,17,18]$. Como exemplificado em [17], o método da contagem de nêutrons para quantificação de emissores alfa, como um método não destrutivo, parte da hipótese de que todos os emissores estão no centro do reservatório, o que seria a pior situação possível, resultando numa superestimação da atividade do material. O mesmo princípio de interrogação ativa de material físsil por meio de fotofissão também tem sido estudado como meio de detecção de urânio em cargas transportadas internacionalmente [19].

Reatores híbridos ADS (da sigla em inglês Accelerator Driven System) ainda em fase de pesquisa e desenvolvimento tem sido propostos como alternativa aos reatores tradicionais. Reatores ADS dependem de uma fonte de nêutrons para alimentar a reação em cadeia. Estes nêutrons provêm de reações de spallation induzidas por prótons de um acelerador externo. Talvez o maior ganho no desenvolvimento desses reatores esteja na possibilidade de transmutar o lixo de reatores tradicionais em elementos com menor meia-vida. Seu funcionamento em regime subcrítico, ainda que não favorável à geração de energia para a rede elétrica, seria o bastante para tornar o reator auto-suficiente. Há um valor prático, portanto, no estudo de reações de spallation, principalmente na boa reprodução dessas reações por códigos de Monte Carlo, já que a medição experimental de todas as reações de interesse é inviável.

Voltando a atenção à fissão nuclear, não há exagero em afirmar que se trata de uma das reações mais estudadas $[19,20,21,22$, 23], e a distribuição de massa dos produtos de fissão talvez seja o observável mais importante do processo. Diversos trabalhos tem se voltado à obtenção de dados experimentais [24, 25, 26, 27, 28], bem como à devida compreensão do processo [22, 23, 29, 30], desde fissão espontânea e a baixa energia até reações induzidas por partículas carregadas e a energias mais altas. Em particular a baixa energia, a distribuição de massa e de carga dos fragmentos de fissão de actinídeos é fonte útil de informação a respeito 
da estrutura nuclear [26]. Já o conhecimento das seções de choque dos produtos de fissão dos nuclídeos ${ }^{238} \mathrm{U},{ }^{237} \mathrm{~Np}$ e ${ }^{241} \mathrm{Am}$, por exemplo, é essencial ao planejamento dos procedimentos empregados na administração de lixo nuclear [27].

Na base dos códigos de Monte Carlo voltados ao cálculo de reações nucleares estão, não apenas a fórmula de massa, mas também a barreira de fissão e o cálculo da densidade de níveis, em particular, dos parâmetros de densidade de níveis, ambos assuntos estudados e analisados há anos, porém não finalizados [31, 32, 33].

\subsection{Objetivos}

O objetivo deste trabalho está centrado na reprodução de dados experimentais de fissão de núcleos actinídeos a energias intermediárias e altas a partir de reações induzidas por fótons e prótons, com subsequente compreensão da física do processo de fissão tendo em vista o sucesso ou insucesso dos modelos e parametrizações utilizados.

Para tanto, algumas fases intermediárias foram adotadas, e de maneira mais específica se objetivou:

- a determinação de uma fórmula de massa adequada ao estudo do tema, que oferecesse precisão na região de nuclídeos de interesse;

- o ajuste dos parâmetros de densidade de níveis, sem alteração do modelo de Dostrovsky [31], com vistas ao cálculo da fotofissão de actinídeos a energias intermediárias e altas. Reações de spallation foram incluídas no ajuste a fim de determinar e, por fim, evidenciar o potencial de cálculo dos modelos implementados quando se trata de estudar uma variedade de reações nucleares;

- o ajuste de diversas parametrizações para o modelo multimodo de fissão com o fim de avaliar a possibilidade de uma única parametrização ser suficiente para a descrição do processo de fissão para várias condições diferentes. O objetivo final deste cálculo foi a 
obtenção das distribuições de massa dos fragmentos de fissão em reações induzidas por fótons e prótons.

O estudo de reações com chumbo e ouro também integrou os objetivos específicos deste trabalho. Todas as reações estudadas estão listadas a seguir:

- ${ }^{208} \mathrm{~Pb}+\gamma,{ }^{232} \mathrm{Th}+\gamma,{ }^{238} \mathrm{U}+\gamma,{ }^{237} \mathrm{~Np}+\gamma$, entre 100 e $1200 \mathrm{MeV}$;

- ${ }^{208} \mathrm{~Pb}+\mathrm{p}$, a 500 e $1000 \mathrm{MeV}$;

- ${ }^{197} \mathrm{Au}+\mathrm{p}$, a $800 \mathrm{MeV}$;

- ${ }^{237} \mathrm{~Np}+\mathrm{pe}{ }^{241} \mathrm{Am}+\mathrm{p}$, a $660 \mathrm{MeV}$

- ${ }^{238} \mathrm{U}+\gamma$ (Bremsstrahlung), com energias máximas de 50 e $3500 \mathrm{MeV}$. 


\section{Metodologia}

\subsection{Fundamentação teórica}

\subsubsection{Modelo estatístico de evaporação de Weisskopf}

Tal como Weisskopf o fez, o desenvolvimento da teoria foi feito aqui inteiramente para nêutrons, uma vez que o cálculo para partículas carregadas é análogo, sendo necessário apenas incluir a energia eletrostática no procedimento. As etapas essenciais à compreensão do modelo de evaporação de nêutrons, prótons e partículas alfa são apresentadas a seguir.

O modelo estatístico desenvolvido por Weisskopf pode ser aplicado ao cálulo do processo de evaporação nuclear desde que a diferença entre a energia de excitação nuclear e a energia de ligação da partícula seja grande quando comparada à energia cinética desta. Em resumo, a energia de excitação do núcleo residual (após evaporação) deve ser elevada para que este modelo seja eficaz.

Um modelo estatístico como esse se faz necessário uma vez que o uso de Mecânica Quântica no cálculo de reações nucleares envolvendo núcleos pesados dá origem a expressões complexas para as quais não há solução aproximada, tendo em vista se tratar de um problema de muitos corpos com forte interação entre os constituintes. Interação esta (força nuclear forte) não inteiramente compreendida. No entanto, voltar a análise para as trocas de energia envolvidas insere uma grande simplificação que permite a tomada de conclusões estatísticas e analogias termodinâmicas que bem descrevem os processos nucleares. A expulsão de partículas, por exemplo, resulta ser análoga ao processo de evaporação de um sólido ou líquido $[34,35]$. 
Fato importante para a aplicação desse método é que a distância entre os níveis de energia de núcleos pesados é pequena, permitindo que as propriedades de estados quânticos individuais sejam descartadas e a informação estatística sobre o comportamento do núcleo seja extraída da média sobre muitos estados com aproximadamente a mesma energia [36].

Um elemento de estrutura nuclear, entretanto, que permanece nas expressões gerais do modelo é a densidade de níveis, dada em função da energia de excitação.

Considera-se, então, um núcleo pesado $A$ com uma energia de excitação $E_{A}$ que se supõe maior do que a energia de ligação da partícula que poderá ser emitida (próton, nêutron ou partícula alfa). Esta energia pode ser obtida pela absorção de um fóton de alto momento ou pela colisão do núcleo com outra partícula de modo a formar o núcleo composto $A$. Antes da colisão a partícula incidente deve ter energia cinética $E_{A}-E_{0}$, sendo $E_{0}$ sua energia de ligação quando ligada ao núcleo $A$.

Ao se considerar agora a emissão de um nêutron por um núcleo excitado $A\left(E_{A}\right)$, vê-se a necessidade de que haja um grande número de possibilidades para a reação $A=B+n$, a fim de que se possa extrair informação estatística. Cada uma dessas possibilidades difere pelos estados excitados do núcleo remanescente $B\left(E_{B}\right)$. A energia $E_{A}$ deve, portanto, ser muito maior do que a energia de ligação que une o nêutron ao núcleo a fim de que exista um grande número de níveis de $B$ com energia de excitação menor do que $E_{A}-E_{0}$. Para núcleos pesados, deve-se ter que $E_{A}-E_{0}>3 \mathrm{MeV}$. O limite superior para a energia de excitação é que seja menor do que a energia de ligação total do núcleo.

Calculamos, então, a probabilidade por unidade de tempo $W_{n}(\varepsilon) d \varepsilon$ de um núcleo $A$, excitado a uma energia $E_{A}$, emitir um nêutron com energia cinética entre $\varepsilon$ e $\varepsilon+d \varepsilon$, transformandose em um núcleo $B$ com energia de excitação $E_{B}=E_{A}-E_{0}-\varepsilon$. Esta probabilidade pode depender de características do estado excitado de $A$, de modo que $W_{n}(\varepsilon) d \varepsilon$ deve ser entendida como a média sobre todos os estados de $A$ com energias próximas de $E_{A}$.

Pode-se escrever a probabilidade $W_{n}(\varepsilon) d \varepsilon$ como uma função da seção de choque do processo inverso, ou seja, da seção de choque $\sigma\left(E_{A}, \varepsilon\right)$ da colisão entre um nêutron com energia $\varepsilon$ 
e um núcleo $B\left(E_{A}-E_{0}-\varepsilon\right)$, produzindo um núcleo composto $A\left(E_{A}\right)$ [36]. Temos, então,

$$
W_{n}(\varepsilon) d \varepsilon=\sigma\left(E_{A}, \varepsilon\right) \frac{g m \varepsilon}{\pi^{2} \hbar^{3}} \frac{\omega_{B}\left(E_{B}\right)}{\omega_{A}\left(E_{A}\right)} d \varepsilon
$$

onde $\omega_{A}(E) d E$ e $\omega_{B}(E) d E$ são os números de níveis dos núcleos $A$ e $B$, respectivamente, entre $E$ e $E+d E$, sendo essas energias medidas a partir do estado fundamental. $m$ é a massa da partícula emitida, $\hbar$ é a constante de Planck dividida por $2 \pi$ e $g$ denota o número de estados de spin da partícula em questão, sendo 2 para nêutrons e prótons e 1 para partículas alfa.

É conveniente escrever a probabilidade de emissão em termos da entropia do núcleo com energia entre $E$ e $E+d E$, usando para isso o logaritmo da densidade de níveis

$$
\begin{aligned}
& S_{A}(E)=\ln \omega_{A}(E), \\
& S_{B}(E)=\ln \omega_{B}(E) .
\end{aligned}
$$

Dessa forma, temos

$$
W_{n}(\varepsilon) d \varepsilon=\sigma\left(E_{A}, \varepsilon\right) \frac{g m \varepsilon}{\pi^{2} \hbar^{3}} \exp \left[S_{B}\left(E_{A}-E_{0}-\varepsilon\right)-S_{A}\left(E_{A}\right)\right] d \varepsilon
$$

Para a obtenção da fórmula usual da probabilidade de evaporação a partir da equação (2.3) é preciso fazer a consideração de que $\varepsilon \ll E_{A}-E_{0}$. Escreve-se, então

$$
S_{B}\left(E_{A}-E_{0}-\varepsilon\right)=S_{B}\left(E_{A}-E_{0}\right)-\frac{\varepsilon}{T_{B}\left(E_{A}-E_{0}\right)}-f(\varepsilon)
$$

onde se usou que,

$$
\frac{d S_{B}}{d E}=\frac{1}{T_{B}(E)}
$$

onde $T_{B}(E)$ é a temperatura correspondente à energia $E$ do núcleo $B$, em equilíbrio termodinâmico.

$f(\varepsilon)$ contém os termos extras do desenvolvimento em série de Taylor. Chegamos, portanto a

$$
W_{n}(\varepsilon) d \varepsilon=\sigma\left(E_{A}, \varepsilon\right) \frac{g m}{\pi^{2} \hbar^{3}} e^{S_{B}\left(E_{A}-E_{0}\right)-S_{A}\left(E_{A}\right)} \varepsilon e^{-\frac{\varepsilon}{T_{B}\left(E_{A}-E_{0}\right)}} e^{-f(\varepsilon)} d \varepsilon
$$


A probabilidade total de emissão de um nêutron é obtida pela integração de (2.6) com respeito a $\varepsilon$. Se multiplicada por $\hbar$, tem-se a "largura do canal de emissão" do nêutron, $\Gamma_{n}$, a parte da largura de nível advinda da emissão de um nêutron,

$$
\Gamma_{n}=\hbar \int W_{n}(\varepsilon) d \varepsilon=\bar{\sigma} \frac{g m}{\pi^{2} \hbar^{2}} T_{B}^{2}\left(E_{A}-E_{0}\right) e^{S_{B}\left(E_{A}-E_{0}\right)-S_{A}\left(E_{A}\right)}
$$

onde $\bar{\sigma}$ é o valor médio $\sigma\left(E_{A}, \varepsilon\right) e^{-f(\varepsilon)}$ sobre a distribuição de Maxwell,

$$
\bar{\sigma}=\frac{\int \varepsilon \sigma\left(E_{A}, \varepsilon\right) e^{-\varepsilon / T_{B}-f(\varepsilon)} d \varepsilon}{\int \varepsilon e^{-\varepsilon / T_{B}} d \varepsilon} .
$$

A análise do comportamento do termo $f(\varepsilon)$ pode ser verificada no trabalho original de Weisskopf [36].

A fórmula acima pode ser aplicada à emissão de partículas carregadas, desde que se leve em conta o potencial coulombiano, o qual tem forte influência sobre a seção de choque do processo inverso, $\sigma\left(E_{A}, \varepsilon\right)$, uma vez que ele repele e deflete a partícula carregada incidente. Weisskopf, em seu trabalho, faz a consideração clássica de que qualquer partícula incidente é absorvida, de modo que se possa escrever

$$
\sigma\left(E_{A}, \varepsilon\right)= \begin{cases}\sigma_{0}(1-V / \varepsilon) & \text { para } \varepsilon>V \\ 0 & \text { para } \varepsilon<V\end{cases}
$$

onde $\sigma_{0}=\pi r^{2}$ e $V=Z Z^{\prime} e^{2} / r$, sendo $Z e$ e $r$ a carga e o raio do núcleo e $Z^{\prime} e$ a carga da partícula.

Tem-se, então, uma nova expansão para a entropia

$$
S_{B}\left(E_{A}-E_{0}-\varepsilon\right)=S_{B}\left(E_{A}-E_{0}-V\right)-\frac{(\varepsilon-V)}{T_{B}\left(E_{A}-E_{0}-V\right)}-f(\varepsilon-V) .
$$

Temos,

$$
W_{P}(\varepsilon) d \varepsilon=\sigma_{0} \frac{g m}{\pi^{2} \hbar^{3}} e^{S_{B}\left(E_{A}-E_{0}-V\right)-S_{A}\left(E_{A}\right)}(\varepsilon-V) e^{-\frac{(\varepsilon-V)}{T_{B}\left(E_{A}-E_{0}-V\right)}} e^{-f(\varepsilon-V)} d \varepsilon
$$


para a probabilidade de emissão. Para a largura de emissão, tem-se

$$
\Gamma_{P}=\sigma_{0} \frac{g m}{\pi^{2} \hbar^{2}} T_{B}^{2}\left(E_{A}-E_{0}-V\right) e^{S_{B}\left(E_{A}-E_{0}-V\right)-S_{A}\left(E_{A}\right)}
$$

Na prática, a maneira de calcular $S(E)$ é por meio de $T(E)$. Precisamos saber a dependência da energia mais provável do núcleo sobre a temperatura em equilíbrio termodinâmico, e então escrevemos

$$
S(E)=\int \frac{d E}{T(E)}
$$

A energia $E$ pode, em geral, ser escrita como

$$
E=\frac{T^{n}}{a}
$$

onde $a$ é uma constante. Pode-se considerar o núcleo como um gás degenerado de partículas. Dessa forma, a energia do núcleo deve obedecer à estatística de Fermi, a qual estabelece que

$$
E=\frac{T^{2}}{a}
$$

Este resultado também é conhecido como expansão de Sommerfeld.

A partir de (2.13) e (2.15), temos, portanto

$$
\begin{aligned}
& S(E)=2(E / a)^{1 / 2}+\text { const. } \\
& \omega(E)=\text { const } . \exp \left[2(E / a)^{1 / 2}\right] .
\end{aligned}
$$

\subsubsection{Modelo para a probabilidade de fissão}

Os fundamentos da teoria que descreve o mecanismo de fissão nuclear foram formalizados e estabelecidos por Bohr e Wheeler [5] em 1939. Desde então se compreende aquilo que aparece ilustrado na Figura 2.1(a). Ela mostra a energia potencial nuclear em função da elongação, a distância entre os centros dos dois futuros fragmentos, produzidos caso a fissão ocorra. Com a deformação nuclear, e aumento da elongação, o núcleo alcança a região da energia potencial 
nuclear chamada de barreira de fissão, indicada na figura como $B_{f}$.

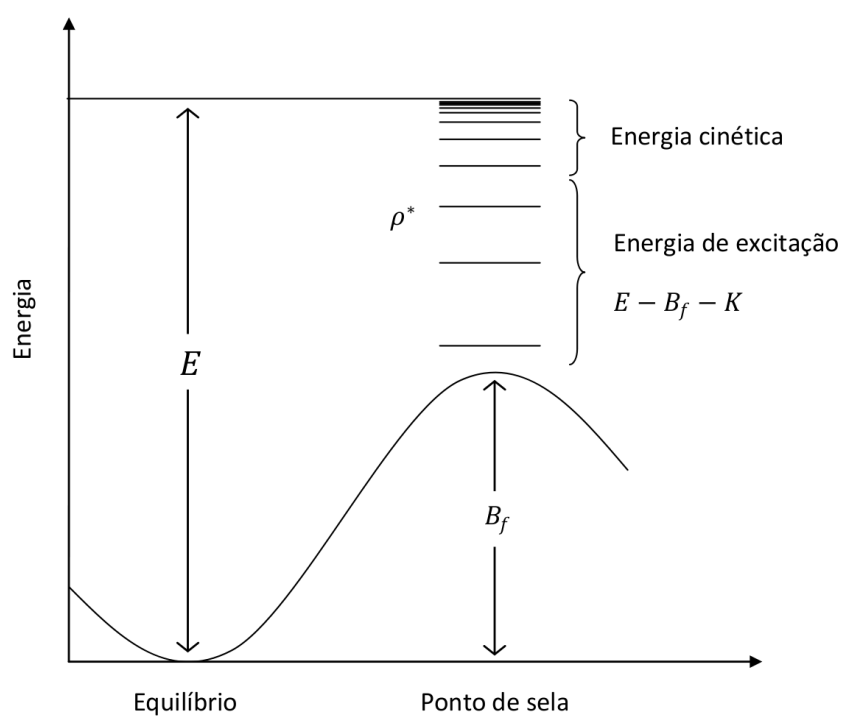

(a)

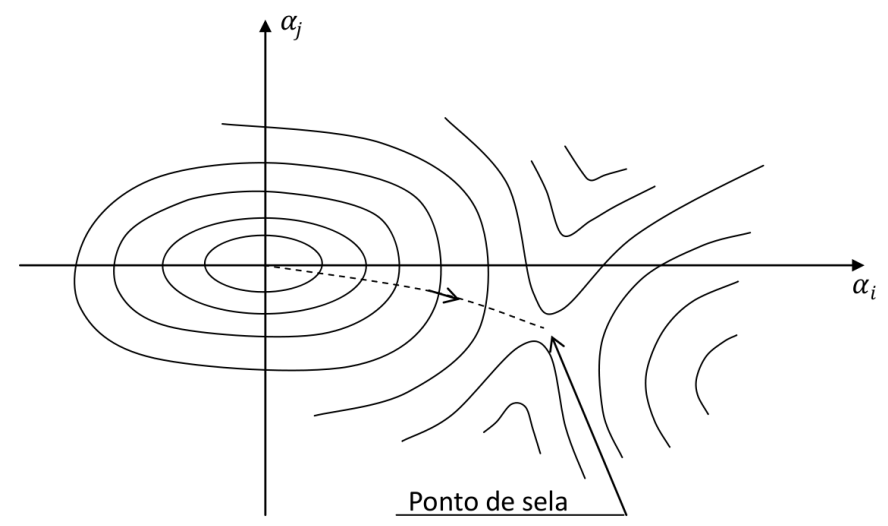

(b)

Figura 2.1: (a) Esquema da energia potencial nuclear no ponto de equilíbrio e no ponto de sela, com indicação dos níveis no estado de transição. (b) Esboço em curvas de nível da superfície de energia potencial em função de dois parâmetros de deformação arbitrários. O ponto de sela está indicado no ponto de equilíbrio instável.

A energia potencial nuclear também pode ser graficada numa superfície em termos de parâmetros que descrevam a deformação do núcleo. A Figura 2.1(b) mostra um esboço dessa superfície em função de dois parâmetros de deformação quaisquer $\alpha_{i}$ e $\alpha_{j}$. A origem e significado detalhado desses parâmetros será apresentada a seguir, ainda nesta seção, no contexto da barreira de fissão.

O ponto de deformação crítica do núcleo é caracterizado pelo ponto de sela na superfície de energia potencial, correspondente à região da barreira. A linha tracejada na figura ilustra o 
caminho que um núcleo percorreria do seu estado fundamental, na origem de coordenadas, até o equilíbrio instável no ponto de sela.

Para além do ponto de sela, tendo ultrapassado portanto a barreira de fissão, o núcleo individualizado dá lugar aos dois fragmentos, de modo que o núcleo naquele ponto está ocupando um estado de transição e é dito composto, naquelas circunstâncias.

Pode-se escrever a largura de fissão, $\Gamma_{f}$, em termos do coeficiente de transmissão $T_{f}$ [37] e do espaçamento médio entre níveis de energia, $D$,

$$
\Gamma_{f}=\frac{D}{2 \pi} \sum T_{f}
$$

A altas energias de excitação, pode-se integrar sobre os níveis de energia no estado de transição, considerando que para todas as energias acima da barreira de fissão se tem $T_{f}=1$, obtendo assim

$$
\Gamma_{f}=\frac{D}{2 \pi} \int_{0}^{E-B_{f}} \rho^{*}\left(E-B_{f}-K\right) d K
$$

Para algumas aplicações, convém calcular a probabilidade de fissão relativa à emissão de nêutrons. Para este fim, pode-se reescrever a largura de emissão de nêutrons de uma forma mais adequada, porém equivalente àquela obtida por Weisskopf.

Temos que, para um único canal de decaimento, $\Gamma_{n}=(D / 2 \pi) T_{n}$, onde $T_{n}$ é o coeficiente de transmissão neste caso. No caso de vários estados finais possíveis, uma soma sobre os diversos coeficientes de transmissão deve ser considerada,

$$
\Gamma_{n}=\frac{D}{2 \pi} \sum T_{n}
$$

Esta expressão é válida a baixas energias, em que apenas a emissão de onda s (caso $l=0$ ) ocorre. A altas energias, em que há a contribuição de outras ondas parciais, deve-se somar sobre todos os momentos angulares em um mesmo nível de energia final. Para altas energias também o momento angular é alto, resultando em maior densidade de níveis, assim a soma $\sum_{l}(2 l+1) T_{l}$ pode ser substituída pela integral $\int(2 l+1) T_{l} d l$. Considerando que $T_{l}$, coeficiente de transmissão associado a cada valor de momento, vale a unidade até o momento angular 
máximo do nêutron, $l_{m}$, e zero para $l>l_{m}$, temos,

$$
\int_{0}^{l_{m}}(2 l+1) T_{l} d l \simeq l_{m}^{2}=\left(\frac{R p}{\hbar}\right)^{2}=\frac{2 m R^{2} \varepsilon}{\hbar^{2}}
$$

onde, para o cálculo de $l_{m}$, se considerou a emissão de um nêutron de energia $\varepsilon$ e massa $m$ da superfície nuclear numa direção tangente à superfície. $R$ é o raio nuclear. Integrando agora sobre os níveis de energia finais do núcleo residual, $\rho^{*}\left(E-B_{n}-\varepsilon\right)$, temos

$$
\Gamma_{n}=\frac{D}{2 \pi} \frac{2 m R^{2} g}{\hbar^{2}} \int_{0}^{E-B_{n}} \varepsilon \rho^{*}\left(E-B_{n}-\varepsilon\right) d \varepsilon
$$

onde $g$ é degenerescência de spin (2 para nêutrons e prótons).

Chegamos então à forma integral da razão $\Gamma_{f} / \Gamma_{n}$ a partir das equações (2.18) e (2.21),

$$
\frac{\Gamma_{f}}{\Gamma_{n}}=\frac{\hbar^{2}}{2 m r_{0}^{2} g A^{2 / 3}} \frac{\int_{0}^{E-B_{f}} \rho^{*}\left(E-B_{f}-K\right) d K}{\int_{0}^{E-B_{n}} \varepsilon \rho^{*}\left(E-B_{n}-\varepsilon\right) d \varepsilon}
$$

Uma forma funcional fechada pode ser obtida pela integração de (2.22) desde que se utilize uma expressão adequada para a densidade de níveis. A mais simples é aquela tomada à temperatura constante

$$
\rho(E)=\text { const } . \exp \left(\frac{E}{T}\right)
$$

que conduz a

$$
\frac{\Gamma_{f}}{\Gamma_{n}}=\frac{K_{0}}{2 T A^{2 / 3}} \exp \left[-\frac{\left(B_{f}-B_{n}\right)}{T}\right]
$$

onde $K_{0}=\hbar^{2} / 2 m r_{0}^{2}$.

\section{Dependência da razão $\Gamma_{f} / \Gamma_{n}$ na energia de excitação}

A expressão (2.23) para a densidade de níveis não é adequada para a inclusão da dependência da razão $\frac{\Gamma_{f}}{\Gamma_{n}}$ na energia de excitação. Uma abordagem mais realista, em que não se considera a temperatura constante, é obtida a partir da expressão para a densidade de níveis já utilizada 
anteriormente na subseção 2.1.1, que considera o núcleo como um gás degenerado,

$$
\rho(E) \propto \exp \left[2(a E)^{1 / 2}\right]
$$

onde $a$ é o parâmetro de densidade de níveis nuclear. A substituição de (2.25) na equação (2.22) conduz, após integração, a

$$
\frac{\Gamma_{f}}{\Gamma_{n}}=K_{0} a_{n} \frac{\left[2 a_{f}^{1 / 2}\left(E-B_{f}\right)^{1 / 2}-1\right]}{4 A^{2 / 3} a_{f}\left(E-B_{n}\right)} \exp \left[2 a_{f}^{1 / 2}\left(E-B_{f}\right)^{1 / 2}-2 a_{n}^{1 / 2}\left(E-B_{n}\right)^{1 / 2}\right]
$$

Esta equação foi primeiramente obtida por Vandenbosch e Huizenga [37].

Como demonstrado na literatura [37], não é possível ajustar a magnitude da razão $\Gamma_{f} / \Gamma_{n}$ a dados experimentais se for considerado $a_{n}=a_{f}$. De fato, quando um bom acordo foi conseguido, a razão $a_{f} / a_{n}$ foi invariavelmente maior do que a unidade, não ultrapassando, entretanto, $20-30 \%$.

\section{Barreira de fissão}

Como ilustrado na Figura 2.1, a barreira de fissão corresponde a energia potencial nuclear atingida no ponto de sela de fissão quando da deformação crítica do núcleo, esta comparada à deformação de uma gota líquida carregada.

Nos últimos 50 anos, avanços teóricos na Física Nuclear permitiram o desenvolvimento de novos meios para se calcular a energia potencial de um núcleo em função de sua forma e do seu número de constituintes. Alguns métodos foram propostos com o fim de determinar a forma nuclear,

- Expansão em polinômios de Legendre;

- Esferóides perturbados;

- Esferóides generalizados;

- Ovais de Cassini perturbados; 
- Parametrização a partir de dois centros (dois corpos em contato em lugar de um);

- Uso de três superfícies quadráticas de revolução.

Detalhes a respeito de cada método podem ser encontrados, por exemplo, em [38].

Assumindo a analogia com uma gota líquida, Cohen e Swiatecki [39] estudaram a configuração da gota (considerando simetria axial) expressando o raio vetor $R(\theta)$, do centro à superfície da gota, em termos de uma expansão nos polinômios de Legendre,

$$
R(\theta)=\frac{R_{0}}{\lambda}\left[1+\sum_{1}^{N} \alpha_{n} P_{n}(\cos \theta)\right]
$$

onde os $N$ coeficientes $\alpha_{n}$ deteminam a deformação da gota e $\lambda$ é um parâmetro de normalização do volume, a fim de mantê-lo constante em $(4 / 3) \pi R_{0}^{3}$.

A Figura 2.2 mostra diversas formas assumidas pela superfície nuclear quando plotadas num gráfico dos coeficientes de deformação $\alpha_{2}$ e $\alpha_{4}$. Como o problema é aproximado para o caso em que se tem apenas deformações simétricas do núcleo, os termos ímpares da expansão em polinômios de Legendre são descartados. As contribuições dos demais termos da expansão, $n>4$, são quase uma ordem de magnitude menores do que os termos $\alpha_{2}$ e $\alpha_{4}$, e portanto, a deformação nuclear costuma ser graficada apenas no plano $\alpha_{2}-\alpha_{4}$.

Parte-se, então, ao cálculo da energia macroscópica do núcleo a partir de sua forma, determinada por um dos métodos acima. Uma vez que se faça uso do modelo da gota líquida, ao todo 4 termos são necessários para o cálculo da energia do núcleo. Um termo de superfície, $B_{S}$, e um coulombiano, $B_{c}$, dependentes apenas da forma, a energia de superfície para um núcleo esférico, $E_{s}^{0}$, e a energia coulombiana, $E_{c}^{0}$, também para um núcleo esférico. Em suma a energia coulombiana tende a separar o núcleo enquanto a energia de superfície é responsável por manter o núcleo coeso.

Então, em analogia com o modelo da gota líquida, escrevemos a energia do núcleo como [38]

$$
E_{g l}(N, Z, \text { forma })=\left\{\left[B_{s}(\text { forma })-1\right]+2 x_{0}\left[B_{c}(\text { forma })-1\right]\right\} E_{s}^{0},
$$




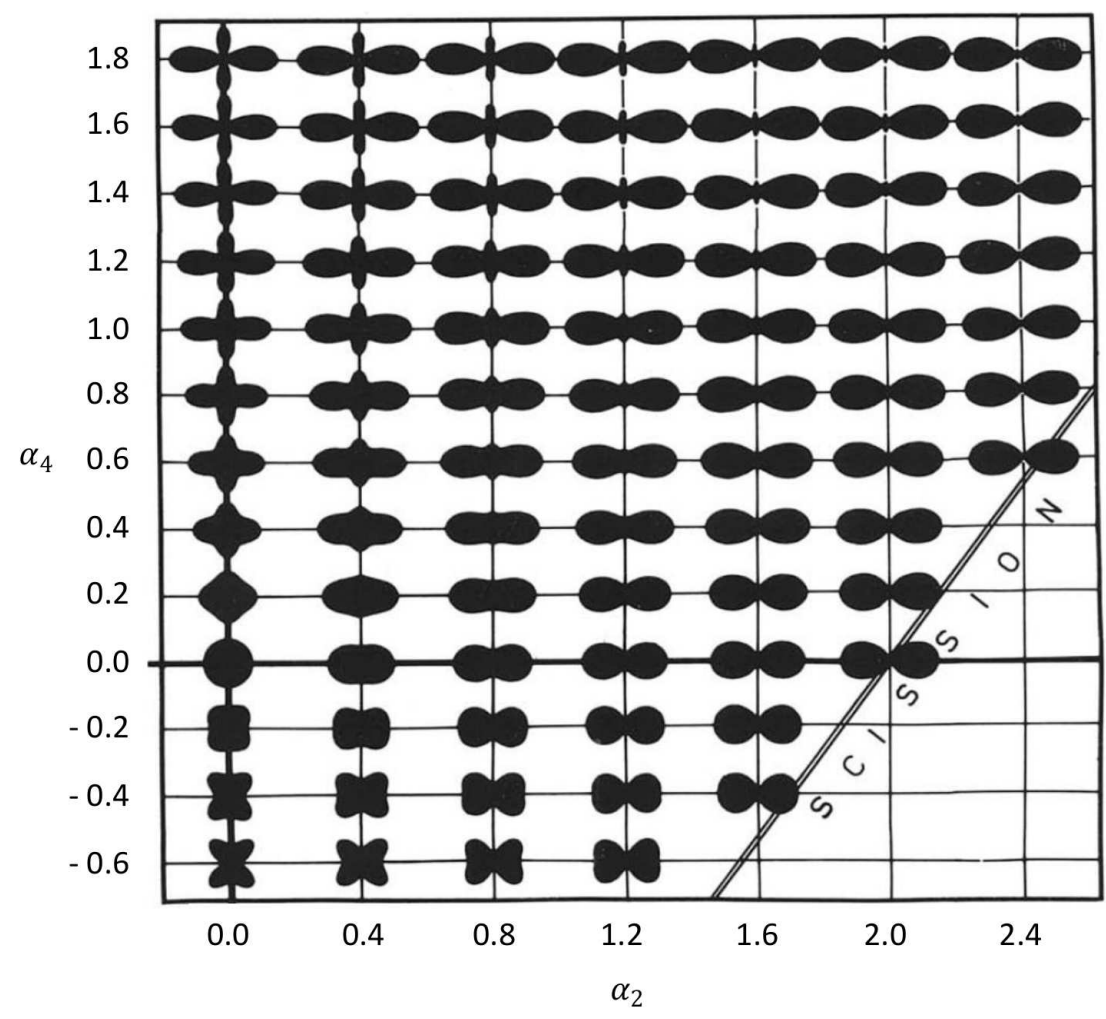

Figura 2.2: Variação da superfície nuclear em função dos coeficientes de deformação $\alpha_{2}$ e $\alpha_{4}$. Adaptado de [40].

O termo de superfície, $B_{S}$, é uma integral unidimensional quando se limita o problema à simetria axial. Se a forma nuclear estiver definida em termos de três superfícies quadráticas de revolução, o problema recai em funções transcendentais elementares [41]. No entanto, mesmo para simetria axial, o termo coulombiano, $B_{c}$, é uma integral bidimensional que envolve integrais elípticas completas de primeira e segunda ordem [40,41], ou ainda uma integral tridimensional de integrando simples [42].

A energia de superfície para um núcleo esférico, $E_{s}^{0}$, é escrita na parametrização de Nix como

$$
E_{s}^{0}=a_{s}\left(1-\kappa I^{2}\right) A^{2 / 3}
$$

sendo $\kappa$ uma constante que determina o decréscimo na energia de superfície com o aumento o excesso de nêutrons, com $I=(N-Z) / A$. A energia coulombiana, também para um núcleo 
esférico, é

$$
E_{c}^{0}=\frac{3 e^{2}}{5 r_{0}} \frac{Z^{2}}{A^{1 / 3}}=a_{c} \frac{Z^{2}}{A^{1 / 3}} .
$$

O parâmetro $x_{0}$ na equação (2.28) é o parâmetro de fissilidade, que relaciona as energias de superfície e coulombiana. Para pequenas distorções, o coeficiente $\alpha_{4}$ em (2.27) é pequeno comparado a $\alpha_{2}$ [37]. Portanto, do trabalho de Bohr e Wheeler [5], tem-se ambas energias para um núcleo deformado, calculadas fazendo-se uso da equação (2.27), escritas como

$$
E_{s}=E_{s}^{0}\left(1+\frac{2}{5} \alpha_{2}^{2}\right), \quad E_{c}=E_{c}^{0}\left(1-\frac{1}{5} \alpha_{2}^{2}\right)
$$

O núcleo passa à instabilidade quando o módulo da variação da energia coulombiana, $\left|\Delta E_{c}\right|=\frac{1}{5} \alpha_{2}^{2} E_{c}^{0}$, é igual à variação da energia de superfície $\Delta E_{s}=\frac{2}{5} \alpha_{2}^{2} E_{s}^{0}$. O parâmetro de fissilidade, $x_{0}$, fica então definido por

$$
x_{0}=\frac{\left|\Delta E_{c}\right|}{\Delta E_{s}}=\frac{E_{c}^{0}}{2 E_{s}^{0}} .
$$

De acordo com o modelo de Nix,

$$
x_{0}=\frac{Z^{2} / A}{\left(2 a_{s} / a_{c}\right)\left(1-\kappa I^{2}\right)},
$$

Para $x_{0}<1$, o núcleo é estável com respeito a pequenas deformações. Para $x_{0}=1$, o núcleo passa a ser instável com respeito a deformações. Quando $x_{0}>1$, ocorre fissão espontânea do núcleo. A Figura 2.3 mostra que quanto menor o valor do parâmetro de fissilidade $x_{0}$, maior deve ser a deformação do núcleo no ponto de sela para que haja fissão.

Os melhores parâmetros encontrados, de acordo com o trabalho de Nix foram,

$$
a_{s}=17,9439 \mathrm{MeV} ; \quad \kappa=1,7826 ; \quad a_{c}=0,7053 \mathrm{MeV}
$$

O uso desses parâmetros implica em $r_{0}=1,2249 \mathrm{fm}$. 


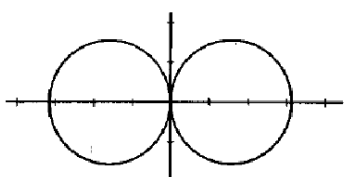

$x_{0}=0.0$

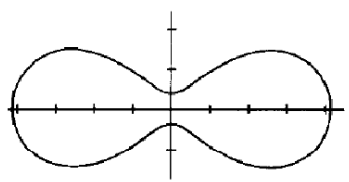

$x_{0}=0.5$

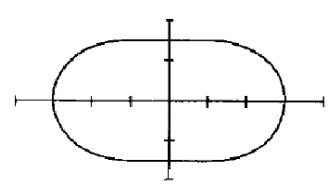

$x_{0}=0.8$

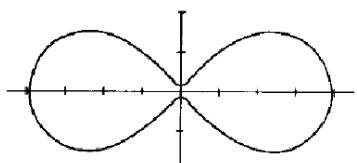

$x_{0}=0.3$

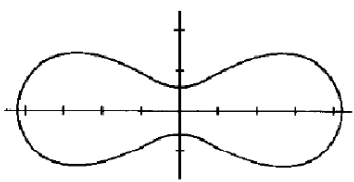

$x_{0}=0.6$

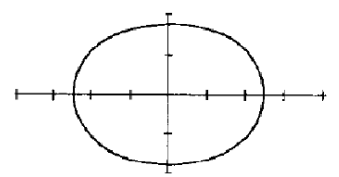

$x_{0}=0.9$

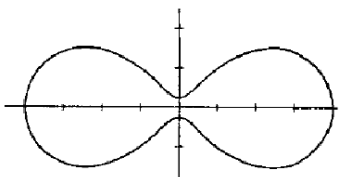

$x_{0}=0.4$

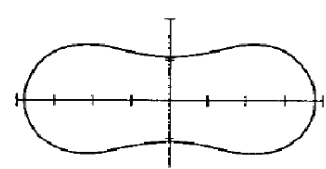

$x_{0}=0.7$

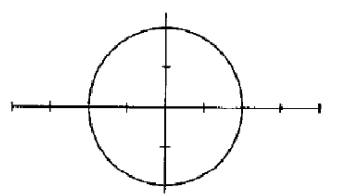

$x_{0}=1.0$

Figura 2.3: Diversos pontos de cela para deformação simétrica, para diferentes valores do parâmetro de fissilidade $x_{0}$. Adaptado de [39].

\subsubsection{Modelo multimodo para distribuições de massa de fragmentos}

O processo pelo qual a fissão se processa tem sido bem descrito pelo Modelo Estatístico de Cisão [22, 23, 30], o qual leva em conta efeitos coletivos da deformação nuclear durante a fissão fazendo uso do modelo da gota líquida assim como efeitos de partícula única que são inseridos por correções do modelo microscópico de camada. As correções microscópicas criam vales no espaço de elongamento e número de massa, cada vale correspondendo a um diferente modo de fissão [23].

A seção de choque resulta da soma incoerente das contribuições de cada canal de fissão, $\sigma_{i}(A, Z)$, o qual é normalmente escrito na forma

$$
\sigma_{i}(A, Z)=\frac{K_{i}}{\sqrt{2 \pi} \Gamma_{i}} \exp \left[-\frac{\left(A-A_{i}\right)^{2}}{2 \Gamma_{i}^{2}}\right] \sigma(Z)
$$

onde $K_{i}$ é a intensidade do i-ésimo canal, o parâmetro $A_{i}$ é a posição da massa mais provável do fragmento de fissão, e $\Gamma_{i}$ é a largura da distribuição de massa de acordo com o Modelo Estatístico de Cisão. 
Para a distribuição de carga, $\sigma(Z)$, muitos autores utilizam a abordagem de uma distribuição uniforme de carga, em que se assume que a densidade de carga dos fragmentos é igual àquela do núcleo fissionante. Entretanto, mostrou-se [43] que para actinídeos a distribuição de carga dos fragmentos é melhor descrita por uma função gaussiana,

$$
\sigma(Z)=\frac{1}{\sqrt{\pi} \Gamma_{Z}} \exp \left[-\frac{\left(Z-Z_{0}\right)^{2}}{\Gamma_{Z}^{2}}\right]
$$

onde $\Gamma_{Z}$ é a largura da distribuição de carga e $Z_{0}$ é o número atômico mais provável.

Este método tem sido utilizado para descrever fissão espontânea [44], fissão induzida a baixa energia [29, 45, 46], fissão induzida por nêutrons térmicos [47, 48, 49] e prótons de 12 $\mathrm{MeV}$ [50], e mesmo fissão induzida por projéteis de energia intermediária, como prótons de $190 \mathrm{MeV}$ [51] e nêutrons com energias até $200 \mathrm{MeV}$ [52], e fissão também induzida por íons pesados $[53,54]$. Os resultados até então obtidos tem mostrado que para os núcleos actinídeos três modos de fissão são suficientes para explicar os dados experimentias existentes, a saber, um modo simétrico, Superlong (SL), e dois modos assimétricos, Standard I (SI) e Standard II (SII).

\subsection{Ferramentas Computacionais}

Todas as reações nucleares estudadas neste trabalho foram calculadas computacionalmente. E não apenas os resultados de cada reação foram inteiramente fruto de simulações como também se fez uso de ferramentas computacionais especializadas em análise e cálculo para o próprio desenvolvimento dos códigos utilizados. O código de Monte Carlo CRISP, acrescido de novos modelos e parametrizações, foi usado na simulação de cada reação. Ferramentas matemáticas presentes na plataforma de cálculo ROOT [55], desenvolvida pelo laboratório CERN, foram em parte integradas ao CRISP para compor suas rotinas de simulação e ainda utilizadas ao final, para análise. Uma descrição dos pormenores mais importantes de cada ferramenta é feita a seguir. 


\subsubsection{Código CRISP}

CRISP é um código de Monte Carlo escrito em C++ para simulação de reações nucleares [56] que utiliza um processo de cálculo baseado em duas etapas. Primeiramente uma cascata intranuclear é simulada. Quando a partícula incidente é um próton, este interage na superfície com algum nucleon do sistema, podendo o espalhamento ser elástico ou inelástico. Fótons podem interagir mais internamente no núcleo e sua absorção dá origem a ressonâncias nucleônicas.

Partículas secundárias são produzidas, as quais possuem energias relativamente altas comparadas às dos demais nucleons no mar de Fermi e ocupam níveis de partícula única altamente energéticos [57, 58, 59]. São chamadas partículas de cascata.

As partículas secundárias geradas na colisão primária se propagam no interior do núcleo e podem interagir com outras partículas ou alcançar a superfície nuclear. Neste caso, se sua energia for superior à energia de ligação nuclear, tal partícula escapará, de outra forma será refletida de volta e continuará sua propagação no interior do núcleo. O número de partículas de cascata aumenta enquanto a cascata intranuclear prossegue, e a decisão de parar esta primeira etapa da reação se baseia em um critério energético, de tal forma que, não havendo qualquer partícula ligada em um estado excitado ou com energia cinética superior à energia de ligação, os processos de cascata são finalizados [60].

No último estágio da cascata, em que nemhuma partícula possui energia suficiente para escapar do núcleo, uma sequência de colisões distribui a energia de excitação nuclear entre todos os nucleons, num processo conhecido por termalização. As principais características do núcleo não mudam neste estágio da cascata, de modo que seu número atômico, número de massa e energia de excitação permanecem os mesmos até o fim do processo.

Um aspecto importante no código CRISP é a abordagem multi-colisional que é dada à simualação da cascata intranuclear, na qual todos os nucleons se movem simultaneamente. A sequência ordenada de colisões considera a probabilidade de interação com todas as partículas, baseando-se em suas respectivas seções de choque. Tal abordagem torna natural a verificação de 
aspectos dinâmicos como modificações na densidade nuclear e evolução dos níveis de ocupação.

O bloqueio de Pauli é outro mecanismo de grande relevânica que está inserido no código CRISP segundo um método preciso de verificação da disponibilidade de estados de partícula única, isto possibilitado pela abordagem multi-colisional. Sem o mecanismo de Pauli, não seria possível um critério energético para término da cascata intranuclear [61].

No código CRISP, reações podem ser iniciadas por prótons [58] ou fótons [21, 58, 59, 61] de energias intermediárias e altas. CRISP fornece bons resultados para seções de choque de fotoabsorção, de aproximadamente $50 \mathrm{MeV}$, região em que o mecanismo de quase-dêuteron é dominante, até $3.5 \mathrm{GeV}$, onde o mecanismo de foto-hadronização é relevante, levando a efeitos de sombreamento na seção de choque [60].

A segunda etapa do processo de cálculo consiste na competição entre evaporação e fissão. O modelo de Weisskopf [36] é adotado para o cálculo das probabilidades de emissão de partículas, no qual as evaporações de nêutrons, prótons e partículas alfa são incluídas [21, 61, 62], como também o modelo de Dostrovsky para o cálculo dos parâmetros de densidade de níveis [31]. O modelo de Bohr-Wheeler é adotado para a fissão [5]. Detalhes a respeito de como estes modelos são empregados no CRISP serão tratados na seção 2.3.

A distinção de uma reação nuclear nas duas etapas acima não é um fato experimental verificável, embora seja de grande valor e utilidade no estudo teórico e fenomenológico dos processos envolvidos.

\subsubsection{Plataforma ROOT}

ROOT é uma plataforma orientada a objeto dedicada a prover soluções de cálculo e análise, em particular para a Física de Altas Energias. A plataforma está escrita em linguagem C++ e suas ferramentas estão implementadas de maneira modular ou em classes. A grande maioria dessas classes fornece funcionalidades de natureza fundamental, de modo a não restringir seu uso apenas à Física. Assim, o ROOT é facilmente integrado ao cálculo e análise em qualquer outra área, seja acadêmica ou tecnológica. 
O pacote Minuit [63] para ajuste de parâmetros possui atualmente uma implementação incorporada ao ROOT o qual fornece duas interfaces para Minuit com ferramentas especializadas na minimização de funções. Pode ser utilizado no ajuste de curvas a certo conjunto de dados experimentais pela verificação dos melhores parâmetros para estas curvas, ou no ajuste de parâmetros relevantes em modelos como os que são utilizados no CRISP, que envolvem uma série de rotinas de cálculo antes que se chegue ao resultado final. Em ambos os casos, a função a ser minimizada é o $\chi^{2}$.

O ROOT v5.28 foi utlizado para a realização deste trabalho.

\subsection{Descrição do método}

O foco deste estudo esteve, do ponto de vista dos modelos trabalhados, na segunda etapa da reação, o processo de competição entre evaporação e fissão. Nesta etapa, a correta reprodução das massas nucleares é essencial dada a sua necessidade no cálculo das energias de separação de partículas que entram no modelo de Weisskopf para o cálculo das probabilidades de emissão.

Sendo assim, a primeira fase do trabalho consistiu em definir a fórmula de massa ótima, que oferecesse bons resultados para a maior região possível de núcleos e em particular para aquela em que o CRISP é usualmente utilizado.

Num segundo momento, os parâmetros de densidade de níveis foram ajustados simultaneamente para reações de fotofissão e spallation. Estudou-se a fotofissão dos núcleos ${ }^{208} \mathrm{~Pb}$, ${ }^{232} \mathrm{Th},{ }^{238} \mathrm{U}$ e ${ }^{237} \mathrm{~Np}$, a energias que vão de 100 a $1200 \mathrm{MeV}$. Foram escolhidas as reações ${ }^{208} \mathrm{~Pb}$ $+1 \mathrm{GeV}$ p e ${ }^{197} \mathrm{Au}+800 \mathrm{MeV}$ p para estudar as parábolas de spallation. Este ajuste global objetivou a minimização do $\chi^{2}$ sobre as seções de choque em todos os casos.

Apenas após a obtenção de um modelo que apresentasse um bom acordo com dados experimentais para uma variedade de núcleos e reações no que diz respeito ao cálculo de evaporação de partículas e de fissão, é que se procedeu ao cálculo das distribuições de massa de fragmentos de fissão com a implementação de um modelo para a determinação dos modos pelos quais um 
núcleo pode fissionar. A fissão induzida por prótons de $660 \mathrm{MeV}$ foi estudada com os núcleos ${ }^{241} \mathrm{Am} \mathrm{e}{ }^{237} \mathrm{~Np}$. Usou-se prótons de $500 \mathrm{MeV}$ e $1000 \mathrm{MeV}$ para o estudo da fissão do ${ }^{208} \mathrm{~Pb}$ bem como prótons de $800 \mathrm{MeV}$ para o estudo da fissão do ${ }^{197} \mathrm{Au}$. Também foram estudados dois casos de reações de Bremsstrahlung com o ${ }^{238} \mathrm{U}$, com duas energias máximas para o fóton, 50 MeV e 3.5 GeV. O CRISP não calcula seções de choque abaixo da região do quase-dêuteron, de modo que para fótons com energia inferior a $40 \mathrm{MeV}$, a energia do fóton era atribuída ao núcleo alvo como energia de excitação e a cascata era finalizada. Por fim, o cálculo da evaporação dos fragmentos de fissão foi adicionado e suas distribuições de massa foram calculadas.

Os detalhes dos modelos referentes a cada fase, bem como do modo como foram inseridos no CRISP são apresentados a seguir.

\subsubsection{Fórmula semi-empírica de massa}

Uma nova fórmula de massa foi introduzida no código CRISP de acordo com a proposta de Pearson [64] para a energia interna de um núcleo [65]. Partindo do fato de que a massa nuclear é dada por

$$
M(A, Z)=Z m_{p}+N m_{n}-B(A, Z)
$$

em que $Z$ é o número de prótons, $N$ é o número de nêutrons, $m_{p}$ e $m_{n}$ são as massas do próton e do nêutron, respectivamente, e $B(A, Z)$ é a energia de ligação nuclear, temos a atual fórmula semi-empírica de massa escrita como

$$
M(A, Z)=Z m_{p}+N m_{n}+a_{v} A+a_{s f} A^{2 / 3}+\frac{3 e^{2}}{5 r_{0}} \frac{Z^{2}}{A^{1 / 3}}+\left(a_{s y m}+a_{s s} A^{-1 / 3}\right) \frac{(N-Z)^{2}}{A},
$$

onde $e$ é a carga elementar e $r_{0}=1.2 \mathrm{fm}$. Os sinais da equação (2.38) foram ajustados com o programa Minuit juntamente com os valores absolutos de cada parâmetro.

\section{Termo de volume}

A Figura 2.4 mostra a energia de ligação nuclear por nucleon em função do número de nucleons. Vê-se que é aproximadamente constante, podendo-se dizer que a energia total de 
ligação é linear com $A$, em primeira aproximação. O termo $a_{v} A$ é portanto o chamado termo de volume da energia de ligação.

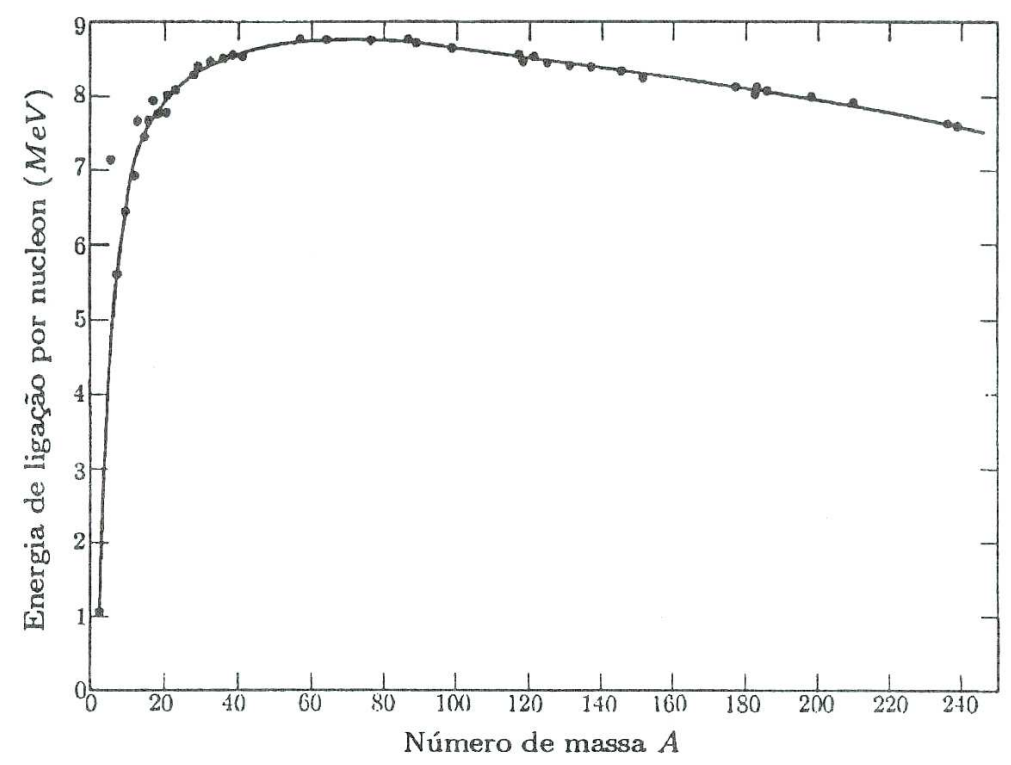

Figura 2.4: Energia de ligação por nucleon [66].

\section{Termo de superfície}

Essa primeira aproximação, no entanto, não leva em conta que os nucleons da superfície nuclear são menos ligados por não estarem rodeados em todos os lados por outros nucleons, sendo assim necessária uma correção, que numa nova aproximação, é proporcional tão somente à superfície nuclear. Tem-se, assim, o termo de superfície dado por $a_{s f} A^{2 / 3}$.

\section{Termo coulombiano}

Como o núcleo é um sistema com carga, deve-se considerar sua energia coulombiana no cálculo de sua energia total. Em particular, a repulsão coulombiana entre os prótons tem o efeito de reduzir a energia de ligação. Usa-se o resultado já conhecido da eletrostática, $\frac{3 e^{2}}{5 r_{0}} \frac{Z^{2}}{A^{1 / 3}}$. 


\section{Termo de simetria}

Devido a prótons e nêutrons serem férmions, obedecendo portanto ao princípio de exclusão de Pauli, a configuração menos energética do sistema, e assim com maior energia de ligação é aquela com menor assimetria no número de nêutrons e prótons. Dessa forma o núcleo tende a apresentar quantidades semelhantes de cada um. Esse efeito é levado em conta pelo termo de simetria, parametrizado por Pearson como $\left(a_{s y m}+a_{s s} A^{-1 / 3}\right) \frac{(N-Z)^{2}}{A}$.

\section{Ajuste dos parâmetros}

No trabalho descrito em [64], os parâmetros da fórmula foram ajustados a partir da compilação de massas atômicas de 1995 feita por Audi e Wapstra [67]. Para este trabalho, um novo ajuste foi realizado utilizando-se para isso o pacote Minuit do ROOT, tendo em vista a nova compilação de Audi e Wapstra de 2003 [68]. Além disso, para o ajuste dos parâmetros os valores de massa nuclear foram restritos à região de $A \geq 12$, por ser este o intervalo de interesse para todos os estudos realizados com o código CRISP até então.

Os valores obtidos pelo Minuit são apresentados na Tabela 3.1, em que cada parâmetro leva seu devido sinal.

\subsubsection{Cálculo de evaporação}

A termalização do núcleo no final da cascata intranuclear é seguida pelo processo de evaporação, quando nucleons ou pequenos clusters $^{1}$ são emitidos carregando parte da energia de excitação nuclear. Esse processo continua enquanto houver energia suficiente no núcleo para a evaporação de alguma partícula. O processo consiste numa seqüência de emissões por parte do núcleo, cada uma governada pela teoria de Weisskopf (subseção 2.1.1). O regime de evaporação é determinado pelas probabilidades relativas dos diferentes canais de emissão.

Estas probabilidades são obtidas pela largura de emissão da partícula, de modo que para a

\footnotetext{
${ }^{1}$ cluster: grupos de mais de um nucleon que também podem ser emitidos no processo de evaporação nuclear
} 
emissão de prótons, tem-se

$$
\frac{\Gamma_{p}}{\Gamma_{n}}=\frac{E_{p}}{E_{n}} \exp \left\{2\left[\left(a_{p} E_{p}\right)^{1 / 2}-\left(a_{n} E_{n}\right)^{1 / 2}\right]\right\}
$$

e para a emissão de partículas alfa

$$
\frac{\Gamma_{\alpha}}{\Gamma_{n}}=\frac{2 E_{\alpha}}{E_{n}} \exp \left\{2\left[\left(a_{\alpha} E_{\alpha}\right)^{1 / 2}-\left(a_{n} E_{n}\right)^{1 / 2}\right]\right\}
$$

onde

$$
\begin{aligned}
& E_{n}=E-B_{n}, \\
& E_{p}=E-B_{p}-V_{p}, \\
& E_{\alpha}=E-B_{\alpha}-V_{\alpha},
\end{aligned}
$$

com os parâmetros de densidade de níveis calculados, respectivamente para nêutrons, prótons e alfas, pelas fórmulas empíricas de Dostrovsky [31],

$$
\begin{aligned}
& a_{n}=\frac{A}{a_{1}}\left(1-a_{2} \frac{A-2 Z}{A^{2}}\right)^{2}, \\
& a_{p}=\frac{A}{a_{3}}\left(1+a_{4} \frac{A-2 Z}{A^{2}}\right)^{2}, \\
& a_{\alpha}=\frac{A}{a_{5}}\left(1-\frac{a_{6}}{Z}\right)^{2} .
\end{aligned}
$$

Além disso, $V_{p}$ e $V_{\alpha}$ são os potenciais de Coulomb para prótons e partículas alfa, respectivamente, e são dados pelas expressões

$$
\begin{aligned}
& V_{p}=C \frac{K_{p}(Z-1) e^{2}}{r_{0}(A-1)^{1 / 3}+R_{p}}, \\
& V_{\alpha}=C \frac{2 K_{\alpha}(Z-2) e^{2}}{r_{0}(A-4)^{1 / 3}+R_{\alpha}}
\end{aligned}
$$

onde $K_{p}=0.70$ e $K_{\alpha}=0,83$ são as penetrabilidades de barreira coulombiana para prótons e partículas alfa. Também, $R_{p}=1,14$ fm é o raio do próton, $R_{\alpha}=2,16$ fm é raio da partícula alfa, e $r_{0}=1,2 \mathrm{fm}$. $C$ é a correção de barreira para partículas carregadas e é calculada de acordo com

$$
C=1-\frac{E}{B}
$$


sendo $B$ a energia de ligação nuclear.

Em (2.41), $B_{n}, B_{p}$, e $B_{\alpha}$ são as energias de separação para nêutrons, prótons e partículas alfas. Das três, apenas a energia de separação de nêutrons não faz uso da fórmula semiempírica de massa, mas sim de uma expressão empírica mais precisa, sendo calculada de acordo $\operatorname{com}[61]$,

$$
B_{n}=-0,16(A-Z)+0,25 Z+5,6 .
$$

Para o cálculo da probabilidade de emissão, assume-se que esta seja proporcional à largura correspondente, ou seja, [69]

$$
P_{k}=\frac{\Gamma_{k}}{\Gamma_{n}+\Gamma_{p}+\Gamma_{\alpha}}
$$

A fase de evaporação acaba quando a energia de excitação nuclear não é suficiente para permitir novas emissões, ou seja, quando as energias calculadas pelas equações (2.41) se tornam negativas. Se o núcleo não fissionar, o processo de evaporação acima descrito será o único a ocorrer e o núcleo final poderá ser completamente diferente daquele no início da reação. A este núcleo chama-se produto de spallation.

\subsubsection{Cálculo de fissão}

A fissão é um processo que compete com a evaporação no sentido de que cada núcleo na sequência de evaporação pode fissionar, formando dois fragmentos de massas que correspondem a aproximadamente metade do núcleo fissionante. A teoria que fundamenta o método a seguir está detalhada na subsecção 2.1.2. Esse processo pode ser facilmente incluído no cenário da evaporação com a inclusão da largura de fissão, $\Gamma_{f}$, na equação $(2.46)$, de tal forma que agora se tem

$$
P_{k}=\frac{\Gamma_{k}}{\Gamma_{n}+\Gamma_{p}+\Gamma_{\alpha}+\Gamma_{f}} .
$$


O canal de fissão é calculado de acordo com a equação (2.26), aqui reescrita como

$$
\frac{\Gamma_{f}}{\Gamma_{n}}=K_{f} \exp \left\{2\left[\left(a_{f} E_{f}\right)^{1 / 2}-\left(a_{n} E_{n}\right)^{1 / 2}\right]\right\}
$$

onde,

$$
K_{f}=K_{0} a_{n} \frac{\left[2\left(a_{f} E_{f}\right)^{1 / 2}-1\right]}{\left(4 A^{2 / 3} a_{f} E_{n}\right)}
$$

$\mathrm{e}$,

$$
\begin{aligned}
& E_{f}=E-B_{f}, \\
& a_{f}=r_{f} a_{n},
\end{aligned}
$$

sendo $B_{f}$ a barreira de fissão calculada conforme o modelo de Nix [38]. Mais detalhes sobre o cálculo da barreira de fissão são tratados a seguir. $r_{f}$ é a razão de fissão, um parâmetro com dependência em $\frac{Z^{2}}{A}$. A forma dessa dependência é fruto de um ajuste não apenas numérico das constantes envolvidas, mas leva em consideração características nucleares variáveis com $\frac{Z^{2}}{A}$, tais como a fissilidade.

Com a equação (2.47) é possível calcular a probabilidade de fissão, $P_{f}$, em cada passo do processo de competição evaporação-fissão.

Para realizar o ajuste do parâmetro $r_{f}$, considerou-se a região de $28,5 \leqslant Z^{2} / A \leqslant 37,5$ como sendo a mais relevante, tendo em vista que para os núcleos e reações estudados os resultados são mais sensíveis a esta região da razão de fissão. De modo que este intervalo foi dividido em 18 segmentos de largura 0,5 e a cada um foi atribuído um valor constante de $r_{f}$. Para as regiões $Z^{2} / A<28,5$ e $Z^{2} / A>37,5$ foram também atribuídos valores constantes de $r_{f}$, totalizando assim 20 parâmetros ajustáveis, com a imposição de que $1 \leqslant r_{f} \leqslant 1,23$.

Esta estratégia de ajuste, apesar de aumentar consideravelmente o número de parâmetros, é a melhor maneira de identificar a forma geral de uma curva desconhecida, especialmente quando se tem em mente a necessidade de se ajustar a razão de fissão para uma variedade considerável de núcleos e reações, situação esta em que diferenças de estrutura nuclear tendem a ser refletidas no valor de $r_{f}$. A segunda etapa, não realizada neste trabalho, é a conversão da 
forma segmentada no menor número possível de funções contínuas.

Com os parâmetros relativos às fórmulas empíricas de Dostrovsky são ao todo 26 parâmetros de evaporação e fissão. O ajuste de todos é inviável computacionalmente, não produzindo os resultados desejados devido à incapacidade do Minuit de avaliar a tendência do $\chi^{2}$ quando este é calculado para vários casos e depende de 26 parâmetros. Portanto, os 6 parâmetros relevantes para evaporação foram ajustados primeiro. Em seguida os parâmetros do $r_{f}$ foram ajustados de 6 em 6 começando de $Z^{2} / A$ mais baixo. A cada passo, os três intervalos $\operatorname{com} Z^{2} / A$ mais baixo eram retirados do ajuste (mantidos fixos) e os três intervalos seguintes ainda não ajustados eram adicionados ao ajuste, de modo a manter sempre uma região de intersecção até que se chegasse ao último intervalo, com $Z^{2} / A$ mais alto.

Os parâmetros presentes nas expressões (2.42) são apresentados na Tabela 3.1. A forma ajustada para a razão de fissão é discutida na seção 3.2 .

\section{Parametrização da barreira de fissão}

Adaptações foram feitas ao modelo de Nix a fim de implementá-lo numa versão anterior do código CRISP. Estas adaptações foram mantidas neste trabalho.

O termo entre chaves na equação (2.28) é uma função inadequada para ser incorporada em um código computacional maior devido ao tempo de computação que este único cálculo requer. De modo que este termo está parametrizado numa sub-rotina de código em função do parâmetro de fissilidade $x_{0}$, que fornece alguns valores conhecidos da função ou os interpola linearmente quando necessário. A sub-rotina é apresentada na Figura 2.5 com os comentários pertinentes em seguida.

Na linha 1 está definido o vetor fission_parm com os 48 valores conhecidos da função que depende da forma nuclear. O valor que a sub-rotina deve fornecer, ou retornar (na linguagem usual da computação), está definido como $f_{0}$, interpolado ou não, na linha 34 . Na linha 13 , define-se uma variável $X$ que representa o valor máximo que $x_{0}$ pode assumir, ou seja, quando $x_{0}=E_{c} / 2 E_{s}=1$, o núcleo se torna instável com respeito a deformações. A variável $i$ na linha 


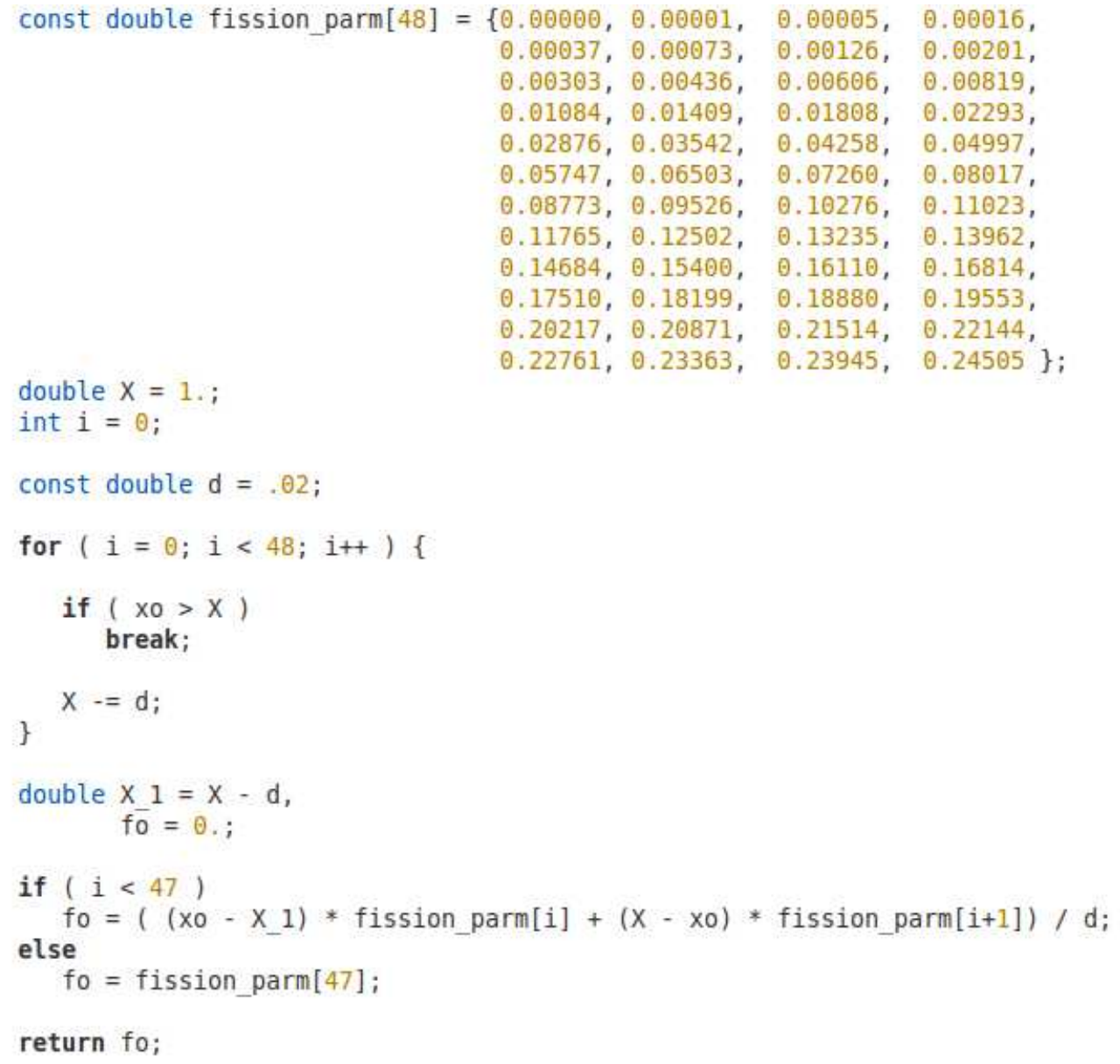

Figura 2.5: Sub-rotina para o cálculo do termo entre chaves na equação (2.28) da barreira de fissão.

14 é apenas um índice, de tal forma que $0 \leqslant i \leqslant 47$. Na linha 16 está definida a precisão do cálculo, estabelecida em $d=0,02$. Das linhas 18 a 24, um loop for faz sucessivas comparações entre $x_{0}$ e $X$, decredementando o valor de $X$ a cada iteração, num número máximo de 48, o que é determinado pelo índice $i$, incrementado sempre em uma unidade a cada iteração.

Quando $x_{0}>X$, linha 20, o loop é encerrado pelo comando break imediatamente, e o cálculo prossegue da linha 26. Do contrário, o cálculo continua na linha 23, onde $X$ é decrecementado do valor de $d$, e retorna-se ao início do loop para que nova comparação seja feita, até que a condição $i=48$ se satisfaça ou $x_{0}$ se torne maior do que $X$.

Na linha 26, $X$ é decrementado uma vez mais e o resultado é atribuído a $X_{1}$. Na linha 29, verifica-se se $i<47$, ou seja, se o cálculo não chegou ao último valor do vetor fission_parm. Se $i<47$, a função deve ser interpolada da forma definida na linha 30, onde o valor utilizado 
do índice $i$ é o último valor registrado na memória quando o cálculo deixou o loop. Porém, se $i=47$ (condição else na linha 31) a função é dada pelo valor estabelecido na posição 47 do vetor fission_parm.

Na linha 34, o comando return determina que o valor calculado, $f_{0}$, da função seja passado ao local adequado no código, i.e., ao cálculo da barreira de fissão.

Finalmente, a fim de corrigir aspectos de estrutura nuclear no cálculo da barreira de fissão, a implementação atual possui uma correção dependente do número de massa $A$, e que consiste num polinômio de grau 3 somado a 7 gaussianas. Esta correção é somada à barreira de fissão e está escrita na forma

$$
\begin{aligned}
C(A)= & -0,0003578 A^{3}+0,2026 A^{2}-28,03 A-230,9+ \\
& 18,03 \exp \left[-\left(\frac{A-10,92}{7,319}\right)^{2}\right]+101,8 \exp \left[-\left(\frac{A-19,77}{17,01}\right)^{2}\right]+ \\
& 934,6 \exp \left[-\left(\frac{A-47,3}{40,18}\right)^{2}\right]+822,3 \exp \left[-\left(\frac{A-94,15}{37,25}\right)^{2}\right]+ \\
& 30,34 \exp \left[-\left(\frac{A-122,8}{22,5}\right)^{2}\right]+341,4 \exp \left[-\left(\frac{A-137,2}{35,46}\right)^{2}\right]+ \\
& 736,5 \exp \left[-\left(\frac{A-167,5}{67,54}\right)^{2}\right] .
\end{aligned}
$$

\subsubsection{Cálculo dos fragmentos de fissão}

Combinando as distribuições gaussianas para o número atômico, equação (2.36), com as distribuições de massa, equação (2.35), de acordo com o modelo multimodo, chega-se ao Yield dos fragmentos produzidos na fissão de actinídeos a energias intermediárias e altas [20, 25],

$$
\begin{array}{r}
\sigma(A, Z)=\left\{\sum_{i}\left[\frac{K_{i}^{L}}{\sqrt{2 \pi} \Gamma_{i}^{L}} \exp \left(-\frac{\left(A-A_{i}^{L}\right)^{2}}{2\left(\Gamma_{i}^{L}\right)^{2}}\right)+\frac{K_{i}^{H}}{\sqrt{2 \pi} \Gamma_{i}^{H}} \exp \left(-\frac{\left(A-A_{i}^{H}\right)^{2}}{2\left(\Gamma_{i}^{H}\right)^{2}}\right)\right]+\right. \\
\left.\frac{K_{S}}{\sqrt{2 \pi} \Gamma_{S}} \exp \left(-\frac{\left(A-A_{S}\right)^{2}}{2\left(\Gamma_{S}\right)^{2}}\right)\right\} \frac{1}{\sqrt{\pi} \Gamma_{Z}} \exp \left(-\frac{\left(Z-Z_{0}\right)^{2}}{\Gamma_{Z}^{2}}\right)
\end{array}
$$

onde a soma é feita sobre os modos assimétricos de fissão. Os parâmetros para o modo simétrico são $K_{S}, A_{S}$ e $\Gamma_{S}$, enquanto $K_{i}^{H(L)}, A_{i}^{H(L)}$ e $\Gamma_{i}^{H(L)}$, são os parâmetros para o fragmento pesado 
(leve) do modo assimétrico $i$. Para a distribuição de número atômico, a parametrização utilizada é [51]

$$
Z_{0}=\mu_{1}+\mu_{2} A
$$

para o número atômico mais provável, e

$$
\Gamma_{Z}=\gamma_{1}+\gamma_{2} A
$$

para a largura da distribuição de número atômico.

Yield, posição e largura para cada modo de fissão da equação (2.52) e $\mu_{1}, \mu_{2}, \gamma_{1}$ e $\gamma_{2}$ em (2.53) e (2.54) são normalmente considerados parâmetros livres no processo de ajuste.

Em muitos trabalhos, os parâmetros dos modos assimétricos para os fragmentos pesados e leves não são considerados independentes, mas relacionados pelas equações $\Gamma_{i}^{L}=\Gamma_{i}^{H}, K_{i}^{L}=K_{i}^{H}$ e $A_{i}^{L}=2 A_{S}-A_{i}^{H}$.

Este fato permitiu uma grande simplificação na implementação do modelo, que em virtude disso está baseado essencialmente no cálculo do fragmento mais pesado.

Após o canal de fissão ser escolhido no processo de competição evaporação-fissão, os números atômico e de massa e a energia de excitação do núcleo fissionante são extraídas e passadas ao cálculo dos fragmentos e suas energias de excitação individuais. A massa do fragmento mais pesado, $A^{H}$, é sorteada de acordo com a distribuição de probabilidade

$$
p(A)=\sum_{i} \frac{p_{i}}{\sqrt{2 \pi} \Gamma_{i}} \exp \left[-\frac{\left(A-A_{i}\right)^{2}}{2 \Gamma_{i}^{2}}\right]
$$

onde $p_{i}$ é a probabilidade que a fissão tem de ocorrer pelo i-ésimo modo e está relacionada com as intensidades $K_{i}$ pela expressão

$$
p_{i}=\frac{K_{i}}{\sum_{i} K_{i}}
$$

Os índices $i=S, 1,2$ correspondem aos modos simétrico e aos modos assimétricos, respectivamente. 
Conhecido $A^{H}$, pode-se calcular o número atômico mais provável e a largura da distribuição de carga pelas equações (2.53) e (2.54). O número atômico $Z^{H}$ é então sorteado de acordo com a distribuição de probabilidade

$$
p(Z)=\frac{1}{\sqrt{\pi} \Gamma_{Z}} \exp \left[-\frac{\left(Z-Z_{0}\right)^{2}}{\Gamma_{Z}^{2}}\right]
$$

O fragmento mais leve é obtido finalmente de acordo com $A^{L}=A_{f}-A^{H}$ e $Z^{L}=Z_{f}-Z^{H}$, onde $A_{f}$ e $Z_{f}$ são o número atômico e de massa do núcleo fissionante.

Um estudo sistemático dos valores dos parâmetros da equação (2.52) por meio de ajuste a dados experimentais de fissão espontânea e a baixa energia para vários núcleos foi realizado por Böckstiegel [29], mostrando que aqueles parâmetros podem ser descritos por funções bem comportadas do número de massa do núcleo fissionante.

Para a análise que se fez neste trabalho de fragmentos de fissão com os núcleos ${ }^{241} \mathrm{Am}$, ${ }^{237} \mathrm{~Np}$ e ${ }^{238} \mathrm{U}$, as larguras dos modos de fissão e as posições do número de massa mais provável foram obtidas daquela sistemática. Apesar da dependência no número de massa do núcleo fissionante, as posições e as larguras apresentam valores aproximadamente constantes para os vários núcleos lá tratados. Esses valores foram extraídos nos gráficos da sistemática por inspeção visual e incorporados ao modelo do CRISP. Um ajuste independente desses parâmetros foi realizado para estudar a distribuição de massa de fragmentos do ${ }^{208} \mathrm{~Pb}$ e do ${ }^{197} \mathrm{Au}$, devido ao fato de não haver um estudo desses parâmetros na região deste nuclídeo. Para todos os casos, no entanto, a posição do número de massa mais provável para o modo simétrico de fissão não foi obtida da sistemática. Uma vez que o CRISP simula a reação completa desde a interação inicial e fornece o núcleo fissionante ao final da competição entre evaporação e fissão, o parâmetro $A_{S}$ foi calculado tendo em vista que $A_{S}=A_{f} / 2$.

Dos trabalhos realizados por Karapetyan [20] e Demekhina [25] foram obtidas as intensidades de cada modo de fissão para os nuclídeos ${ }^{241} \mathrm{Am},{ }^{237} \mathrm{~Np}$ e os parâmetros que constam das equações (2.53) e (2.54) para os nuclídeos ${ }^{241} \mathrm{Am},{ }^{237} \mathrm{~Np}$ e ${ }^{238} \mathrm{U}$. Os dados experimentais são igualmente de suas autorias. Para ${ }^{208} \mathrm{~Pb}$ e ${ }^{197} \mathrm{Au}$, os parâmetros das equações (2.53) e (2.54) 
foram obtidos do estudo realizado por Duijvestijn [51].

A partir da sistemática de Böckstiegel, fez-se um ajuste das intensidades de cada modo de fissão em sua dependência com o número de massa do núcleo fissionante para os núcleos ${ }^{238} \mathrm{U}$, ${ }^{208} \mathrm{~Pb}$ e ${ }^{197} \mathrm{Au}$.

Para o ${ }^{238} \mathrm{U}$, o ajuste obtido foi inserido no modelo na forma,

$$
\begin{aligned}
& K_{S}=\frac{b_{1}}{\sqrt{2 \pi} b_{3}} \exp \left[-\frac{\left(A_{f}-b_{2}\right)^{2}}{2 b_{3}^{2}}\right], \\
& K_{2}=\frac{b_{4}}{\sqrt{2 \pi} b_{6}} \exp \left[-\frac{\left(A_{f}-b_{5}\right)^{2}}{2 b_{6}^{2}}\right], \\
& K_{1}=100-\left(K_{S}+K_{2}\right) .
\end{aligned}
$$

Para ${ }^{208} \mathrm{~Pb}$ e ${ }^{197} \mathrm{Au}$, chegou-se a um modelo distinto para as intensidades,

$$
\begin{aligned}
& K_{S}=c_{1}-\frac{c_{1}}{1+\exp \left[-c_{2}\left(A_{f}-c_{3}\right)\right]} \\
& K_{2}=\frac{c_{4}}{\sqrt{2 \pi} c_{6}} \exp \left[-\frac{\left(A-c_{5}\right)^{2}}{2 c_{6}^{2}}\right], \\
& K_{1}=\frac{c_{7}}{\sqrt{2 \pi} c_{9}} \exp \left[-\frac{\left(A-c_{8}\right)^{2}}{2 c_{9}^{2}}\right] .
\end{aligned}
$$

Ainda para ${ }^{208} \mathrm{~Pb}$ e ${ }^{197} \mathrm{Au}$, as posições dos números de massa mais prováveis para os modos assimétricos de fissão foram calculadas de acordo com

$$
\begin{aligned}
& A_{1}^{H}=c_{10} A_{f}+c_{11}, \\
& A_{2}^{H}=c_{12} A_{f}+c_{13},
\end{aligned}
$$

enquanto as larguras para cada um dos três modos de fissão considerados foram assumidas constantes,

$$
\begin{gathered}
\Gamma_{S}=c_{14}, \\
\Gamma_{1}^{H}=c_{15}, \\
\Gamma_{2}^{H}=c_{16} .
\end{gathered}
$$

A inclusão da dependência na massa do núcleo fissionante para os núcleos ${ }^{238} \mathrm{U},{ }^{208} \mathrm{~Pb} \mathrm{e}$ 
${ }^{197} \mathrm{Au}$ foi uma primeira tentativa de obter um modelo único para o cálculo dos modos de fissão. Todos os parâmetros acima referidos são apresentados na Tabela 3.3.

As seções de choque totais das reações ${ }^{241} \mathrm{Am}+660 \mathrm{MeV}$ p e ${ }^{237} \mathrm{~Np}+660 \mathrm{MeV}$ p foram calculadas pelo CRISP. As reações de Bremsstrahlung estudadas para o ${ }^{238} \mathrm{U}$ tiveram suas seções de choque normalizadas pelos dados experimentais devido à impossibilidade atual do CRISP de fornecer seções de choque abaixo da região do quase-dêuteron situada em aproximadamente $50 \mathrm{MeV}$. Para as reações ${ }^{208} \mathrm{~Pb}+500 \mathrm{MeV}$ p, ${ }^{208} \mathrm{~Pb}+1000 \mathrm{MeV}$ p e ${ }^{197} \mathrm{Au}+800 \mathrm{MeV}$ p, os resultados normalizados são apresentados no Capítulo 3 junto aos resultados com seção de choque total calculada pelo CRISP.

\section{Evaporação dos fragmentos}

Dada a forma típica da curva de energia de ligação por nucleon (Figura 2.4), tendo um máximo na região de número de massa próximo a $A=56$ (núcleo de $\mathrm{Fe}$ ), quando um núcleo pesado se quebra em dois fragmentos, o aumento na energia de ligação por partícula é liberado na forma de vários tipos de radiação e, em sua maior parte, na energia cinética dos fragmentos de fissão. De fato, a contribuição da energia cinética dos fragmentos de fissão ao total liberado (Q da fissão) pode chegar a mais de 80\% [70].

Além disso, como a linha de estabilidade beta exibe uma curvatura em direção à região em que $N>Z$, os produtos de fissão tendem a apresentar excesso de nêutrons e usualmente passam por alguns passos de decaimento $\beta^{-}$.

Por fim, os fragmentos de fissão carregam uma fração da energia total da fissão na forma de energia interna de excitação e, não raras as vezes, se encontram em condição energética de emitir nêutrons, ou seja, sua energia de excitação é superior à energia de separação de nêutrons.

Um estudo ideal da energética do processo de fissão até a obtenção dos fragmentos deve portanto levar em conta os seguintes elementos:

- Energia cinética dos fragmentos de fissão; 
- Neutrinos emitidos pelos produtos de fissão;

- Partículas beta emitidas pelos produtos de fissão;

- Energia de raios gama instantâneos;

- Raios gama emitidos pelos produtos de fissão;

- Energia cinética dos nêutrons de fissão.

A aplicação do princípio de conservação de energia ao processo de fissão, começando no núcleo fissionante, conduz a que

$$
M_{f}+E_{f}=m_{f r a g 1}+m_{f r a g}+T_{f r a g}+E_{f r a g},
$$

onde $M_{f}$ e $E_{f}$ são a massa e a energia de excitação do núcleo fissionante, $m_{f r a g 1}+m_{f r a g 2}$ são as massas dos fragmentos de fissão e $T_{\text {frag }}$ e $E_{\text {frag }}$ são as energias cinética e de excitação dos fragmentos, sendo esta última a fonte dos vários tipos de radiação emitidos citados acima, que, somados à energia cinética dos fragmentos, compõem a energia total liberada no processo.

Da equação (2.62) podemos tirar uma expressão simples para o cálculo da energia de excitação dos fragmentos de fissão,

$$
E_{\text {frag }}=M_{f}-\left(m_{\text {frag } 1}+m_{\text {frag } 2}\right)+E_{f}-T_{\text {frag }} .
$$

As massas são calculadas de acordo com a fórmula semi-empírica de massa, equação (2.38). A energia de excitação do núcleo fissionante é fornecida pelo CRISP, como já antes descrito, e a energia cinética dos fragmentos é calculada diretamente da energia eletrostática do sistema composto pelos dois fragmentos, conforme o modelo de Böckstiegel [29],

$$
V_{C}=\frac{Z_{1} \cdot Z_{2} \cdot e^{2}}{r_{0}\left[A_{1}^{1 / 3} \cdot\left(1+\frac{2 \beta_{1}}{3}\right)+A_{2}^{1 / 3} \cdot\left(1+\frac{2 \beta_{2}}{3}\right)\right]+d},
$$

onde $Z_{1}, Z_{2}, A_{1}$ e $A_{2}$ são os números atômico e de massa dos fragmentos, $\beta_{i}$ é o parâmetro de deformação do núcleo fixado em 0,6 e $d$ é a distância entre as superfícies dos fragmentos. 
Como proposto em [29], fez-se neste trabalho, um ajuste linear do valor de $d$ para vários núcleos em função de $\frac{Z^{2}}{A^{1 / 3}}$ do núcleo fissionante, chegando-se ao resultado

$$
d=d_{1} \frac{Z^{2}}{A^{1 / 3}}+d_{2}
$$

válido para o intervalo $\frac{Z^{2}}{A^{1 / 3}}>1300$. Abaixo desse limite, o valor de $d$ é assumido constante em $d(1300)$. Os parâmetros relativos a equação (2.65) são apresentados na Tabela 3.3 e o gráfico do ajuste está apresentado na Figura 2.6.

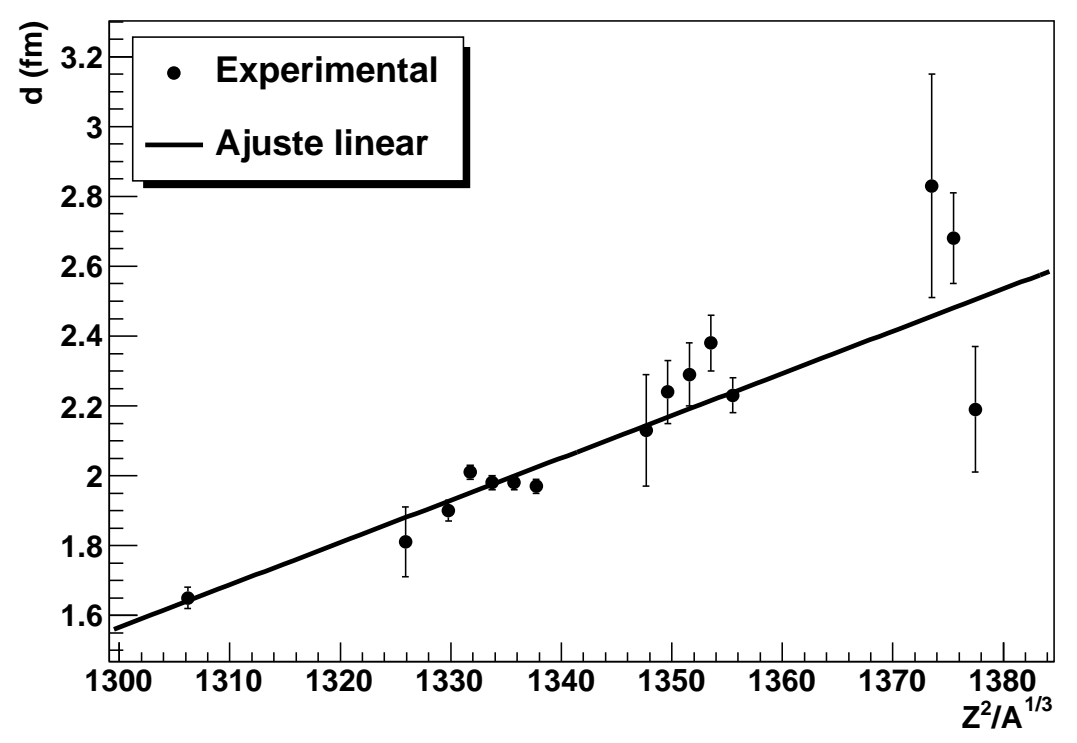

Figura 2.6: Distância $d$ entre as superfícies de cada fragmento em função de $Z^{2} / A^{1 / 3}$. Os dados experimentais foram obtidos de [29].

A energia de excitação, $E_{\text {frag }}$, é então dividida entre os fragmentos de acordo com

$$
\begin{aligned}
& E_{1}=\frac{A_{1}}{A_{f}} E_{\text {frag }}, \\
& E_{2}=\frac{A_{2}}{A_{f}} E_{\text {frag }} .
\end{aligned}
$$

onde $E_{1}$ e $A_{1}, E_{2}$ e $A_{2}$ são, respectivamente, a energia de excitação e número de massa de cada fragmento. Neste ponto, o modelo de evaporação de Weisskopf é novamente empregado para se obter os fragmentos evaporados.

Este modelo é utlizado para a obtenção da distribuição de massa dos fragmentos de fissão apenas para os nuclídeos ${ }^{241} \mathrm{Am},{ }^{237} \mathrm{~Np},{ }^{208} \mathrm{~Pb}$ e ${ }^{197} \mathrm{Au}$. Voltando à equação (2.63), nota-se 
que o balanço correto de energia depende da fórmula de massa e da expressão utilizada para o cálculo da energia potencial eletrostática. Quanto a esta última, a maior incerteza reside no valor de $d$, a distância entre as superfícies dos fragmentos, que resulta numa incerteza menor sobre a energia cinética dos fragmentos do que a fórmula de massa sobre o Q da fissão, uma vez que se faz necessário calcular com precisão as massas dos fragmentos e do núcleo fissionante, o que cobre uma área vasta de nuclídeos.

A presença de imprecisões dessa natureza na atual fórmula de massa deu origem a energias negativas para os fragmentos, de acordo com a equação (2.63). Isso obrigou a utilização de uma aproximação no cálculo da energia de excitação dos fragmentos para as reações de Bremsstrahlung estudadas. No caso do ${ }^{238} \mathrm{U}$ para ambas as energias de ponto final do fóton, a energia de excitação do núcleo fissionante é diretamente atribuída aos fragmentos segundo a mesma regra expressa nas equações (2.66).

Há dois motivos para se considerar esta uma boa aproximação, uma delas é o fato já citado acima da energia cinética dos fragmentos corresponder à quase totalidade do Q da fissão, a energia total liberada, de modo que as duas quantidades podem ser consideradas aproximadamente iguais na equação (2.63). O segundo motivo reside no efeito desta aproximação nos resultados obtidos para os demais nuclídeos. As distribuições de massa dos fragmentos para ${ }^{241} \mathrm{Am}$, ${ }^{237} \mathrm{~Np},{ }^{208} \mathrm{~Pb}$ e ${ }^{197} \mathrm{Au}$ são apenas minimamente modificadas pela aproximação e, conquanto seja desnecessária para estes três nuclídeos, resolve o problema físico de atribuir energias negativas aos fragmentos de fissão no estudo do ${ }^{238} \mathrm{U}$.

Todos os detalhes concernentes à fórmula de massa serão abordados no contexto da discussão dos resultados na seção 3.1. Da mesma forma, os efeitos da aproximação utilizada e suas implicações para o código CRISP serão tratados em detalhes na seção 3.4.

\subsubsection{Modelo microscópico da barreira de fissão}

Para todos os resultados apresentados neste trabalho, a barreira de fissão consiste no modelo de Nix [38]. O uso deste modelo permitiu a obtenção de bons resultados a partir do ajuste 
dos parâmetros relevantes já tratados nas últimas seções. Realizou-se, no entanto, um estudo particular da barreira de fissão.

Estão disponíveis valores de barreira para 2301 núcleos com $78 \leqslant Z \leqslant 120$, obtidas com o método ETFSI (Extended Thomas-Fermi plus Strutinsky Integral) [71, 72, 73], Figura 2.7. Procurou-se, então, o melhor ajuste possível a esses valores previstos. De fato, núcleos com $Z<78$ não são incomuns nas aplicações do CRISP e portanto, o modelo de Nix seria ainda mantido para tratar tais situações no caso de uma substituição de modelo.

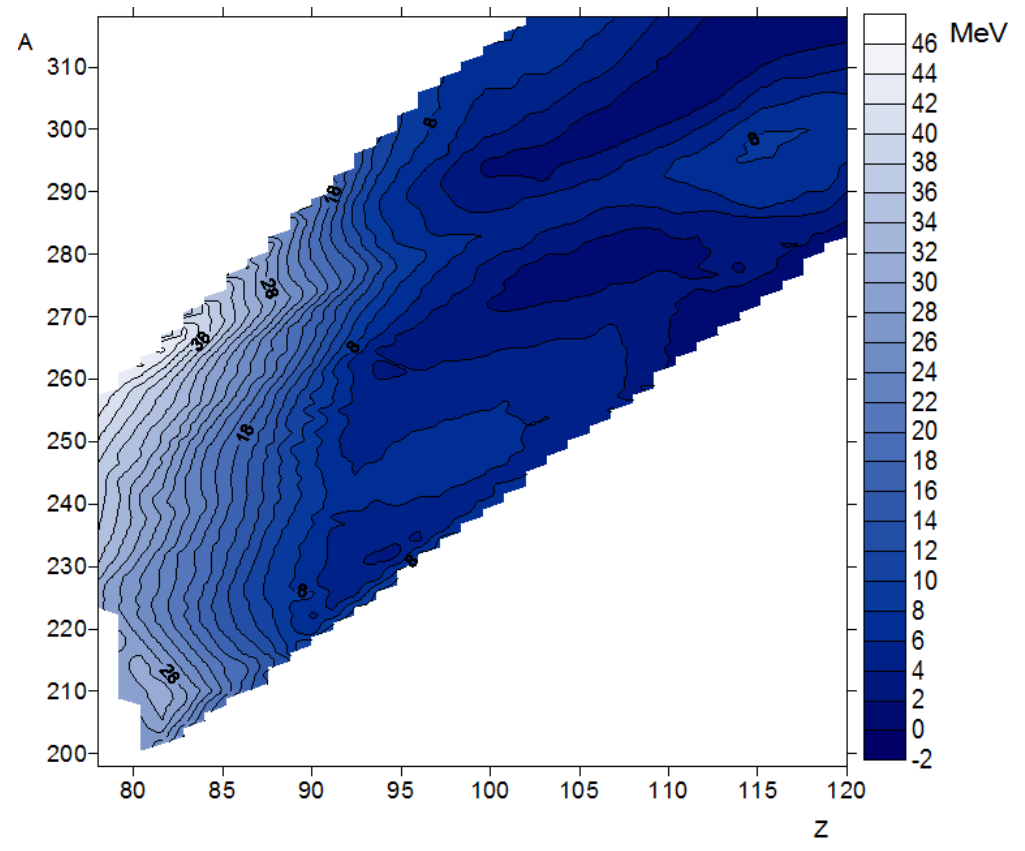

Figura 2.7: Barreira de fissão prevista pelo método ETFSI.

O melhor ajuste que se obteve aos dados calculados com o método ETFSI foi colocado como opção de cálculo, desde que o CRISP seja novamente reestruturado e seus parâmetros reajustados a fim de se adequar a esse novo modelo.

A expressão proposta para a barreira de fissão tem a forma

$$
B(A, Z)=e_{1}+e_{2} Z+e_{3} A+e_{4} \frac{Z^{2}}{A}+e_{5} Z^{2}+e_{6} A^{2}
$$

Os resultados alcançados para os valores de barreira de fissão são discutidos na seção 3.5 e os parâmetros do ajuste estão disponíveis na Tabela 3.3. 


\section{$3 \quad$ Resultados e Discussão}

Os parâmetros relevantes aos modelos descritos no Capítulo 2 são apresentados a seguir. Constam da Tabela 3.1 os parâmetros da fórmula semi-empírica de massa, equação (2.38), assim como aqueles relativos às fórmulas empíricas de Dostrovsky para os parâmetros de densidade de níveis, equações (2.42).

Tabela 3.1: Valores dos parâmetros relevantes da fórmula semi-empírica de massa e das fórmulas empíricas de Dostrovsky para o cálculo de densidade de níveis.

\begin{tabular}{cccccc}
\hline \multicolumn{6}{c}{ Fórmula semi-empírica de massa } \\
\hline$a_{v}$ & $a_{s f}$ & $a_{s y m}$ & $a_{s s}$ \\
$-15,018$ & 15,598 & $-7,097$ & 144,764 \\
\multicolumn{6}{c}{} \\
\hline \multicolumn{1}{c}{ Parâmetros para o cálculo da densidade de níveis de Dostrovsky } \\
\hline$a_{1}$ & $a_{2}$ & $a_{3}$ & $a_{4}$ & $a_{5}$ & $a_{6}$ \\
18,813 & 1,300 & 18,670 & 4,235 & 18,890 & 24,820 \\
\hline
\end{tabular}

\subsection{Fórmula semi-empírica de massa}

A Figura 3.1 mostra a diferença entre a massa experimental [68] e a massa calculada pela fórmula semi-empírica de massa quando utilizados os parâmetros da referência [64]. Nota-se que o erro se torna maior quando mais pesado o núcleo em questão, chegando-se a diferenças próximas de $40 \mathrm{MeV}$ para núcleos a partir de $A \approx 170$ e $Z \approx 75$. Em particular, na região dos núcleos pesados de interesse o erro chega a aproximadamente $45-50 \mathrm{MeV}$. Abaixo dessa região, na zona correspondente à maioria dos fragmentos de fissão obtidos neste trabalho, acima de $A \approx 100$ e $Z \approx 40$, as massas já são subestimadas em mais de $20 \mathrm{MeV}$. 


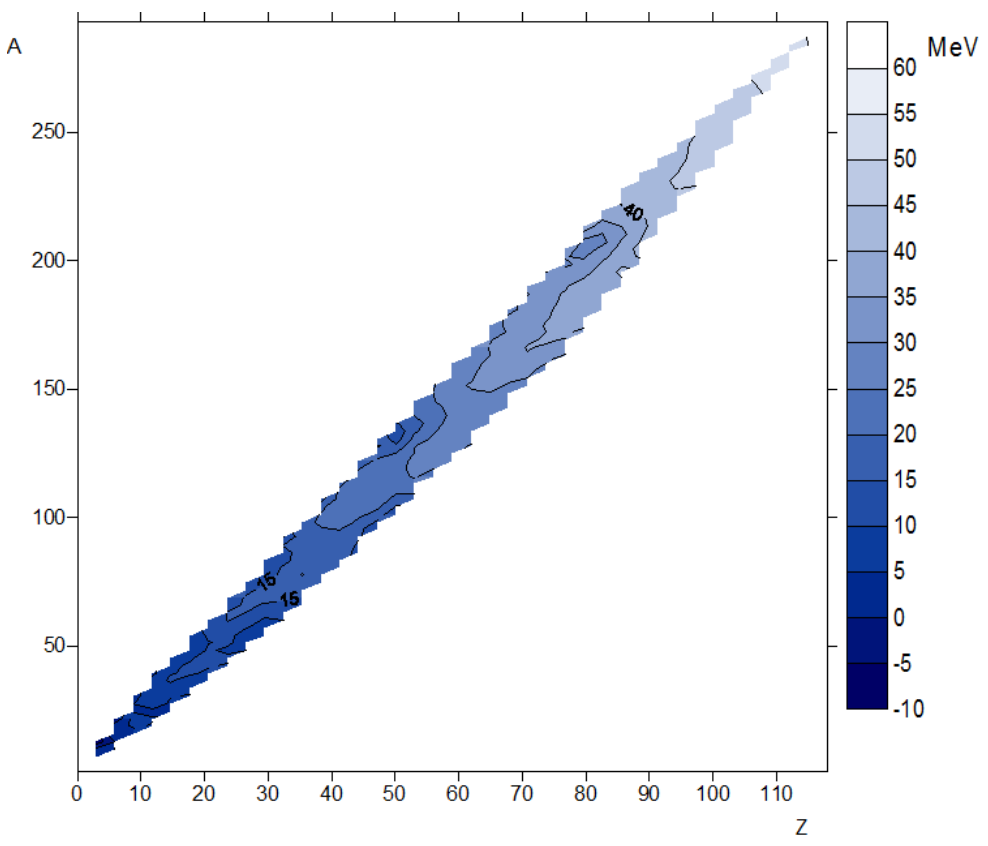

Figura 3.1: Diferença entre a massa experimental [68] e a massa calculada pela fórmula semiempírica de massa quando utilizados os parâmetros da referência [64].

Este resultado já poderia ser considerado bom, lembrando que mesmo o maior erro cometido, de $50 \mathrm{MeV}$ para os núcleos mais pesados, corresponde a apenas 5\% da massa do próton. No entanto, os modelos nucleares voltados ao cálculo de processos como evaporação e fissão são muito sensíveis ao valor da massa nuclear. De modo que a precisão máxima possível deve ser buscada, ainda que isso implique na priorização de uma certa região de nuclídeos de interesse até que uma fórmula de massa mais bem sucedida num intervalo mais amplo seja encontrada.

Foi em virtude dessa necessidade que esta mesma fórmula de massa foi ajustada não apenas para novos dados experimentais como também na região restrita a $A \geqslant 12$.

A diferença entre a massa experimental e a massa calculada pela fórmula ajustada está apresentada na Figura 3.2. Os núcleos pesados ainda são subestimados em $\approx 40-50 \mathrm{MeV}$ quanto às suas massas. Numa dessas faixas o erro pode ultrapassar $50 \mathrm{MeV}$. Ainda assim, todas as faixas de erro nessa região são estreitas, e nota-se que a diferença entre os valores experimental e calculado cai rapidamente em um intervalo curto de massa. Como há pouco interesse em núcleos de massa superior a $A \simeq 245$, que possuem pouca ou nenhuma aplicação, estes não são exibidos. Pela mesma razão são mostrados apenas núcleos com massa $A \geqslant 40$. 
Portanto, a região com maiores problemas, considerando o intervalo de massas de relevância, é bastante reduzida.

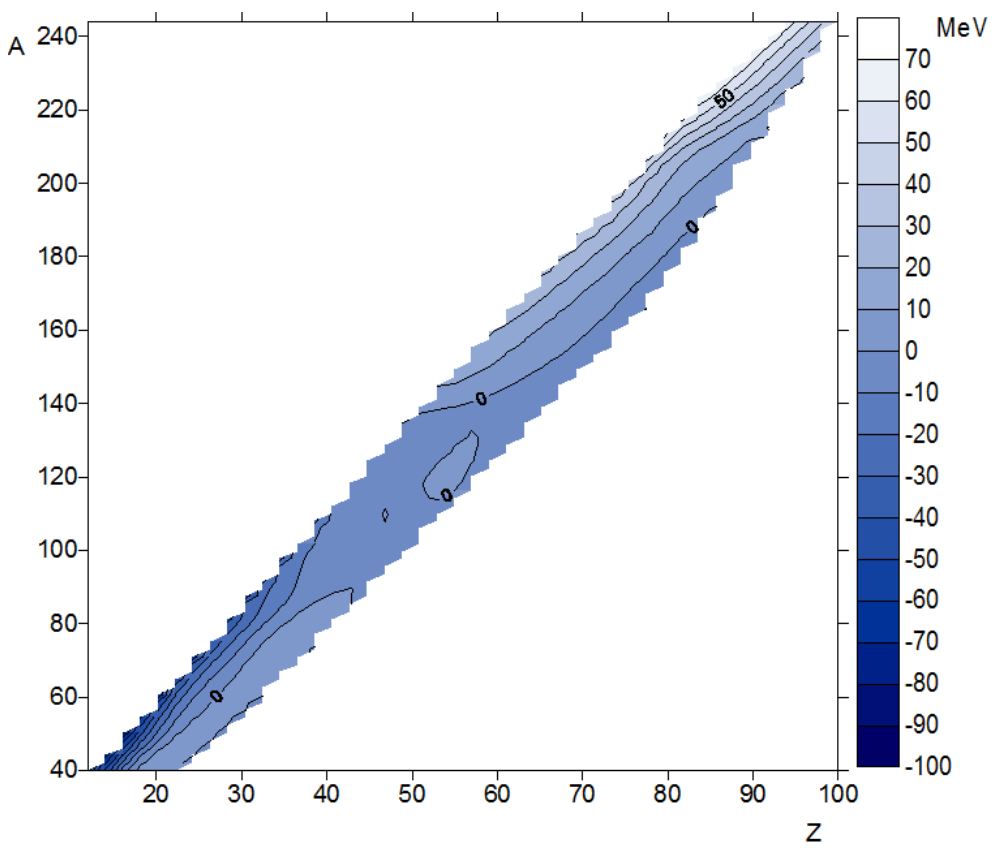

Figura 3.2: Diferença entre a massa experimental e a massa calculada pela fórmula ajustada.

Como a multiplicidade de nêutrons para núcleos pesados é maior tanto na cascata intranuclear como na fase de evaporação, os núcleos filhos subsequentes estarão submetidos a menor erro. Além disso, a fórmula de massa só é utilizada na segunda fase da reação, integrando os modelos de Weisskopf e Bohr-Wheeler, quando o núcleo inicial é na verdade o residual da cascata, e portanto, já é mais leve. Por mais este motivo, os efeitos do erro introduzido por esta fórmula de massa na região de núcleos pesados são ainda menores.

A imprecisão mencionada na subseção 2.3.4, responsável pela atribuição de energias negativas aos fragmentos de fissão, se deve ao fato das massas dos fragmentos serem calculadas com relativa precisão enquanto o núcleo fissionante tem sua massa subestimada, resultando num $\mathrm{Q}$ da fissão sistematicamente menor. Para os nuclídeos ${ }^{241} \mathrm{Am},{ }^{237} \mathrm{~Np},{ }^{208} \mathrm{~Pb}$ e ${ }^{197} \mathrm{Au}$, as energias de excitação dos núcleos fissionantes são mais altas do que para as reações de Bremsstrahlung com o ${ }^{238} \mathrm{U}$, como é possível notar pelas Figuras 3.3 e 3.4. Isso associado ao fato da energia eletrostática do sistema formado pelos fragmentos em todos os casos ser da mesma ordem de grandeza faz com que uma subestimação do Q da fissão dê origem a somente poucos casos de 
energia negativa para ${ }^{241} \mathrm{Am},{ }^{237} \mathrm{~Np},{ }^{208} \mathrm{~Pb}$ e ${ }^{197} \mathrm{Au}$ (Figura 3.3), que são descartados, mas a vários casos (a maioria deles) de energia negativa para Bremsstrahlung quando se faz o balanço de energia da equação (2.63), como mostra a Figura 3.4.

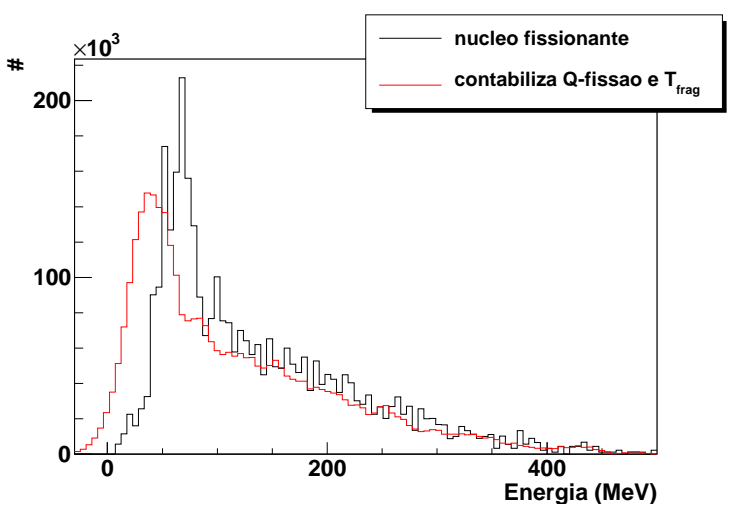

(a)

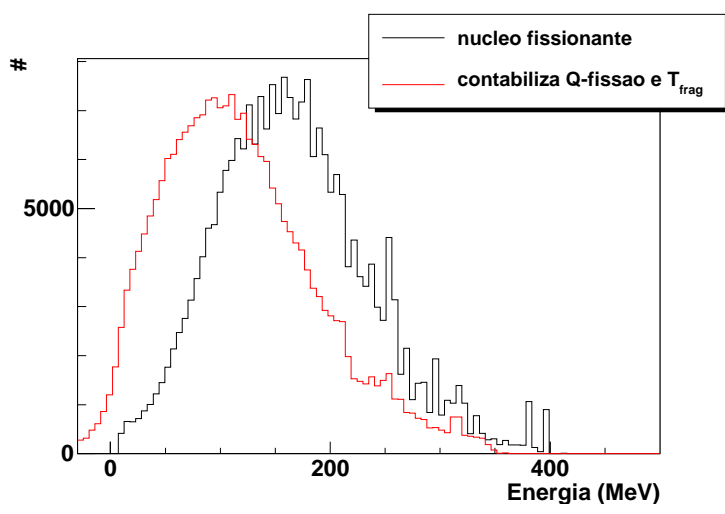

(c)

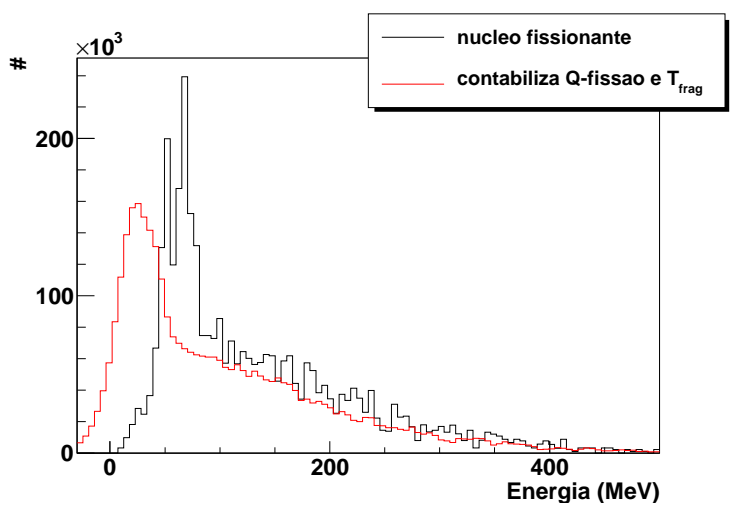

(b)

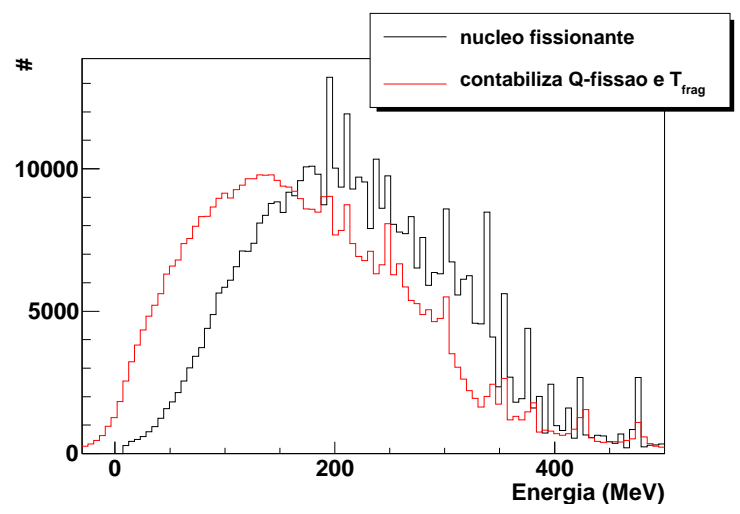

(d)

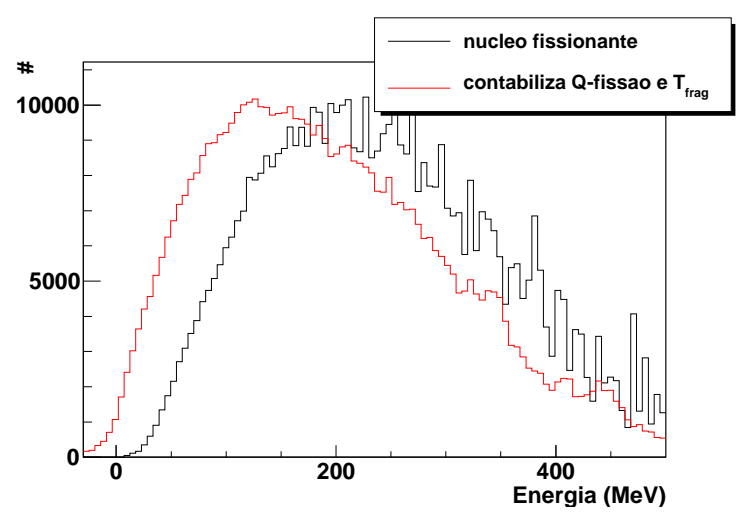

(e)

Figura 3.3: Energia de excitação dos fragmentos de fissão na aproximação $E_{f r a g} \simeq E_{f}$ (linha preta) e quando contabilizada de acordo com $E_{\text {frag }}=M_{f}-\left(m_{\text {frag } 1}+m_{\text {frag } 2}\right)+E_{f}-T_{\text {frag }}$ (linha vermelha) para (a) ${ }^{241} \mathrm{Am}+660 \mathrm{MeV} \mathrm{p}$ (b) ${ }^{237} \mathrm{~Np}+660 \mathrm{MeV} \mathrm{p} \mathrm{(c)}{ }^{208} \mathrm{~Pb}$ a $500 \mathrm{MeV} \mathrm{p}$ (d) ${ }^{208} \mathrm{~Pb}$ a $1000 \mathrm{MeV}$ p (e) ${ }^{197} \mathrm{Au}+800 \mathrm{MeV}$.

Reações com o ${ }^{208} \mathrm{~Pb}$ sempre estiveram sujeitas a erro. Devido à sua baixa fissilidade, muitos passos de evaporação com consequente produção de núcleos mais leves acontecem antes da 


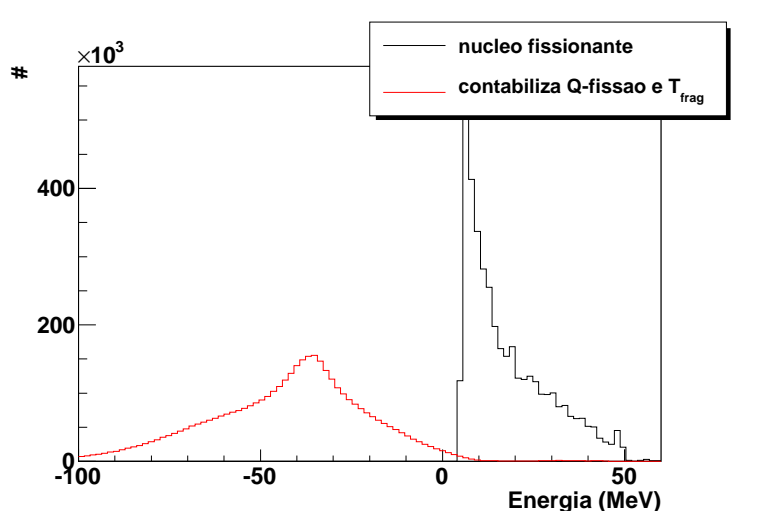

(a)

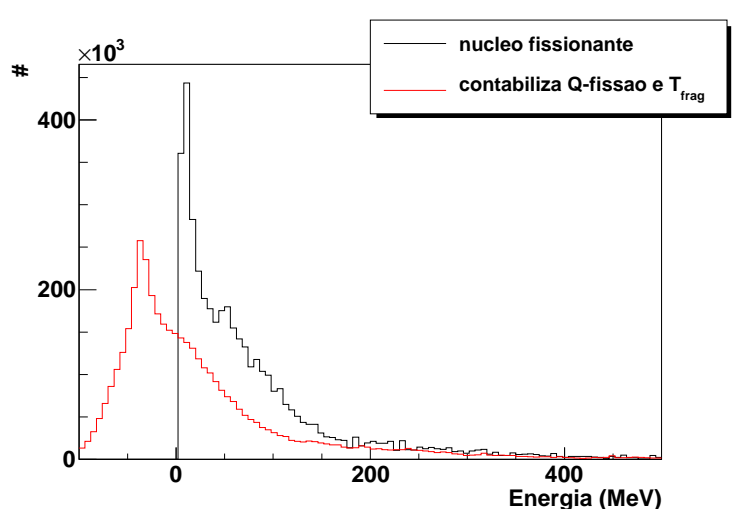

(b)

Figura 3.4: Energia de excitação dos fragmentos de fissão na aproximação $E_{f r a g} \simeq E_{f}$ (linha preta) e quando contabilizada de acordo com $E_{\text {frag }}=M_{f}-\left(m_{\text {frag } 1}+m_{\text {frag } 2}\right)+E_{f}-T_{\text {frag }}$ (linha vermelha) para (a) ${ }^{238} \mathrm{U}$ a $50 \mathrm{MeV}$ e (b) ${ }^{238} \mathrm{U}$ a $3.5 \mathrm{GeV}$.

fissão, e calcular corretamente a massa da maioria deles permitiu a obtenção de bons resultados para a seção de choque de fotofissão, Figura 3.6(a) apresentada na seção 3.3, e para as distribuições de massa dos fragmentos de fissão, Figuras 3.11(e) e 3.11(f), e 3.12(a) 3.12(b) discutidas na seção 3.4, onde está incluída a evaporação dos fragmentos.

Em todos os casos apresentados na seção 3.4, a evaporação dos fragmentos teve papel essencial no resultado final, e portanto, também a fórmula de massa.

O ajuste da fórmula de massa utilizando o pacote Minuit possui um $\chi^{2}$ reduzido de $7.56 \times$ $10^{6}$. O elevado valor do $\chi^{2}$ se justifica pela precisão do modelo ser ainda muito baixa quando comparada à alta precisão dos dados experimentais, da ordem de $10^{-3}$.

\subsection{Razão de fissão}

Como indicado na seção 2.3, o parâmetro $r_{f}$, assim como os parâmetros do modelo de Dostrovsky para evaporação, foi ajustado apenas para as seções de choque de fotofissão e spallation, e foi o último parâmetro de densidade de níveis a ser ajustado.

Esse ajuste do $r_{f}$, intervalo a intervalo de $Z^{2} / A$, permitiu identificar as regiões mais relevantes a cada núcleo estudado. Devido à suas baixas fissilidades e extensão dos processos de evaporação, o ${ }^{197} \mathrm{Au}$ e o ${ }^{208} \mathrm{~Pb}$ compartilham a maior parte da região de $Z^{2} / A<36$, o ${ }^{197} \mathrm{Au}$ 
tendo suas seções de choque mais influenciadas por alterações de $r_{f}$ na região $26 \lesssim Z^{2} / A \lesssim 35$ e o ${ }^{208} \mathrm{~Pb}$ na região $28 \lesssim Z^{2} / A \lesssim 36$.

$\mathrm{O} \mathrm{Pb}$ partilha a região em torno de $Z^{2} / A \simeq 35 \mathrm{com}{ }^{232} \mathrm{Th}$, que não apresenta tantos passos de evaporação e pode ter sua seção de choque alterada por mudanças no valor de $r_{f}$ até $Z^{2} / A \simeq$ 36. Acima deste valor, está o domínio do ${ }^{238} \mathrm{U}$ e do ${ }^{237} \mathrm{~Np}$, que compartilham esta região até $Z^{2} / A \simeq 38$.

A Figura 3.5 mostra o resultado obtido para a razão de fissão no intervalo de $Z^{2} / A$ de interesse. A presença de variações bruscas no valor de $r_{f}$ é uma indicação de que o atual modelo de barreira de fissão não descreve totalmente o comportamento da barreira para os núcleos estudados. Sendo $r_{f}$ o último parâmetro a ser ajustado, podendo variar livremente nos 20 intervalos nos quais foi dividido e tendo como única restrição $1 \leq r_{f} \leq 1,23$, os efeitos de estrutura não resolvidos pelo cálculo da barreira de fissão tendem a se apresentar na forma da razão de fissão. Uma melhor reprodução da barreira deve permitir a obtenção de uma forma suave para o $r_{f}$, em particular monotonicamente crescente.

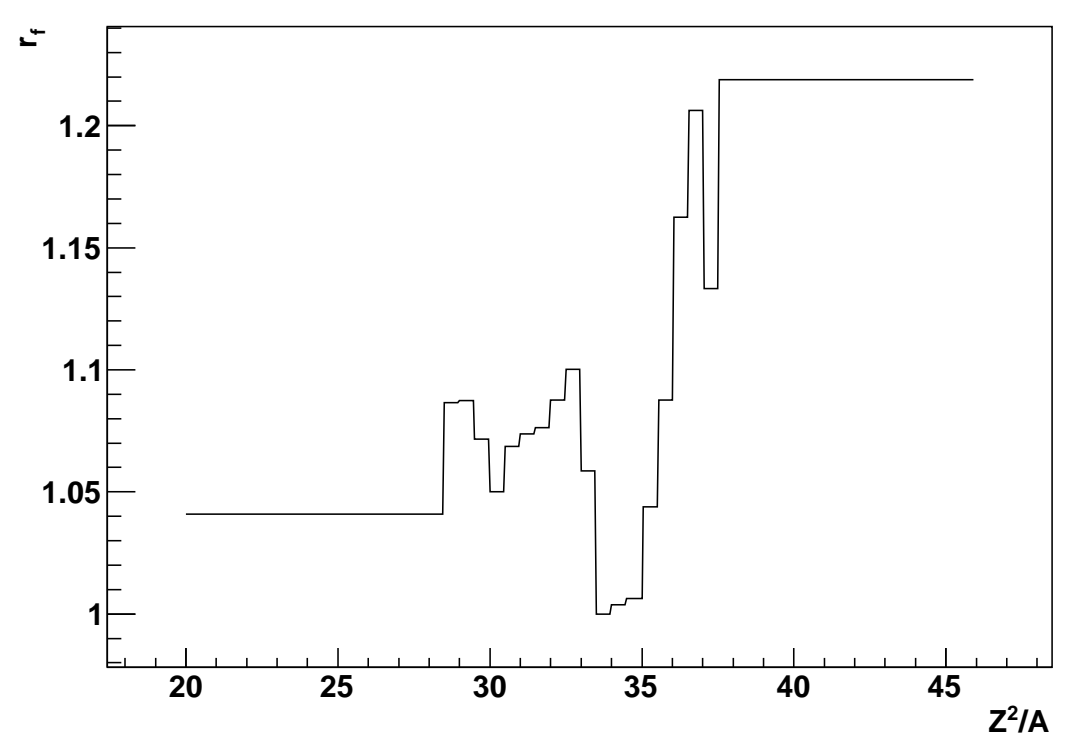

Figura 3.5: Forma do parâmetro $r_{f}$, razão de fissão.

A dificuldade natural no ajuste da seção de choque de fotofissão do ${ }^{208} \mathrm{~Pb}$ se vê refletida na maneira como a razão de fissão muda para os núcleos filhos na cadeia de evaporação do 
$\mathrm{Pb}$. Durante o processo de ajuste, a forma da seção de choque podia mudar consideravelmente para as várias energias do fóton incidente a depender dos valores de $r_{f}$ em cada uma das suas subdivisões. Para os demais núcleos, a forma da curva sofria pouca variação com mudanças no valor de $r_{f}$, ao contrário do que ocorria com a seção de choque total, que passou a ser o alvo do ajuste nesses casos.

Os valores de $r_{f}$ para cada intervalo de $Z^{2} / A$ estão apresentados na Tabela 3.2, em ordem crescente de $Z^{2} / A$.

Tabela 3.2: Valores da razão de fissão, $r_{f}$, para cada intervalo de $Z^{2} / A$.

\begin{tabular}{cccccccc}
\hline Parâmetro & Valor & Parâmetro & Valor & Parâmetro & Valor & Parâmetro & Valor \\
\hline$r f_{1}$ & 1,041 & $r f_{6}$ & 1,069 & $r f_{11}$ & 1,059 & $r f_{16}$ & 1,088 \\
$r f_{2}$ & 1,087 & $r f_{7}$ & 1,074 & $r f_{12}$ & 1,000 & $r f_{17}$ & 1,163 \\
$r f_{3}$ & 1,087 & $r f_{8}$ & 1,076 & $r f_{13}$ & 1,004 & $r f_{18}$ & 1,206 \\
$r f_{4}$ & 1,072 & $r f_{9}$ & 1,088 & $r f_{14}$ & 1,006 & $r f_{19}$ & 1,133 \\
$r f_{5}$ & 1,050 & $r f_{10}$ & 1,100 & $r f_{15}$ & 1,044 & $r f_{20}$ & 1,219 \\
\hline
\end{tabular}

\subsection{Fotofissão e spallation}

A Figura 3.6 mostra as seções de choque de fotofissão calculadas pelo CRISP em comparação aos dados experimentais [15]. Nota-se um bom acordo entre cálculo e experimento em três das reações estudadas. A forma da seção de choque do ${ }^{208} \mathrm{~Pb}$, Figura 3.6(a), em particular, acompanha a forma experimental em toda a extensão de energias consideradas. Um único ponto apresenta forte divergência, aquele situado a $300 \mathrm{MeV}$.

Para os núcleos ${ }^{232}$ Th e ${ }^{238}$ U, Figuras 3.6(b) e 3.6(c), vê-se bons resultados obtidos pelo CRISP tanto em forma quanto em valor de seção de choque, embora a seção de choque total para o ${ }^{238} \mathrm{U}$, esteja pouco abaixo do correto.

Para a fotofissão do ${ }^{237} \mathrm{~Np}$, Figura 3.6(d), há um desacordo nítido no que diz respeito à seção de choque total, conquanto a forma esteja corretamente reproduzida. Já foi observado em [56] que a seção de choque experimental de fotoabsorção para o ${ }^{237} \mathrm{~Np}$ está acima da chamada curva universal de fotoabsorção total, de modo que seria necessário supor uma fissilidade superior a 


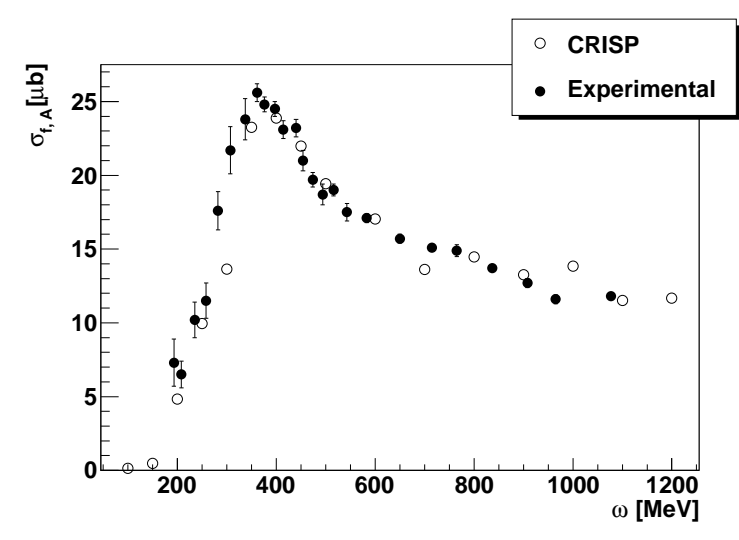

(a)

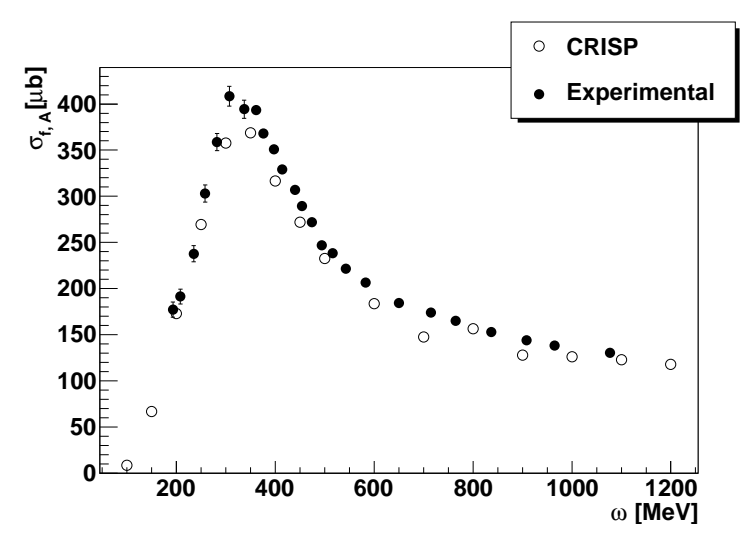

(c)

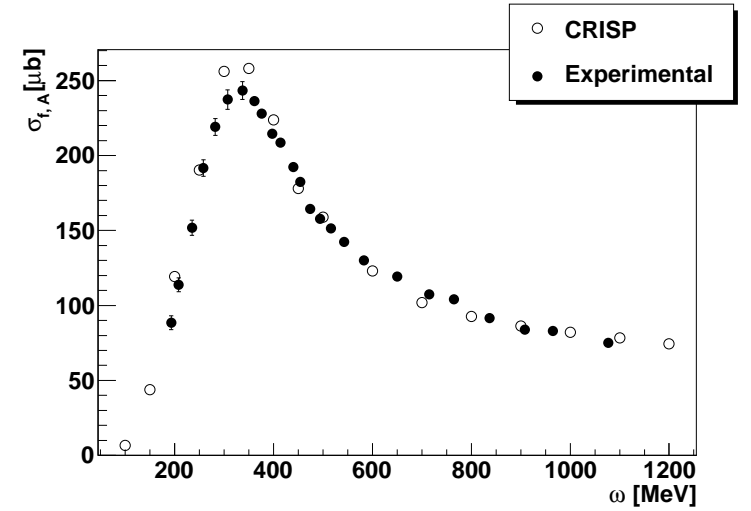

(b)

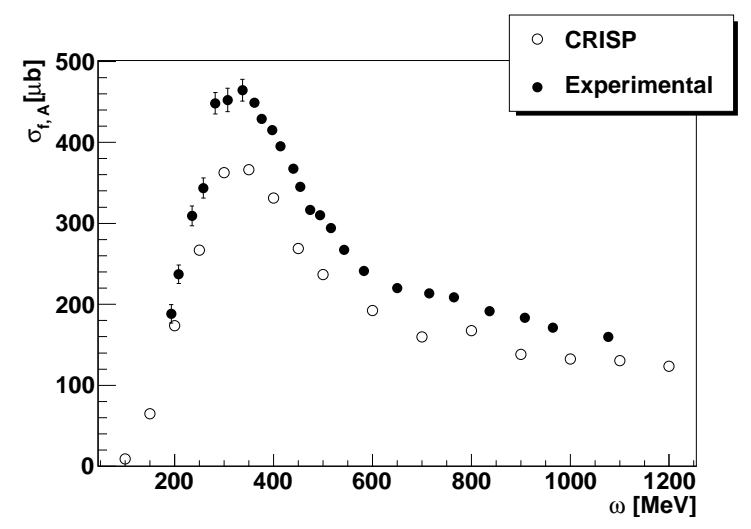

(d)

Figura 3.6: Seções de choque de fotofissão. (a) ${ }^{208} \mathrm{~Pb}$ (b) ${ }^{232} \mathrm{Th}$ (c) ${ }^{238} \mathrm{U}$ e (d) ${ }^{237} \mathrm{~Np}$.

$100 \%$ a fim de reproduzir estes dados experimentais. Um dos motivos para isso seria que a seção de choque total de fotoabsorção do ${ }^{237} \mathrm{~Np}$ é de fato superior à curva universal assumida para todos os demais núcleos. Outro motivo pode ser um erro experimental, particularmente na determinação da massa do ${ }^{237} \mathrm{~Np}$ alvo, resultando em um desvio sistemático das seções de choque medidas. Não esteve entre os objetivos deste trabalho estudar novamente a fotoabsorção, processo este já bem simulado pelo CRISP para uma variedade de núcleos [60].

As reações de spallation inserem uma dificuldade a mais no ajuste, tendo em vista que para cada caso estudado se busca reproduzir 12 parábolas referentes aos produtos da reação. Resultados melhores do que esses já foram obtidos para estas mesmas reações [74], muito embora, neste trabalho se obteve um ajuste global envolvendo fotofissão e spallation para uma variedade de núcleos, algo que não fazia parte dos objetivos do trabalho exposto na Ref. [74].

A Figura 3.7 apresenta a comparação entre o cálculo do CRISP e as parábolas experi- 
mentais [75] de spallation para a reação ${ }^{197} \mathrm{Au}+800 \mathrm{MeV}$ p. O maior desacordo se dá no posicionamento das parábolas, com um deslocamento para a direita em todos os casos, apontando excesso de nêutrons, o qual se torna ainda pior para menor número atômico. Apesar de conhecido este fato, não foi possível resolver o equilíbrio entre emissão de nêutrons e prótons de forma a melhor posicionar as parábolas sem que isso afetasse para pior os resultados de fotofissão.

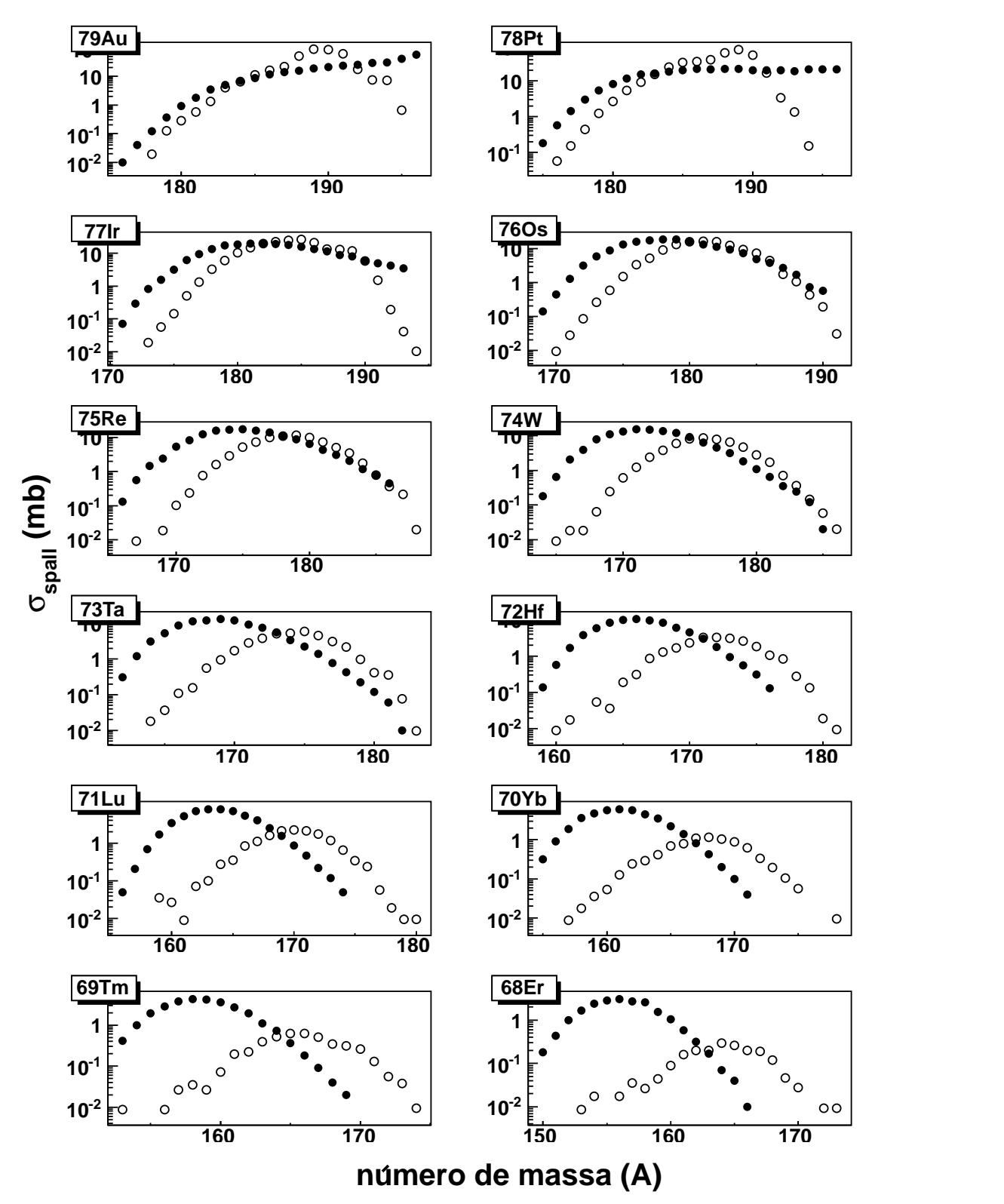

Figura 3.7: Seções de choque dos produtos de spallation da reação ${ }^{197} \mathrm{Au}+800 \mathrm{MeV}$ p. 
Há desacordo também na forma das parábolas, maior em alguns casos, menor em outros. Este erro cometido pelo cálculo pode ser considerado menos grave do que o anterior, tendo em vista que alguma semelhança foi alcaçada, em alguns casos, entre as formas calculada e experimental.

Outro elemento com o qual é difícil lidar num ajuste global como este é a seção de choque total, que deve diminuir quanto menor o Z. Nesta simulação verificou-se uma redução excessiva na seção de choque com a redução de $Z$, embora tal variação tenha, de fato, ido na direção correta.

A Figura 3.8 apresenta as parábolas de spallation para a reação ${ }^{208} \mathrm{~Pb}+1 \mathrm{GeV}$ p em comparação aos dados experimentais [76]. Valem para este caso as mesmas considerações já feitas para o ${ }^{197} \mathrm{Au}$. A diferença fundamental está no fato dos resultados serem nitidamente melhores, com alguns bons acordos tanto de forma como de seção de choque total para as primeiras três parábolas. Um acordo inferior porém valioso também se nota para os produtos ${ }^{79} \mathrm{Au},{ }^{78} \mathrm{Pt} \mathrm{e}{ }^{77} \mathrm{Ir}$.

Aqui, erra-se menos na posição de cada parábola. A partir das equações (2.39), (2.40) e (2.42), verifica-se facilmente que a redução em $\mathrm{Z}$ implica um aumento da emissão de prótons relativo a emissão de nêutrons pelo aumento do parâmetro $a_{p}$ e redução do parâmetro $a_{n}$, do modelo de Dostrovsky. Isso está de acordo com a realidade física conhecida, uma barreira coulombiana menor aumenta a chance de emissão de prótons. Além disso, núcleos mais leves possuem uma relação entre o número de nêutrons e o número de prótons menor, reduzindo a multiplicidade de nêutrons. Já núcleos mais pesados possuem excesso de nêutrons. Isso somado ao fato de estes não possuirem carga aumenta a sua probabilidade de emissão. No caso de emissão alfa, esta sofre redução para Z menor. Sua chance de emissão aumenta para núcleos que sejam maiores e mais deformados, uma vez que isso aumenta a chance de formação de clusters de partículas alfa que possam ser emitidas. O aumento da esfericidade inibe esta formação.

A dificuldade reside na correta calibração dessas relações, necessidade esta não garantida pelas fórmulas empíricas de Dostrovsky para todas as reações e núcleos que se procure analisar. 

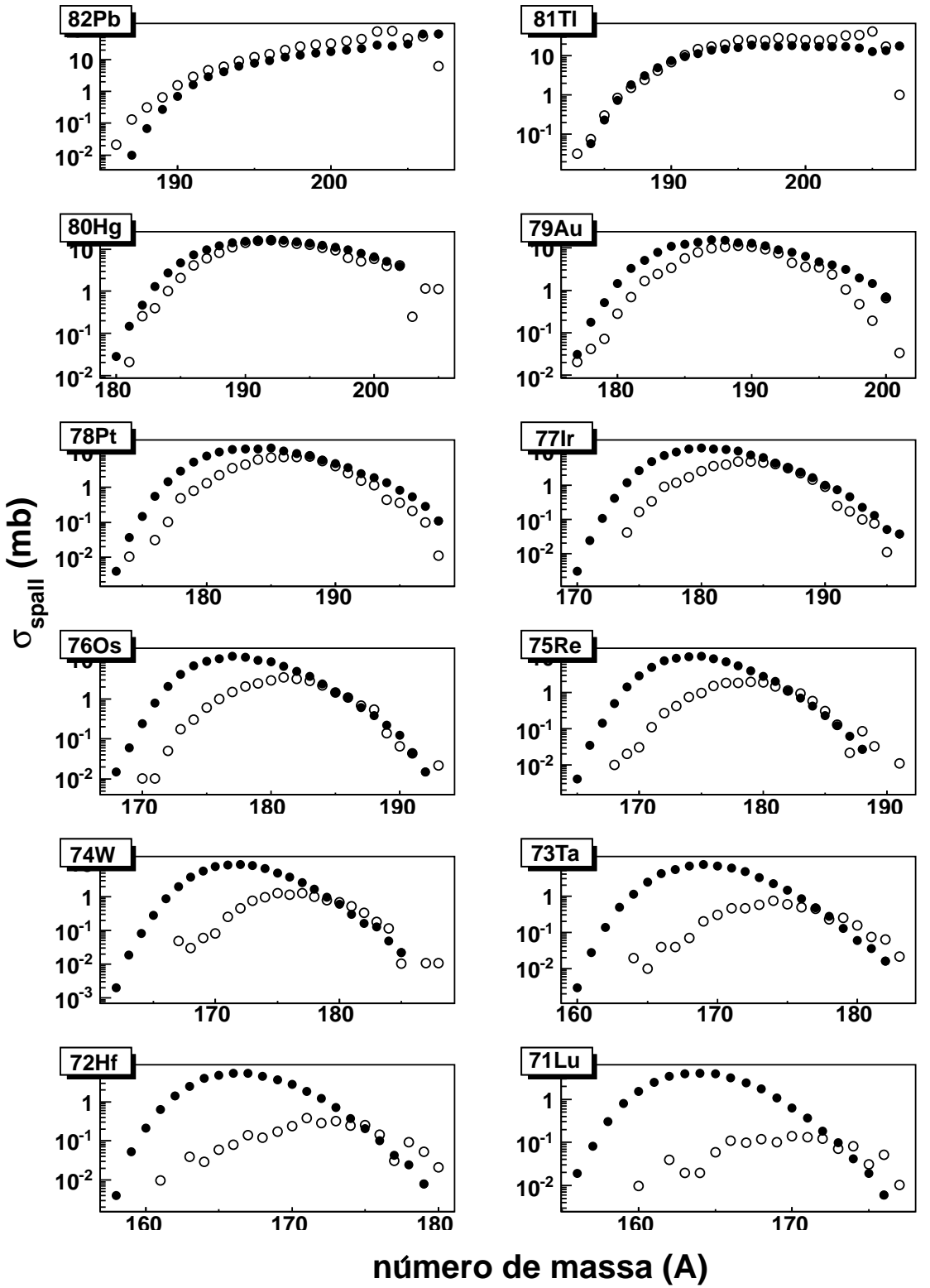

Figura 3.8: Seções de choque dos produtos de spallation da reação ${ }^{208} \mathrm{~Pb}+1 \mathrm{GeV}$.

O estudo de um grupo restrito de reações pode, inclusive, levar a conclusões erradas quanto aos melhores valores dos parâmetros de densidade de níveis, devido ao fato de haver um número maior de combinações de parâmetros que resultam no correto cálculo de uma única seção de choque do que numa situação em que se busca calcular várias seções de choque para reações diferentes, com núcleos que apresentam propriedades diferentes. 
O Minuit forneceu para este ajuste um $\chi^{2}$ reduzido de 353.224.

\subsection{Distribuição de massa de fragmentos de fissão}

A Tabela 3.3 resume todos os parâmetros necessários ao cálculo dos modos de fissão para todos os casos estudados, correspondendo portanto às equações (2.52), (2.53), (2.54), (2.58), (2.59), (2.60), (2.61) e (2.65). São também apresentados os valores de $\chi^{2}$ reduzido correspondentes a cada ajuste. Como mencionado no capítulo 2, alguns parâmetros da Tabela 3.3 foram obtidos diretamente da literatura, e portanto, nenhum ajuste foi feito.

Tabela 3.3: Valores dos parâmetros relevantes do modelo de fissão multimodo.

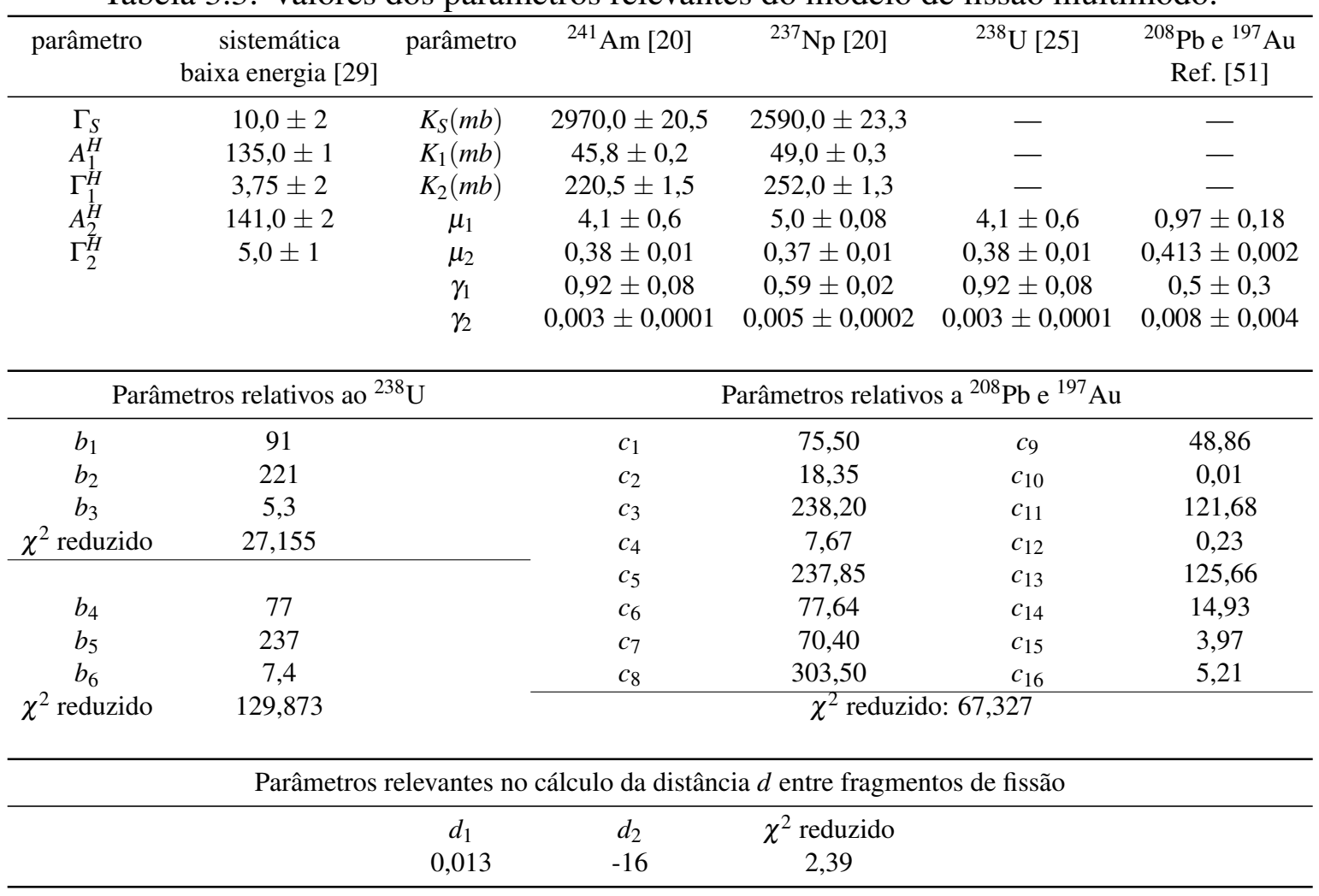

Para fissão espontânea ou a baixa energia, o parâmetro $A_{S}$ na equação (2.52) pode ser corretamente substitudído por $A_{0} / 2$, sendo $A_{0}$ o número de massa do núcleo alvo. No entanto, para fissão induzida a energias intermediárias e altas, esta substituição não pode ser feita e $A_{S}$ passa a ser então um parâmetro livre no procedimento de ajuste, sendo associado ao número de massa do núcleo fissionante, $A_{f}$. Este número de massa, no entanto, depende da partícula incidente, de sua energia e de propriedades do núcleo alvo. Além disso, trata-se, de fato, de uma distribuição 
de massa, não de um valor fixo, como se nota pelas Figuras 3.9 e 3.10.

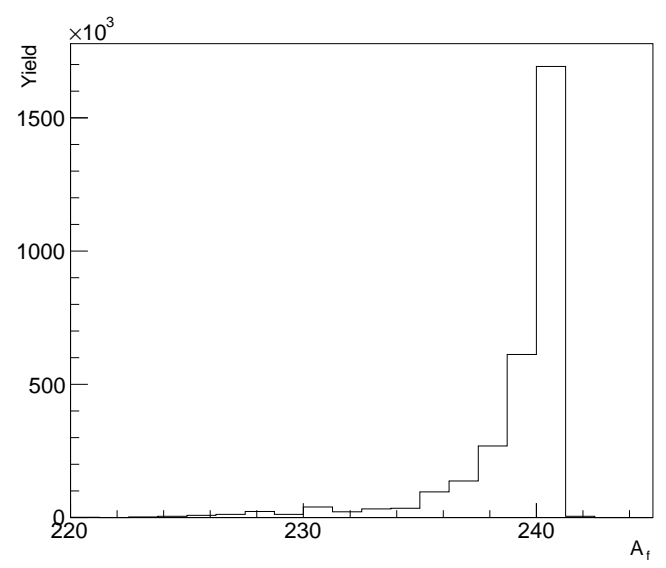

(a)

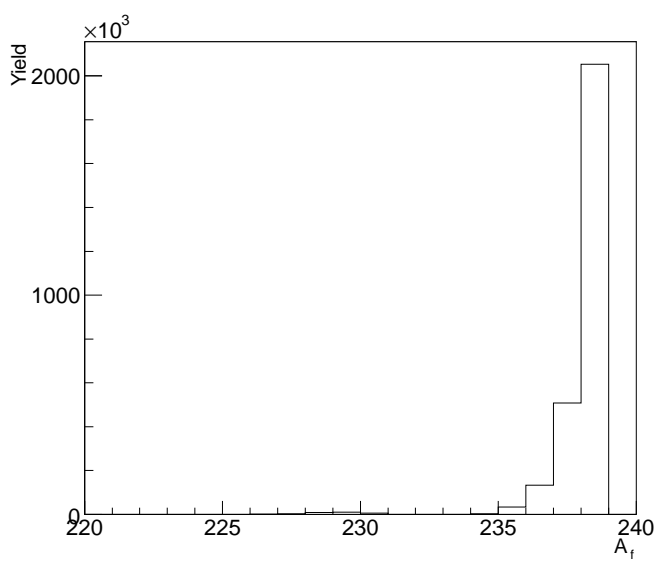

(c)

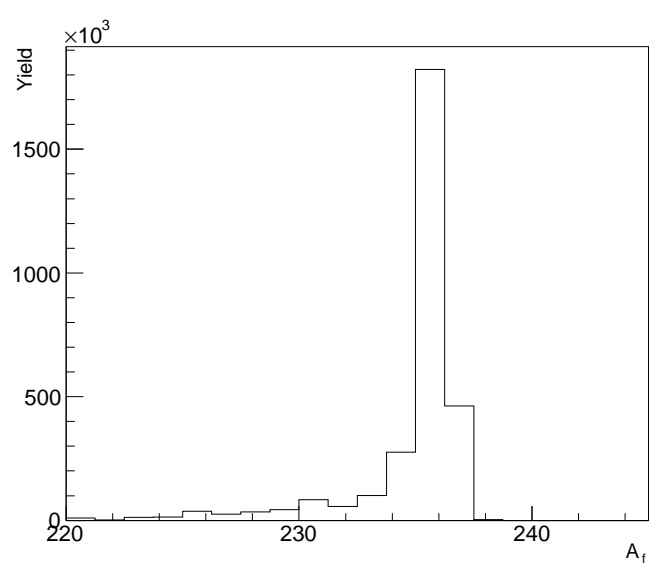

(b)

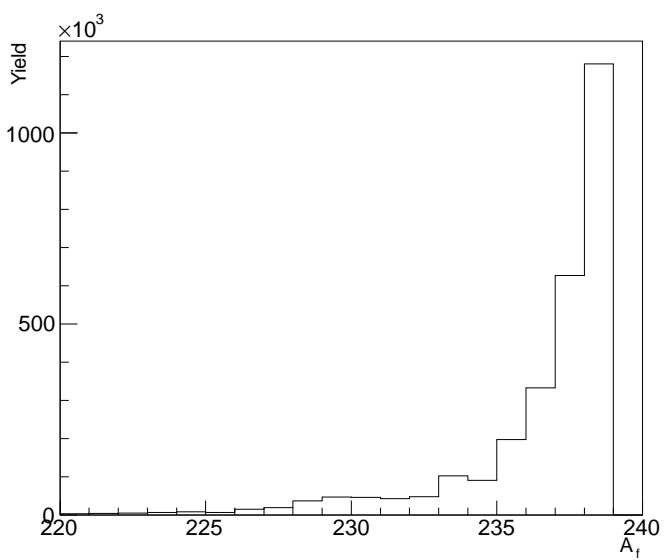

(d)

Figura 3.9: Distribuições de massa do núcleo fissionante. (a) ${ }^{241} \mathrm{Am}$, (b) ${ }^{237} \mathrm{~Np}$ (c) ${ }^{238} \mathrm{U}$ a 50 $\mathrm{MeV}$ e (d) ${ }^{238} \mathrm{U}$ a $3500 \mathrm{MeV}$.

A energias intermediárias e altas, os valores de posição e largura para cada modo de fissão, como obtidos de um ajuste direto da expressão (2.52) podem ser alterados em virtude das distribuições de massa e número atômico do núcleo fissionante $[77,78,79]$. Os efeitos da distribuição de massa do núcleo fissionante na descrição dos modos de fissão já foram estudados em reações entre ${ }^{238} \mathrm{U}$ e deutério a $1 \mathrm{GeV} /$ nucleon [77], e podem também ter efeitos sobre os resultados de reações com fótons e prótons a energias intermediárias [20, 25]. Portanto, a distribuição de massa dos fragmentos está composta na distribuição de massa do núcleo fissionante. Um cálculo mais realístico das distribuições de massa dos fragmentos de fissão deve levar em conta a distribuição dos sistemas fissionantes. 


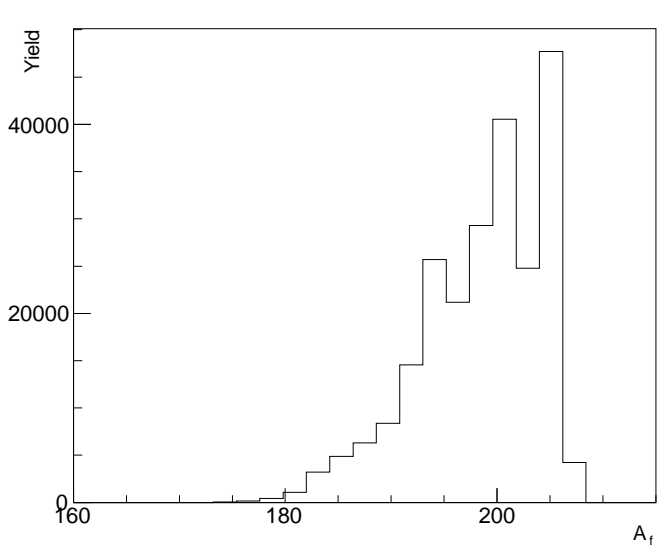

(a)

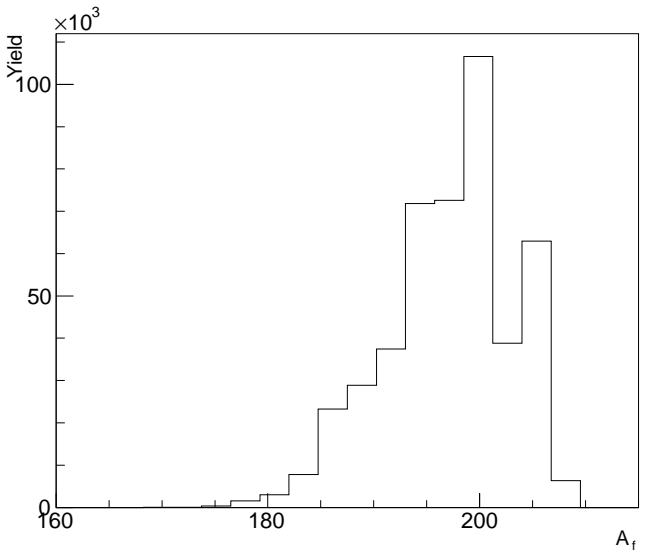

(b)

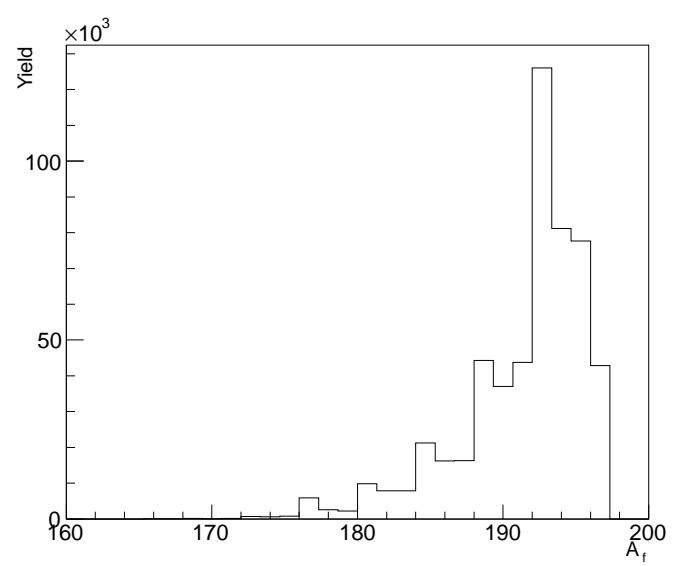

(c)

Figura 3.10: Distribuições de massa do núcleo fissionante. (a) ${ }^{208} \mathrm{~Pb}$ a $500 \mathrm{MeV}$ p (b) ${ }^{208} \mathrm{~Pb}$ a $1000 \mathrm{MeV}$ p e (c) ${ }^{197} \mathrm{Au}$ a $800 \mathrm{MeV}$.

A extração das distribuições de massa dos fragmentos conhecendo-se a distribuição de núcleos fissionantes é viável uma vez que se tenha um código de Monte Carlo capaz de simular cada processo de fissão individualmente, para cada núcleo fissionante e, assim, separar as contribuições ao resultado final de cada modo de fissão e da distribuição de massa dos sistemas que fissionam.

Os resultados obtidos com o CRISP para os núcleos ${ }^{241} \mathrm{Am},{ }^{237} \mathrm{~Np},{ }^{208} \mathrm{~Pb}$ e ${ }^{197} \mathrm{Au}$ podem ser vistos nas Figuras 3.11 e 3.12, onde se faz a comparação entre os resultados obtidos quando se atribui aos fragmentos a energia de excitação do núcleo fissionante, à esquerda na figura, e os resultados calculados conforme o modelo descrito na subseção 2.3.4, à direita.

Como já antecipado na subseção 2.3.4, as distribuições de massa dos fragmentos são alte- 


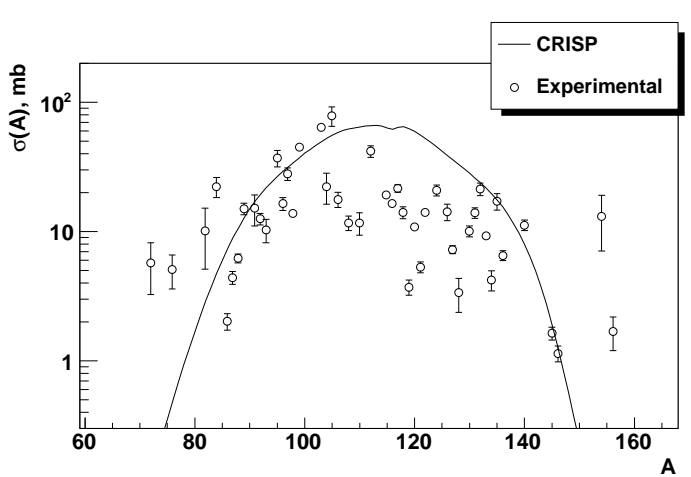

(a)

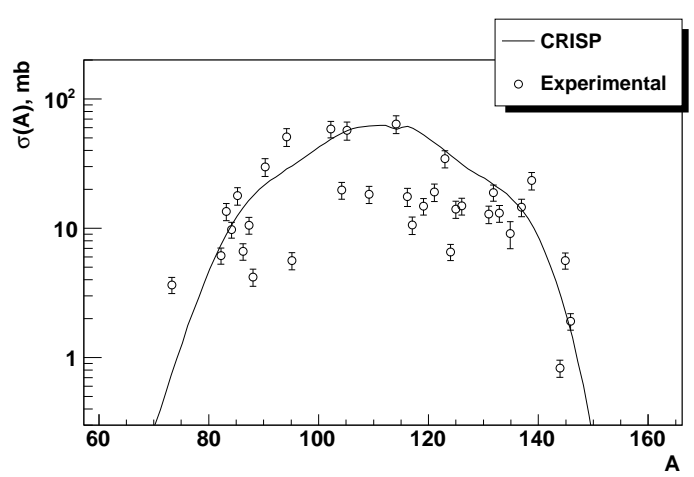

(c)

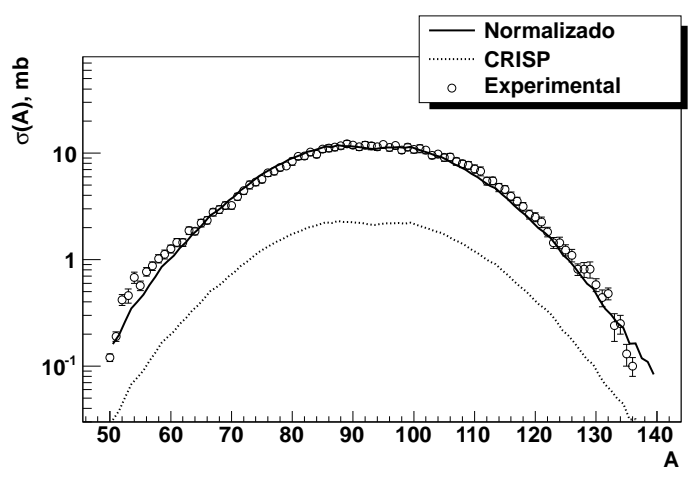

(e)

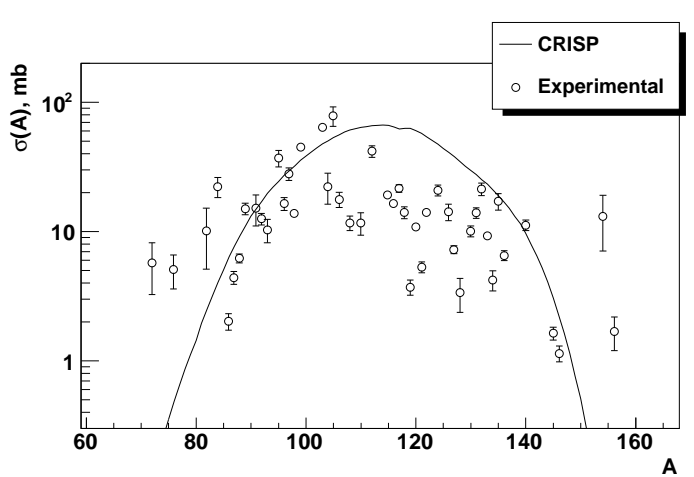

(b)

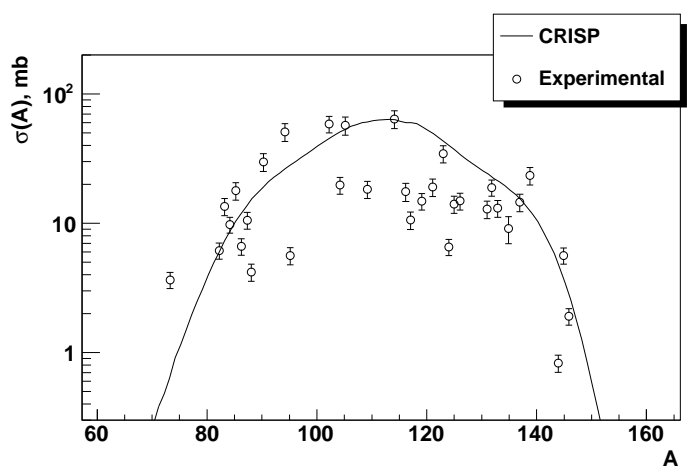

(d)

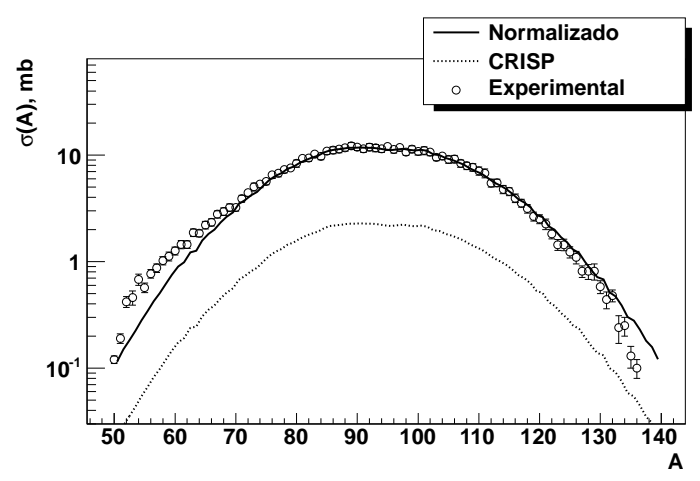

(f)

Figura 3.11: Distribuições de massa dos fragmentos. (a) ${ }^{241} \mathrm{Am}\left(E_{\text {frag }} \simeq E_{f}\right)$, (b) ${ }^{241} \mathrm{Am}$, (c) ${ }^{237} \mathrm{~Np}\left(E_{\text {frag }} \simeq E_{f}\right),(\mathrm{d}){ }^{237} \mathrm{~Np},(\mathrm{e}){ }^{208} \mathrm{~Pb}$ a $500 \mathrm{MeV} \mathrm{p}\left(E_{\text {frag }} \simeq E_{f}\right)$ e (f) ${ }^{208} \mathrm{~Pb} \mathrm{a} 500 \mathrm{MeV}$.

radas muito sutilmente quando se aplica a aproximação $E_{\text {frag }} \simeq E_{f}$. Quando se contabiliza o Q da fissão e a energia cinética dos fragmentos, a energia de excitação atribuída aos fragmentos é um pouco menor, resultando em um número menor de evaporações. A distribuição, então, aparece na figura levemente deslocada para número de massa maiores.

Quanto ao acordo obtido, vê-se que os dados experimentais para ${ }^{241} \mathrm{Am}$ e ${ }^{237} \mathrm{~Np}$, obtidos da Ref. [20], não permitem uma análise mais definitiva, mas ainda assim é possível reconhecer um bom ajuste entre a curva e a tendência geral dos pontos em ambos os casos, bem como uma 


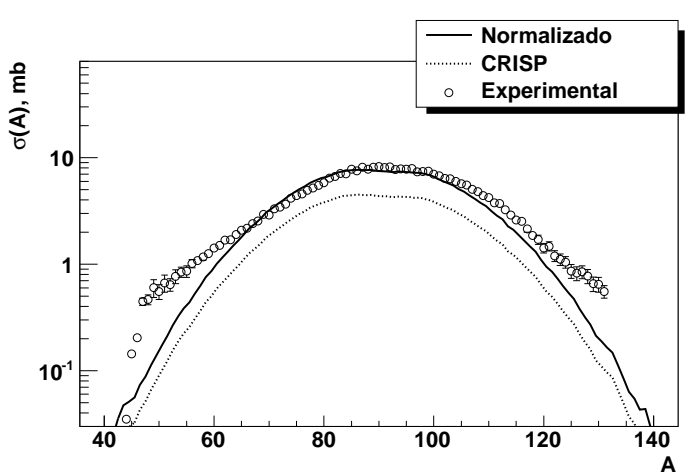

(a)

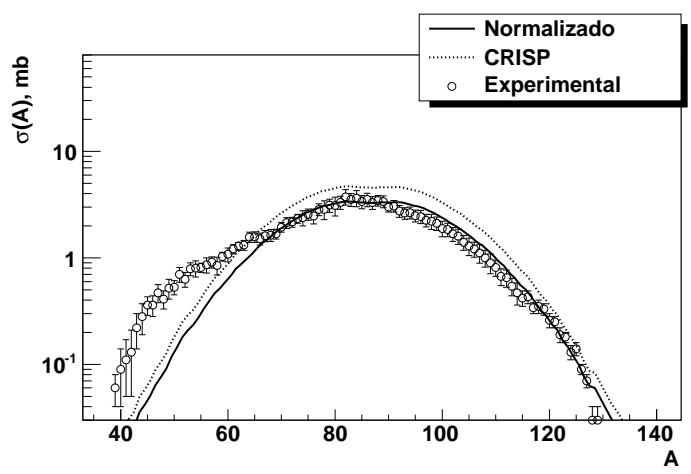

(c)

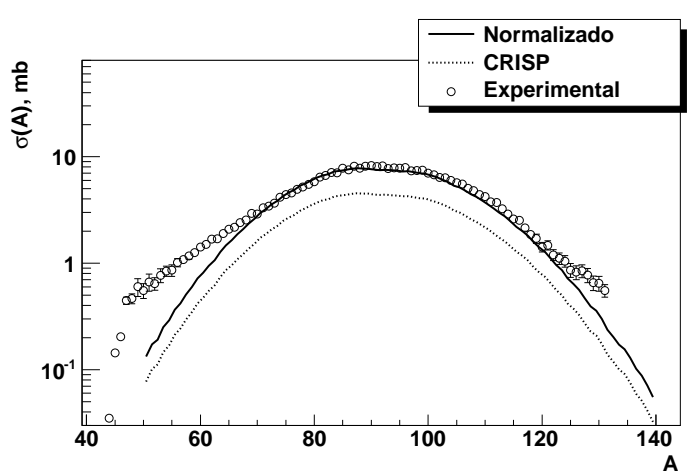

(b)

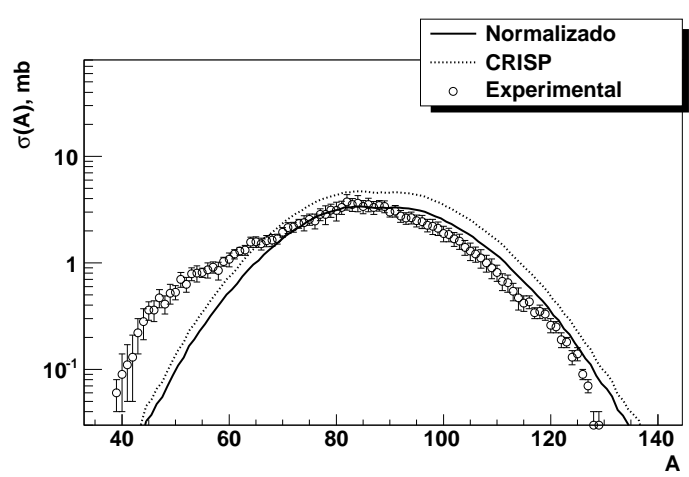

(d)

Figura 3.12: Distribuições de massa dos fragmentos. (a) ${ }^{208} \mathrm{~Pb}$ a $1000 \mathrm{MeV} \mathrm{p}\left(E_{\text {frag }} \simeq E_{f}\right)$ (b) ${ }^{208} \mathrm{~Pb} \mathrm{a} 1000 \mathrm{MeV} \mathrm{p} \mathrm{(c)}{ }^{197} \mathrm{Au} \mathrm{a} 800 \mathrm{MeV} \mathrm{p}\left(E_{\text {frag }} \simeq E_{f}\right)$ e (d) ${ }^{197} \mathrm{Au}$ a $800 \mathrm{MeV} \mathrm{p}$.

boa reprodução da seção de choque total, calculada pelo CRISP.

Nas Figuras 3.11(e) e 3.11(f) apresenta-se, juntamente com a comparação aos dados experimentais [24], o mesmo cálculo quando normalizado aos dados e quando se usa a seção de choque total calculada pelo código para a reação ${ }^{208} \mathrm{~Pb}+500 \mathrm{MeV}$ p. O mesmo temos para as Figuras 3.12(a) e 3.12(b) em que se vê os resultados obtidos para a reação ${ }^{208} \mathrm{~Pb}+1000 \mathrm{MeV}$ p, e para as Figuras 3.12(c) e 3.12(d), que apresentam as distribuições de massa dos fragmentos para a reação ${ }^{197} \mathrm{Au}+800 \mathrm{MeV}$ p. Os dados experimentais para os últimos dois casos foram obtidos, respectivamente, de [76] e [80].

Verifica-se para os casos estudados com o ${ }^{208} \mathrm{~Pb}$ um excelente acordo com os pontos tanto na posição da curva quanto na sua forma. Nestes últimos casos, os dados experimentais já permitem uma análise mais segura.

A única divergência séria nos resultados se dá pela baixa seção de choque total calculada tanto para o caso a $500 \mathrm{MeV}(\approx 5 \times$ menor do que a experimental $)$ quanto no caso a $1000 \mathrm{MeV}$ 
$(\approx 2 \times$ menor do que a experimental). De acordo com o trabalho publicado em [76], foram feitas correções relativas ao aparato experimental para tratar de reações secundárias que pudessem ocorrer com os fragmentos de fissão, por exemplo, interações entre estes e o material que constitui o próprio equipamento. Foi ressaltado naquele trabalho que a região de $A \simeq 130$ apresentou maior mistura entre produtos de fissão e de spallation. Sendo esta uma possível fonte de contaminação em muitos experimentos, não se pode descartá-la como a causa da elevação da seção de choque para $A \simeq 130$ nos dados referentes a ${ }^{208} \mathrm{~Pb}+1000 \mathrm{MeV}$ p.

Também foi relatado que os fragmentos não foram detectados pelo método de coincidência. Sem uma garantia de que a reação tenha produzido apenas 2 fragmentos, processos que competem com a fissão, como multifragmentação e fissão ternária, passam a ser uma possibilidade não descartada de contaminação, neste caso, para massas mais leves, o que explicaria, se confirmado o fato, a seção de choque experimental mais elevada em torno de $A \simeq 50$.

As dificuldades para a correta reprodução das seções de choque totais já foram esclarecidas na discussão das seções anteriores no que se refere aos parâmetros de densidade de níveis. Para evidenciar ainda mais este fato, considere-se a Figura 3.13. Ela apresenta a distribuição de $Z^{2} / A$ de núcleos no final da cascata intranuclear para 6 reações com ${ }^{208} \mathrm{~Pb}$. Há 3000 núcleos residuais ao final de cada cascata. Quatro delas são induzidas por fótons a 100, 500, 900 e $1000 \mathrm{MeV}$, e duas delas por prótons a 500 e $1000 \mathrm{MeV}$.

Nota-se que independentemente da reação as distribuições de núcleos residuais da cascata se interceptam de tal forma que o $Z^{2} / A$ médio em todos os casos é muito próximo. Em particular, para fótons de $500 \mathrm{MeV}$, tem-se $\frac{\overline{Z^{2}}}{A}=31.9746$ e para prótons de $500 \mathrm{MeV}, \frac{\overline{Z^{2}}}{A}=32.1311$. Portanto, vê-se que o uso da razão de fissão para a melhora no cálculo da seção de choque da reação ${ }^{208} \mathrm{~Pb}+500 \mathrm{MeV}$ p conduziria, inevitavelmente, a uma perda de qualidade no cálculo da seção de choque da fotofissão do ${ }^{208} \mathrm{~Pb}$, uma vez que um ajuste de ampla aplicação desse parâmetro depende da boa distinção que há no valor de $Z^{2} / A$ para núcleos distintos, originados ou não do mesmo núcleo pai.

Os resultados obtidos para o caso ${ }^{197} \mathrm{Au}+800 \mathrm{MeV}$ p podem ser considerados em bom 


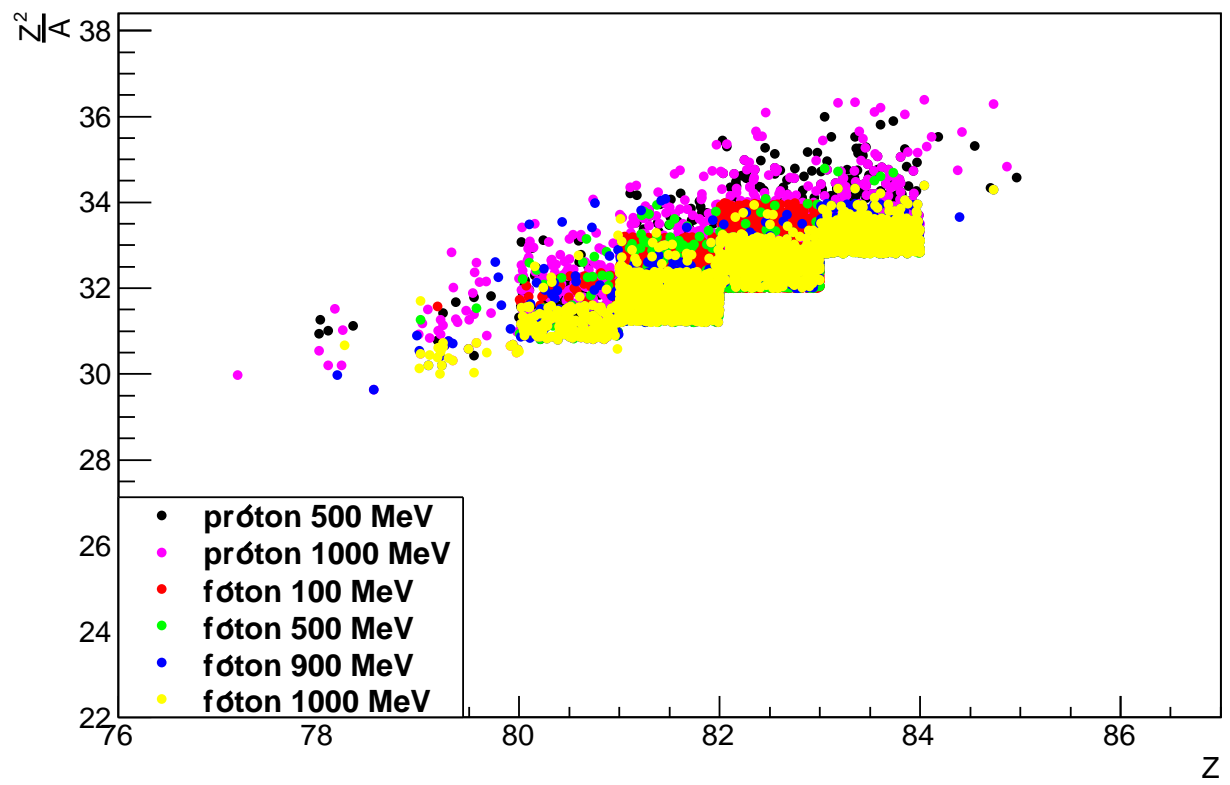

Figura 3.13: Distribuição de $Z^{2} / A$ para núcleos no final da cascata intranuclear para as reações ${ }^{208} \mathrm{~Pb}+500 \mathrm{MeV} \mathrm{p},{ }^{208} \mathrm{~Pb}+1000 \mathrm{MeV}$ p, ${ }^{208} \mathrm{~Pb}+100 \mathrm{MeV} \gamma,{ }^{208} \mathrm{~Pb}+500 \mathrm{MeV} \gamma,{ }^{208} \mathrm{~Pb}+$ $900 \mathrm{MeV} \gamma \mathrm{e}^{208} \mathrm{~Pb}+1000 \mathrm{MeV} \gamma$.

acordo com os dados experimentais, em particular nas regiões de maior seção de choque. A seção de choque total, apesar de superestimada, foi aqui melhor calculada pelo CRISP do que nos casos do ${ }^{208} \mathrm{~Pb}$. O real desacordo se encontra de fato na região de núcleos mais leves. Estes dados experimentais procedem do mesmo laboratório responsável pelo estudo da reação ${ }^{208} \mathrm{~Pb}$ $+1000 \mathrm{MeV}$ p [80]. As mesmas considerações feitas anteriormente com respeito a contaminações podem ser feitas aqui, ressaltando que neste último trabalho nenhuma menção foi feita quanto aos fragmentos terem ou não sido detectados em coincidência ou quanto aos produtos de spallation terem contaminado a detecção dos fragmentos de fissão. Até o presente momento, estas são apenas possibilidades. Outra possível explicação para o desacordo na região de massas menores pode ser obtidida a partir da distribuição de massa do núcleo fissionante, Figura 3.10(c). A ausência de uma cauda mais acentuada na região de núcleos mais leves pode ser considerada a causa, ao menos em parte, da baixa seção de choque calculada para fragmentos mais leves.

Vê-se que o modelo para o cálculo da competição entre evaporação e fissão, apesar de bom e com excelentes resultados em alguns casos, ainda não é o ideal. Apesar de não ser possível 
determinar o quão distante o modelo de evaporação e fissão está da sua parametrização correta, sabemos que ele é dependente em grande medida da fórmula de massa, a qual é fonte de erros, como já foi discutido na seção 3.1 .

A boa reprodução dos dados experimentais, apenas com variações muito pequenas entre as condições com e sem aproximação para a energia de excitação dos fragmentos, é uma demonstração da robustez do código, resultado da consistência na implentação dos modelos.

As distribuições de massa dos fragmentos de fissão obtidas no estudo de Bremsstrahlung são apresentadas na Figura 3.14. Uma vez verificada como boa a aproximação de atribuir aos fragmentos a energia de excitação do núcleo fissionante, vê-se um bom acordo entre a curva e os pontos experimentais, estes obtidos de [25], no que diz respeito às posições e às larguras das distribuições.

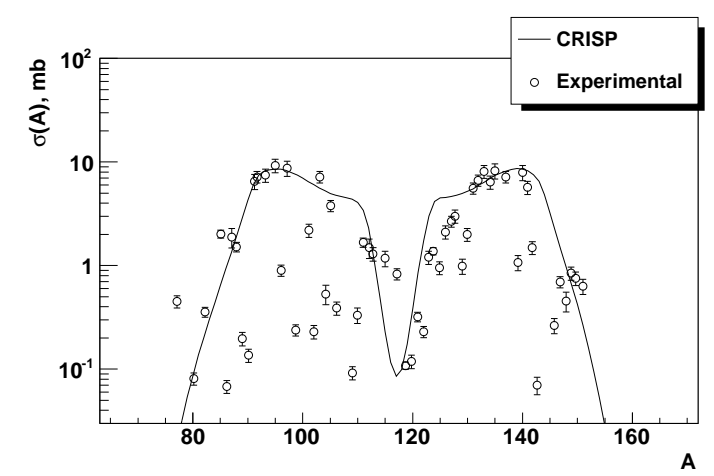

(a)

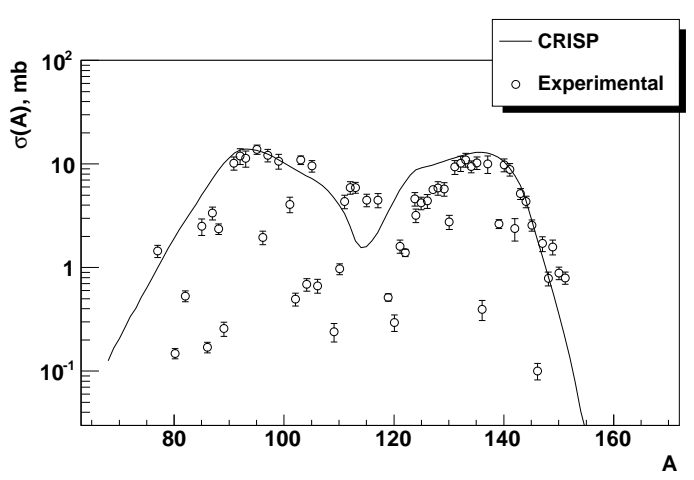

(b)

Figura 3.14: Distribuições de massa dos fragmentos. (a) ${ }^{2238} \mathrm{U}$, energia máxima do fóton em 50 $\mathrm{MeV}$ e (b) ${ }^{2238} \mathrm{U}$, energia máxima do fóton em $3500 \mathrm{MeV}$.

Tanto nos resultados exibidos nas Figuras 3.11(e) e 3.11(f) como nas Figuras 3.12 e 3.14, as intensidades dos modos de fissão são funções do número de massa do núcleo fissionante. $\mathrm{O}$ bom ajuste obtido com a inserção dessa dependência nos parâmetros atesta novamente a importância da distribuição de massa dos núcleos fissionantes no estudo da distribuição de massa dos fragmentos. 


\subsection{Barreira de fissão}

O correto cálculo da barreira de fissão é fundamental à determinação da probabilidade de fissão, como fica evidente pelas equações (2.48), (2.49) e (2.50). Em particular é importante a este trabalho cujo foco esteve no estudo da fissão de núcleos pesados.

A barreira de fissão atualmente implementada no CRISP obedece ao modelo de Nix [38], o qual tem sido bem sucedido particularmente na região de núcleos pesados, como se pode notar pela Figura 3.15, que mostra a diferença entre a barreira de fissão calculada pelo método ETFSI e aquela obtida pelo modelo de Nix.

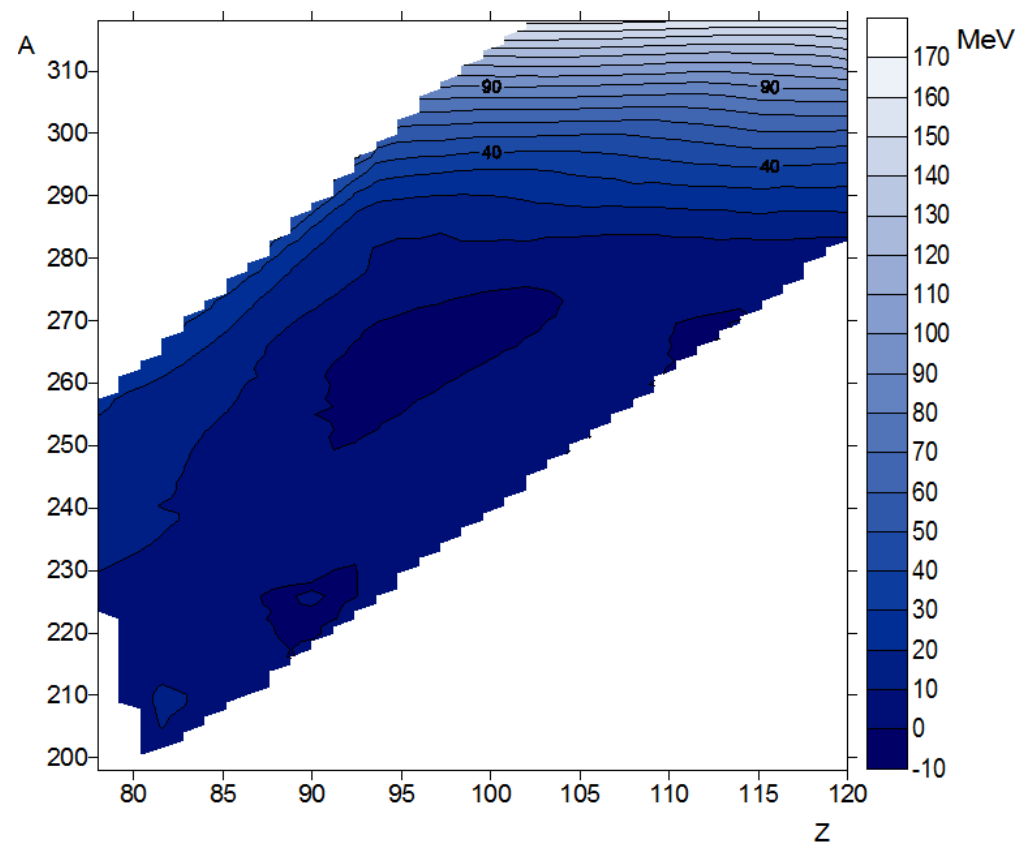

Figura 3.15: Diferença entre a barreira de fissão calculada pelo método ETFSI e aquela obtida pelo modelo de Nix.

$\mathrm{O}$ erro não ultrapassa $10 \mathrm{MeV}$ numa vasta região de núcleos de interesse para a Física Nuclear. No entanto, percebe-se na vizinhança do $\mathrm{Pb}$ um aumento no erro, que chega a aproximadamente $20 \mathrm{MeV}$. Esta região é de difícil ajuste como já evidenciado pela Figura 2.7. No intuito de reproduzir mais corretamente a barreira de fissão nessa região, foi proposto o modelo descrito na subseção 2.3.5, uma superfície dependente de Z e A. Todos os parâmetros do ajuste são apresentados na Tabela 3.4.

A diferença entre a barreira de fissão calculada pelo método ETFSI e aquela obtida pelo 
Tabela 3.4: Valores dos parâmetros da fórmula sugerida para ajustar as previsões de barreira de fissão calculadas com o método ETFSI.

\begin{tabular}{cccc}
\hline Parâmetro & Valor & Parâmetro & Valor \\
\hline$e_{1}$ & 1152 & $e_{4}$ & 8,6 \\
$e_{2}$ & $-15,60$ & $e_{5}$ & 0,0422 \\
$e_{3}$ & $-4,699$ & $e_{6}$ & 0,01315 \\
\hline
\end{tabular}

modelo proposto neste trabalho é mostrada na Figura 3.16. A superfície foi bem sucedida na redução do erro em toda a região abaixo de $A \simeq 250$, mantendo a diferença muito próxima de zero.

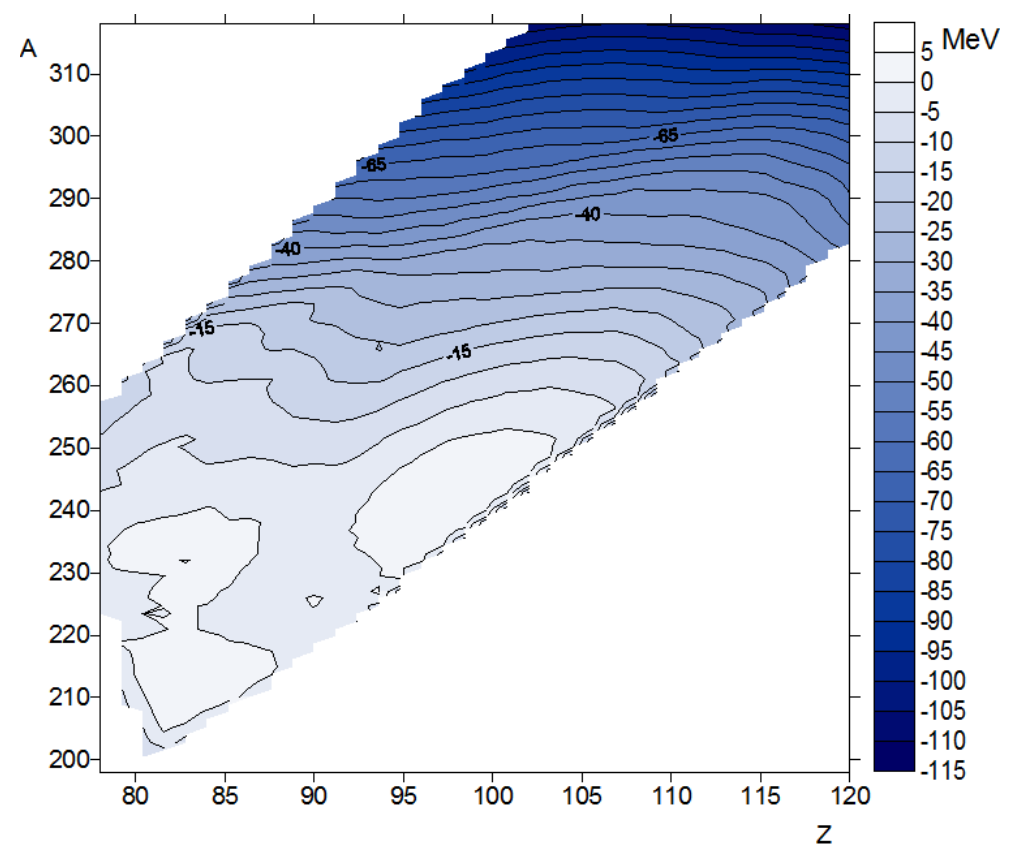

Figura 3.16: Diferença entre a barreira de fissão calculada pelo método ETFSI e aquela obtida pelo modelo proposto neste trabalho.

Houve uma melhora considerável na determinação da barreira de fissão na vizinhança do $\mathrm{Pb}$. Apenas duas faixas bastante estreitas tanto em $\mathrm{Z}$ quanto em A divergem do valor calculado pelo método ETFSI, e ainda assim, em não mais do $\sim 10 \mathrm{MeV}$. Para este ajuste obteve-se $\chi^{2}=2,196$ (reduzido). 


\subsection{Perspectivas do trabalho}

No que diz respeito à fórmula semi-empírica de massa, novos ajustes podem ser testados com vistas a atender outras regiões de nuclídeos. No entanto, é do maior interesse encontrar uma fórmula que forneça valores ótimos de massa nuclear tanto para núcleos pesados até $A \simeq 250$ quanto para núcleos leves na região do Carbono. Essa extensão para núcleos leves faz parte dos objetivos futuros de ampliação da aplicabilidade do código CRISP.

A introdução de outra fórmula de massa implicará no reajuste de todos os parâmetros de densidade de níveis. Isso será feito tencionando-se aumentar a precisão em reproduçao de seções de choque tanto de fotofissão quanto de spallation com o mínimo de perdas. A correção das parábolas de spallation constituem o próximo passo no desenvolvimento do CRISP. Após processos exaustivos de ajuste com diferentes fórmulas de massa, sem que haja ganho significativo, um novo modelo para o cálculo dos parâmetros de densidades de níveis deverá ser o passo seguinte, dado que após todas as tentativas precedentes poder-se-á dizer que as fórmulas empíricas de Dostrovsky tenham chegado ao seu limite de acomodação aos resultados.

Embora o valor da razão de fissão em cada intevalo mude em virtude de um reajuste global dos parâmetros, espera-se que a tendência crescente da curva se mantenha. Ao final, toda sequência de intervalos será substituída por uma ou mais funções contínuas.

A barreira de fissão já obtida será inserida no início do ajuste a fim de que todos os parâmetros se adequem consistentemente à nova barreira.

No âmbito do cálculo dos fragmentos de fissão, o próximo passo será dado no sentido da unificação do modelo tanto quanto for possível, de modo a permitir que o CRISP decida para cada núcleo e reação quais as intensidades relativas dos modos de fissão a partir de uma única sistemática de cálculo. Este trabalho já demonstrou que tratar os parâmetros de largura, posição e intensidade de cada modo de fissão como dependentes do núcleo fissionante é a alternativa com melhores perspectivas. Ainda neste contexto, um modelo para a inclusão do cálculo de multifragmentação já está sendo estudado [81]. 


\section{Conclusões}

Cabe inicialmente enfatizar os resultados importantes obtidos, a começar pela fórmula de massa que, com os parâmetros atuais, permitiu uma redução considerável do erro na região de massas intermediárias até boa parte da região de núcleos pesados. Este fato ficou evidenciado pela Figura 3.2.

Em seguida, há os resultados para as seções de choque de fotofissão, apresentados na Figura 3.6, em que se nota um excelente acordo de cálculo com os dados experimentais, especialmente para o ${ }^{208} \mathrm{~Pb}$, um nuclídeo cujas características são conhecidamente difíceis de reproduzir.

Os resultados de spallation das Figuras 3.7 e 3.8 mostram que o código CRISP é capaz de reproduzir com alguma precisão algumas das parábolas de maior seção de choque, acertando ou na forma ou na posição ou mesmo em ambas, como é o caso do ${ }^{208} \mathrm{~Pb}$ a $1 \mathrm{GeV}$ p, ainda quando a mesma parametrização é utilizada tanto para fotofissão quanto para spallation.

Finalmente, as distribuições de massa dos fragmentos de fissão foram em geral bem reproduzidas, na forma ou não seção de choque total, como mostram as Figuras 3.11, 3.12 e 3.14. Mesmo para as reações estudadas com ${ }^{241} \mathrm{Am},{ }^{237} \mathrm{~Np}$ e ${ }^{238} \mathrm{U}$, em que os dados experimentais não permitem uma análise mais definitiva, o acordo entre a curva calculada e a tendência geral dos pontos, bem como na seção de choque total, caso dos núcleos ${ }^{241} \mathrm{Am}$ e ${ }^{237} \mathrm{~Np}$, é digno de nota.

O ajuste proposto para a barreira de fissão, calculada a partir do método ETFSI, não integrou os objetivos deste trabalho, mas o resultado obtido merece ser mencionado como de grande utilidade a melhoramentos futuros no código CRISP ou a outros estudos que envolvam núcleos 
na região de aplicação do método ETFSI. A qualidade do ajuste ficou evidenciada pela Figura 3.16 .

Conclui-se, assim, que o objetivo central do trabalho de reproduzir dados experimentais de fissão de núcleos actinídeos a energias intermediárias e altas foi alcançado com bom aproveitamento. De modo específico, a fórmula de massa obtida atende às necessidades de precisão de estudos nas regiões de energias e de massas contempladas neste trabalho.

O modelo de Dostrovsky [31] para os parâmetros de densidade de níveis se mostrou eficaz para o estudo de uma variedade de reações nucleares, em particular reações de fissão, tema deste trabalho. Portanto, a maior dificuldade para o modelo de Dostrovsky resulta ser a correta reprodução de seções de choque de fotofissão e de spallation simultaneamente.

O modelo multimodo de fissão para o cálculo dos fragmentos de fissão demonstrou ser o mais adequado em todos os casos, seja a baixa ou a alta energia. A parametrização, contudo, não pode ser considerada única. As intensidades relativas de cada modo de fissão tem forte dependência na energia da reação e, segundo mostrou Böckstiegel [29], também o tem na massa do núcleo fissionante. A dependência na massa do núcleo fissionante foi a alternativa empregada no estudo das reações com ${ }^{238} \mathrm{U},{ }^{208} \mathrm{~Pb}$ e ${ }^{197} \mathrm{Au}$. No entanto, a limitação na região de dados experimentais conhecidos para as intensidades relativas dos modos de fissão não permite até o momento uma análise mais conclusiva.

Este trabalho confirma a necessidade de se conhecer a distribuição de massa dos núcleos fissionantes no estudo dos fragmentos de fissão, o que ficou aqui demonstrado tanto a baixa energia, quanto a energias intermediárias e altas, Figuras 3.11, 3.12 e 3.14. 


\section{Referências Bibliográficas}

[1] FERMI, E. Radioactivity induced by neutron bombardment. Nature, v. 133, p. 757-757, 1934. ISSN 0028-0836.

[2] FERMI, E. Possible production of elements of atomic number higher than 92. Nature, v. 133, p. 898-899, 1934. ISSN 0028-0836.

[3] HAHN, O.; STRASSMANN, F. Über die bruchstücke beim zerplatzen des urans. Naturwissenschaften, Springer Berlin / Heidelberg, v. 27, p. 163-164, 1939. ISSN 0028-1042. 10.1007/BF01489658. Disponível em: <http://dx.doi.org/10.1007/BF01489658>.

[4] MEITNER, L.; FRISCH, O. R. Disintegration of uranium by neutrons - a new type of nuclear reaction. Nature, v. 143, p. 239-240, 1939. ISSN 0028-0836.

[5] BOHR, N.; WHEELER, J. A. The mechanism of nuclear fission. Phys. Rev., American Physical Society, v. 56, p. 426-450, Sep 1939. Disponível em: $<$ http://link.aps.org/doi/10.1103/PhysRev.56.426>.

[6] WEIZSAECKER, C. F. v. Regarding theory of nuclear masses. Zeitschrift fur Physik, v. 96, n. 7-8, p. 431-458, 1935. ISSN 0044-3328.

[7] W., M.; KIRSON. Mutual influence of terms in a semi-empirical mass formula. $\mathrm{Nu}$ clear Physics A, v. 798, n. 1-2, p. 29-60, 2008. ISSN 0375-9474. Disponível em: $<$ http://www.sciencedirect.com/science/article/pii/S0375947407007531>.

[8] WANG, N.; LIU, M.; WU, X. Modification of nuclear mass formula by considering isospin effects. Phys. Rev. C, American Physical Society, v. 81, p. 044322, Apr 2010. Disponível em: <http://link.aps.org/doi/10.1103/PhysRevC.81.044322>.

[9] WANG, N. et al. Mirror nuclei constraint in nuclear mass formula. Phys. Rev. $C$, American Physical Society, v. 82, p. 044304, Oct 2010. Disponível em: $<$ http://link.aps.org/doi/10.1103/PhysRevC.82.044304>.

[10] GORIELY, S.; CHAMEL, N.; PEARSON, J. M. Skyrme-hartree-fock-bogoliubov nuclear mass formulas: Crossing the 0.6 mev accuracy threshold with microscopically deduced pairing. Phys. Rev. Lett., American Physical Society, v. 102, p. 152503, Apr 2009. Disponível em: < http://link.aps.org/doi/10.1103/PhysRevLett.102.152503>.

[11] BAO-HUA, S.; JIE, M. Challenge on the astrophysical r-process calculation with nuclear mass models. Chinese Physics Letters, v. 25, n. 7, p. 2429, 2008. Disponível em: $<$ http://stacks.iop.org/0256-307X/25/i=7/a=027 > .

[12] LIU, M. et al. Further improvements on a global nuclear mass model. Phys. Rev. C, American Physical Society, v. 84, p. 014333, Jul 2011. Disponível em: $<$ http://link.aps.org/doi/10.1103/PhysRevC.84.014333>. 
[13] NASSERIPOUR, R. et al. Coherent photoproduction of $\pi^{+}$from ${ }^{3} \mathrm{He}$. Phys. Rev. C, American Physical Society, v. 83, p. 034001, Mar 2011. Disponível em: $<$ http://link.aps.org/doi/10.1103/PhysRevC.83.034001>.

[14] FROMMHOLD, T. et al. Total photofission cross section for ${ }^{238} U$ as a substitute for the photon absorption cross section in the energy range of the first baryon resonances. Physics Letters B, v. 295, n. 1-2, p. 28-31, 1992. ISSN 0370-2693. Disponível em: $<$ http://www.sciencedirect.com/science/article/pii/037026939290084H $>$.

[15] CETINA, C. et al. Photofission of heavy nuclei from 0.2 to $3.8 \mathrm{GeV}$. Phys. Rev. C, American Physical Society, v. 65, p. 044622, Apr 2002. Disponível em: $<$ http://link.aps.org/doi/10.1103/PhysRevC.65.044622>.

[16] GMAR, M. et al. Assessment of actinide mass embedded in large concrete waste packages byphoton interrogation and photofission. Applied Radiation and Isotopes, v. 63, p. 613-619, 2005. ISSN 0969-8043. Disponível em: $<$ http://www.sciencedirect.com/science/article/pii/S0969804305001399>.

[17] SAUREL, N. et al. Experimental and simulated assay of actinides in a real waste package. Nuclear Instruments and Methods in Physics Research Section A: Accelerators, Spectrometers, Detectors and Associated Equipment, v. 550, n. 3, p. 691-699, 2005. ISSN 0168-9002. Disponível em: <http://www.sciencedirect.com/science/article/pii/S0168900205012787>.

[18] GMAR, M. et al. Photofission tomography of nuclear waste packages. Nuclear Instruments and Methods in Physics Research A, v. 562, p. 1089-1092, 2006. ISSN 0168-9002. Disponível em: <http://www.sciencedirect.com/science/article/pii/S0168900206002336>.

[19] MORSE, D. H.; ANTOLAK, A. J.; DOYLE, B. L. Photofission in uranium by nuclear reaction gamma-rays. Nuclear Instruments and Methods in Physics Research B, v. 261, p. 378-381, 2007. ISSN 0168-583X. Disponível em: $<$ http://www.sciencedirect.com/science/article/pii/S0168583X07008014>.

[20] KARAPETYAN, G. et al. Multimode approach to ${ }^{241} \mathrm{Am}$ and ${ }^{237} \mathrm{~Np}$ fission induced by $660-\mathrm{MeV}$ protons. Physics of Atomic Nuclei, MAIK Nauka/Interperiodica distributed exclusively by Springer Science+Business Media LLC., v. 72, p. 911-916, 2009. ISSN 1063-7788. 10.1134/S1063778809060027. Disponível em: $<\mathrm{http}: / / \mathrm{dx}$. doi.org/10.1134/S1063778809060027>.

[21] DEPPMAN, A. et al. Photofissility of heavy nuclei at intermediate energies. Phys. Rev. C, American Physical Society, v. 66, p. 067601, Dec 2002. Disponível em: $<$ http://link.aps.org/doi/10.1103/PhysRevC.66.067601>.

[22] WILKINS, B. D.; STEINBERG, E. P.; CHASMAN, R. R. Scission-point model of nuclear fission based on deformed-shell effects. Phys. Rev. C, American Physical Society, v. 14, p. 1832-1863, Nov 1976. Disponível em: $<$ http://link.aps.org/doi/10.1103/PhysRevC.14.1832>.

[23] BROSA, U.; GROSSMANN, S.; MÜLLER, A. Nuclear scission. Physics Reports, v. 197, n. 4, p. 167-262, 1990. ISSN 0370-1573. Disponível em: $<\mathrm{http}: / / \mathrm{www}$.sciencedirect.com/science/article/pii/037015739090114H >. 
[24] FERNÁNDEZ-DOMÍNGUEZ, B. et al. Nuclide cross-sections of fission fragments in the reaction ${ }^{208} \mathrm{~Pb}+\mathrm{p}$ at $500 \mathrm{~A}$ MeV. Nuclear Physics A, v. 747, n. 2-4, p. 227-267, 2005. ISSN 0375-9474. Disponível em: $<$ http://www.sciencedirect.com/science/article/pii/S0375947404010838>.

[25] DEMEKHINA, N.; KARAPETYAN, G. Multimode approximation for ${ }^{238} \mathrm{U}$ photofission at intermediate energies. Physics of Atomic Nuclei, MAIK Nauka/Interperiodica distributed exclusively by Springer Science+Business Media LLC., v. 71, p. 27-35, 2008. ISSN 1063-7788. 10.1134/S1063778808010031. Disponível em: $<$ http://dx.doi.org/10.1134/S1063778808010031>.

[26] NAIK, H. et al. Mass-yield distribution of fission products from photo-fission of ${ }^{n a t} \mathrm{~Pb}$ induced by $2.5 \mathrm{GeV}$ bremsstrahlung. The European Physical Journal A - Hadrons and Nuclei, Springer Berlin / Heidelberg, v. 47, p. 1-10, 2011. ISSN 1434-6001. 10.1140/epja/i201111037-0. Disponível em: <http://dx.doi.org/10.1140/epja/i2011-11037-0>.

[27] BALABEKYAN, A. et al. Symmetric and asymmetric fission modes in proton-induced fission at $660 \mathrm{MeV}$ of ${ }^{238} \mathrm{U}$. Physics of Atomic Nuclei, MAIK Nauka/Interperiodica distributed exclusively by Springer Science+Business Media LLC., v. 73, p. 1814-1819, 2010. ISSN 1063-7788. 10.1134/S1063778810110025. Disponível em: $<$ http://dx.doi.org/10.1134/S1063778810110025>.

[28] PÉREZ-LOUREIRO, D. et al. Production of neutron-rich nuclei in fragmentation reactions of projectiles at relativistic energies. Physics Letters B, v. 703, n. 5, p. 552-556, 2011. ISSN 0370-2693. Disponível em: $<$ http://www.sciencedirect.com/science/article/pii/S0370269311009853>.

[29] BÖCKSTIEGEL, C. et al. Nuclear-fission studies with relativistic secondary beams: Analysis of fission channels. Nuclear Physics A, v. 802, p. 1225, 2008. ISSN 0375-9474. 10.1016/j.nuclphysa.2008.01.012. Disponível em: $<$ (http://www.sciencedirect.com/science/article/pii/S0375947408000328) >.

[30] V.V.; PASHKEVICH. On the asymmetric deformation of fissioning nuclei. $\mathrm{Nu}$ clear Physics A, v. 169, n. 2, p. 275-293, 1971. ISSN 0375-9474. Disponível em: $<$ http://www.sciencedirect.com/science/article/pii/0375947471908840>.

[31] DOSTROVSKY, I.; RABINOWITZ, P.; BIVINS, R. Monte carlo calculations of high-energy nuclear interactions. i. systematics of nuclear evaporation. Phys. Rev., American Physical Society, v. 111, p. 1659-1676, Sep 1958. Disponível em: $<$ http://link.aps.org/doi/10.1103/PhysRev.111.1659>.

[32] MÖLlER, P. et al. Heavy-element fission barriers. Phys. Rev. C, American Physical Society, v. 79, p. 064304, Jun 2009. Disponível em: $<$ http://link.aps.org/doi/10.1103/PhysRevC.79.064304>.

[33] EGIDY, T. v.; BUCURESCU, D. Systematics of nuclear level density parameters. Phys. Rev. C, American Physical Society, v. 72, p. 044311, Oct 2005. Disponível em: $<$ http://link.aps.org/doi/10.1103/PhysRevC.72.044311>.

[34] FRENKEL, I. Sov. Phys., v. 9, p. 553, 1936. 
[35] BOHR, N. Transmutations of atomic nuclei. Science, v. 86, n. 2225, p. 161-165, 1937. Disponível em: <http://www.sciencemag.org/content/86/2225/161.short>.

[36] WEISSKOPF, V. Statistics and nuclear reactions. Phys. Rev. American Physical Society, v. 52, p. 295-303, Aug 1937. Disponível em: $<$ http://link.aps.org/doi/10.1103/PhysRev.52.295>.

[37] VANDENBOSCH, R.; HUIZENGA, J. R. Nuclear Fission. 1st. ed. [S.1.]: Academic Press., New York, 1973.

[38] NIX, J. R. Calculation of fission barriers for heavy and superheavy nuclei. Annual Review of Nuclear Science, v. 22, n. 1, p. 65-120, 1972. Disponível em: $<$ http://www.annualreviews.org/doi/abs/10.1146/annurev.ns.22.120172.000433>.

[39] COHEN, S.; SWIATECKI, W. J. The deformation energy of a charged drop: Part v: Results of electronic computer studies. Annals of Physics, v. 22, n. 3, p. 406-437, 1963. ISSN 0003-4916. Disponível em: $<$ http://www.sciencedirect.com/science/article/pii/0003491663903853>.

[40] COHEN, S.; SWIATECKI, W. The deformation energy of a charged drop: IV. evidence for a discontinuity in the conventional family of saddle point shapes. Annals of Physics, v. 19, n. 1, p. 67-164, 1962. ISSN 0003-4916. Disponível em: $<$ http://www.sciencedirect.com/science/article/pii/0003491662902348>.

[41] NIX, J. R. Berkeley Rep. UCRL-17958, p. 151, 1968.

[42] LAWRENCE, J. N. P. Phys. Rev. B., v. 139, p. 1227-31, 1965.

[43] KUDO, $\mathrm{H}$. et al. Most probable charge of fission products in $24 \mathrm{MeV}$ proton induced fission of ${ }^{238}$ U. Phys. Rev. C, American Physical Society, v. 57, p. 178-188, Jan 1998. Disponível em: <http://link.aps.org/doi/10.1103/PhysRevC.57.178>.

[44] WAGEMANS, C.; SCHILLEBEECKX, P.; DERUYTTER, A. Investigation of neutron shell effects and fission channels in the spontaneous fission of the pu-isotopes. Nuclear Physics A, v. 502, n. 0, p. 287-296, 1989. ISSN 0375-9474. Disponível em: $<$ http://www.sciencedirect.com/science/article/pii/0375947489906696>.

[45] WEBER, T. et al. Evidence for different fission fragment mass asymmetries for specific nuclear excitations studied in (e.e'f) and $(\gamma, \mathrm{f})$ reactions. Nuclear Physics A, v. 502, n. 0, p. 279-286, 1989. ISSN 0375-9474. Disponível em: $<$ http://www.sciencedirect.com/science/article/pii/0375947489906684>.

[46] SIDA, J. et al. Mass, charge, and energy distributions in very asymmetric thermal fission of ${ }^{238}$ U. Nuclear Physics A, v. 502, n. 0, p. 233-242, 1989. ISSN 0375-9474. Disponível em: $<$ http://www.sciencedirect.com/science/article/pii/0375947489906647>.

[47] HAMBSCH, F.-J. et al. Prompt fission neutron multiplicity and spectra evaluation in the frame of the multi-modal fission model for ${ }^{237} \mathrm{~Np}(\mathrm{n}, \mathrm{f})$ and ${ }^{238} \mathrm{U}(\mathrm{n}, \mathrm{f}) . \mathrm{Nu}$ clear Physics A, v. 709, n. 1-4, p. 85-102, 2002. ISSN 0375-9474. Disponível em: $<$ http://www.sciencedirect.com/science/article/pii/S0375947402010412>. 
[48] HAMBSCH, F.-J. et al. Prompt fission neutron multiplicity and spectrum evaluation for ${ }^{235} \mathrm{U}(\mathrm{n}, \mathrm{f})$ in the frame of the multi-modal fission model. Nuclear Physics A, v. 726, n. 3-4, p. 248-264, 2003. ISSN 0375-9474. Disponível em: $<$ http://www.sciencedirect.com/science/article/pii/S0375947403016300>.

[49] WEIGMANN, H.; KNITTER, H.-H.; HAMBSCH, F.-J. Light particle and photo induced fission. Nuclear Physics A, v. 502, n. 0, p. 177-194, 1989. ISSN 0375-9474. Disponível em: $<$ http://www.sciencedirect.com/science/article/pii/0375947489906611>.

[50] OHTSUKI, T. et al. Systematic analysis of mass yield curves in low-energy fission of actinides. Phys. Rev. C, American Physical Society, v. 40, p. 2144-2153, Nov 1989. Disponível em: <http://link.aps.org/doi/10.1103/PhysRevC.40.2144>.

[51] DUIJVESTIJN, M. C. et al. Proton-induced fission at $190 \mathrm{MeV}$ of ${ }^{\text {nat }} \mathrm{W},{ }^{197} \mathrm{Au}$, ${ }^{\text {nat }} \mathrm{Pb}$, ${ }^{208} \mathrm{~Pb}$, and ${ }^{232}$ Th. Phys. Rev. C, American Physical Society, v. 59, p. 776-788, Feb 1999. Disponível em: <http://link.aps.org/doi/10.1103/PhysRevC.59.776>.

[52] MASLOV, M. V. Symmetric/asymmetric ${ }^{238} \mathrm{U}$ source neutron-induced fission up to $200 \mathrm{MeV}$. Nuclear Physics A, v. 717, p. 3-20, 2003. Disponível em: $<$ http://dx.doi.org/10.1016/S0375-9474(03)00593-1>.

[53] ITKIS, M. G. et al. Asymmetric fission of the pre-actinide nuclei. Zeitschrift für Physik A Hadrons and Nuclei, Springer Berlin / Heidelberg, v. 320, p. 433-441, 1985. ISSN 09397922. 10.1007/BF01415720. Disponível em: <http://dx.doi.org/10.1007/BF01415720>.

[54] POKROVSKY, I. V. et al. Fission modes in the reaction ${ }^{208} \mathrm{~Pb}\left({ }^{18} \mathrm{O}, f\right)$. Phys. Rev. C, American Physical Society, v. 62, p. 014615, Jun 2000. Disponível em: $<$ http://link.aps.org/doi/10.1103/PhysRevC.62.014615>.

[55] ROOT: An object-oriented data analysis framework - user's guide 5.26. [S.1.], December 2009. Disponível em: <http://root.cern.ch/drupal/>.

[56] DEPPMAN, A. et al. The crisp package for intermediate- and high-energy photonuclear reactions. Journal of Physics G: Nuclear and Particle Physics, v. 30, n. 12, p. 1991, 2004. Disponível em: <http://stacks.iop.org/0954-3899/30/i=12/a=016>.

[57] CUGNON, J. Proton-nucleus interaction at high energy. Nuclear Physics $A$, v. 462, n. 4, p. 751 - 780, 1987. ISSN 0375-9474. Disponível em: $<$ http://www.sciencedirect.com/science/article/pii/0375947487905756>.

[58] GONÇALVES, M. et al. Many-body cascade calculation for photonuclear reactions. Physics Letters B, v. 406, n. 1-2, p. 1 - 6, 1997. ISSN 0370-2693. Disponível em: $<$ http://www.sciencedirect.com/science/article/pii/S037026939700662X>.

[59] PINA, S. de et al. Photonuclear k+ production calculation near threshold. Physics Letters B, v. 434, n. 1-2, p. 1 - 6, 1998. ISSN 0370-2693. Disponível em: $<$ http://www.sciencedirect.com/science/article/pii/S0370269398007266>.

[60] DEPPMAN, A. et al. Photofission and total photoabsorption cross sections in the energy range of shadowing effects. Phys. Rev. C, American Physical Society, v. 73, p. 064607, Jun 2006. Disponível em: <http://link.aps.org/doi/10.1103/PhysRevC.73.064607>. 
[61] DEPPMAN, A. et al. The mcef code for nuclear evaporation and fission calculations. Computer Physics Communications, v. 145, n. 3, p. 385-394, 2002. ISSN 0010-4655. Disponível em: <http://www.sciencedirect.com/science/article/pii/S0010465502002783>.

[62] DEPPMAN, A. et al. Photofissility of actinide nuclei at intermediate energies. Phys. Rev. Lett., American Physical Society, v. 87, p. 182701, Oct 2001. Disponível em: $<$ http://link.aps.org/doi/10.1103/PhysRevLett.87.182701>.

[63] JAMES, F. Minuit: Function Minimization and Error Analysis - Reference Manual Version 94.1. [S.1.]. Disponível em: $<$ http://wwwasdoc.web.cern.ch/wwwasdoc/minuit/minmain.html $>$.

[64] PEARSON, J. The quest for a microscopic nuclear mass formula. Hyperfine Interactions, Springer Netherlands, v. 132, p. 59-74, 2001. ISSN 0304-3843. 10.1023/A:1011973100463. Disponível em: <http://dx.doi.org/10.1023/A:1011973100463>.

[65] SOUZA, D. A. Influência da Densidade de Niveis nas Reações de Spallation. Dissertação (mestrado). Bahia: Universidade Estadual de Santa Cruz, 2011.

[66] CHUNG, K. C. Introdução à Física Nuclear. Rio de Janeiro: EdUERJ, 2001. ISSN 8575110152.

[67] AUDI, G.; WAPSTRA, A. The 1995 update to the atomic mass evaluation. $\mathrm{Nu}$ clear Physics A, v. 595, n. 4, p. 409-480, 1995. ISSN 0375-9474. Disponível em: $<$ http://www.sciencedirect.com/science/article/pii/0375947495004459>.

[68] AUDI, G.; WAPSTRA, A.; THIBAULT, C. The 2003 nubase and atomic mass evaluations. Nuclear Physics A, v. 729, p. 337-676, 2003. ISSN 0375-9474. Disponível em: $<$ http://www.sciencedirect.com/science/article/pii/S0375947403018098>.

[69] DEPPMAN, A. et al. A monte carlo method for nuclear evaporation and fission at intermediate energies. Nuclear Instruments and Methods in Physics Research Section B: Beam Interactions with Materials and Atoms, v. 211, n. 1, p. 15-21, 2003. ISSN 0168-583X. Disponível em: <http://www.sciencedirect.com/science/article/pii/S0168583X03012655>.

[70] ENGE, H. A. Introduction to nuclear physics. [S.1.]: Addison-Wesley publishing company, 1966. (World student series edition).

[71] MAMDOUH, A. et al. Large-scale fission-barrier calculations with the etfsi method. Nuclear Physics A, v. 644, n. 4, p. 389-414, 1998. ISSN 0375-9474. Disponível em: $<\mathrm{http}: / / \mathrm{www}$. sciencedirect.com/science/article/pii/S0375947498005764>.

[72] MAMDOUH, A. et al. Fission barriers of neutron-rich and superheavy nuclei calculated with the etfsi method. Nuclear Physics A, v. 679, n. 3-4, p. 337-358, 2001. ISSN 0375-9474. Disponível em: <http://www.sciencedirect.com/science/article/pii/S0375947400003584>.

[73] SMIRENKIN, G. N. IAEA-Report INDC(CCP)-359. [S.1.], 1993.

[74] ANÉFALOS, S. et al. The utilization of crisp code in hybrid reactor studies. Brazilian Journal of Physics, scielo, v. 35, p. 912-914, 09 2005. ISSN 0103-9733. 
[75] REJMUND, F. et al. Measurement of isotopic cross sections of spallation residues in 800 A MeV ${ }^{197} \mathrm{Au}+\mathrm{p}$ collisions. Nuclear Physics A, v. 683, n. 1-4, p. 540-565, 2001. ISSN 0375-9474. Disponível em: <http://dx.doi.org/10.1016/S0375-9474(00)00468-1>.

[76] ENQVIST, T. et al. Isotopic yields and kinetic energies of primary residues in $1 \mathrm{~A} \mathrm{GeV}$ ${ }^{208} \mathrm{~Pb}+$ p reactions. Nuclear Physics A, v. 686, n. 1-4, p. 481-524, 2001. ISSN 0375-9474. Disponível em: <http://dx.doi.org/10.1016/S0375-9474(00)00563-7>.

[77] PEREIRA, J. et al. Comprehensive analysis of fission-reaction properties in the nuclear spallation of ${ }^{238} \mathrm{U}(1 \mathrm{GeV} /$ nucleon $)$ on deuterium. Phys. Rev. $C$, American Physical Society, v. 75, p. 044604, Apr 2007. Disponível em: $<$ http://link.aps.org/doi/10.1103/PhysRevC.75.044604>.

[78] ANDRADE-II, E. et al. Monte Carlo Simulation of Heavy Nuclei Photofission at Intermediate Energies. In: Guimaraes, V and BrandaoDeOliveira, JR and Macario, KCD and Genezini, FA (Ed.). NUCLEAR PHYSICS 2008: XXXI WORKSHOP ON NUCLEAR PHYSICS IN BRAZIL. [S.1.], 2009. (AIP Conference Proceedings, 1139), p. 64-69. ISBN 978-07354-0676-6. ISSN 0094-243X. 31st Workshop on Nuclear Physics in Brazil, Sao Sebastiao, BRAZIL, SEP 08-12, 2008.

[79] ANDRADE-II, E. et al. Fragment mass distributions in the fission of heavy nuclei by intermediate- and high-energy probes. Journal of Physics G: Nuclear and Particle Physics, v. 38, n. 8, p. 085104, 2011. Disponível em: <http://stacks.iop.org/0954$3899 / 38 / \mathrm{i}=8 / \mathrm{a}=085104>$.

[80] BENLLIURE, J. et al. Isotopic production cross sections of fission residues in ${ }^{197} \mathrm{Au}-\mathrm{on}-$ proton collisions at $800 \mathrm{~A} \mathrm{MeV.} \mathrm{Nuclear} \mathrm{Physics} \mathrm{A,} \mathrm{v.} \mathrm{683,} \mathrm{n.} \mathrm{1-4,} \mathrm{p.} \mathrm{513-539,} \mathrm{2001.} \mathrm{ISSN}$ 0375-9474. Disponível em: <http://dx.doi.org/10.1016/S0375-9474(00)00472-3>.

[81] ROSSI, P. C. R. Reações Nucleares de Alta energia (Spallation) e Sua Aplicação em calculo de Sistemas Nucleares. Tese (doutorado). São Paulo: Instituto de Pesquisas Nucleares, 2011. 